\title{
A Review of the Mechanical and Tribological Behavior of Cold Spray Metal Matrix Composites
}

\author{
Lewei $\mathrm{He}^{1} \cdot$ Mostafa Hassani $^{1}$ (C)
}

Submitted: 16 April 2020/in revised form: 31 July 2020/Published online: 24 September 2020

(C) ASM International 2020

\begin{abstract}
Cold spray is an effective solid-state process for the fabrication of metal matrix composites where metallic, ceramic, or intermetallic reinforcements are embedded in a metallic matrix. Cold-sprayed metal matrix composites (CS MMCs) enable combining favorable properties of their constituent phases. Combinations of the ductility of metals with the high strength of ceramics or with the creep resistance of intermetallics are two typical examples. Here, we review recent advances in the understanding of the mechanical and tribological behavior of CS MMCs, with particular emphasis on the physical mechanisms and predictive understanding. We start the review with deposition mechanisms, defects, and microstructural features in CS MMCs. We continue the discussion with the mechanical behavior of CS MMCs, including elastic modulus, hardness, strength, ductility, as well as adhesive and cohesive failures. We also explore various aspects of the tribology of CS MMCs, from frictional response to abrasive and erosive wear. We discuss the effect of cold spray parameters and post-spray thermal and mechanical treatments on the microstructure and properties of CS MMCs. We connect experimental findings on the mechanics and tribology of CS MMCs with theoretical frameworks to the extent possible. Finally, we propose several critical unresolved issues in the field as future research directions.
\end{abstract}

Keywords cold spray $\cdot$ mechanical properties $\cdot$ metal matrix composites $\cdot$ tribological properties $\cdot$ review

Mostafa Hassani

hassani@ cornell.edu

1 Sibley School of Mechanical and Aerospace Engineering, Cornell University, Ithaca, NY 14853, USA

\section{Introduction}

Cold spray is a solid-state process in which micrometersized particles $(5-50 \mu \mathrm{m})$ are accelerated by a supersonic carrier gas in a de Laval nozzle to high velocities (300$1200 \mathrm{~m} / \mathrm{s}$ ) and impact a substrate material. If the impact velocity of the particles exceeds a threshold, referred to as critical velocity, the particles bond to the substrates in solid state without having to induce high homologous temperatures or melt either material. As a result, limitations associated with high temperatures such as phase transformation, tensile residual stresses, and significant distortion can be avoided, making cold spray a competitive deposition technology for different classes of materials. Ever since the first "cold" deposition of metallic particles onto metallic substrates was reported after Papyrin et al.'s classic two-phase flow experiments (Ref 1), cold spray has proven successful in the deposition of not only pure metals and engineering alloys, but also metallic glasses $(\operatorname{Ref} 2,3)$, ceramics (Ref 4-7), high entropy alloys (Ref 8), and composites (Ref 9-11) onto a variety of substrates including metals, ceramics (Ref 12), polymers (Ref 13), and metalloids (Ref 14, 15). Several books (Ref 16-20), as well as thorough reviews (Ref 21-30), have covered different aspects of the remarkable progress in the field in the past decades, from processing science of cold spray to microstructural characteristics and properties of the coatings.

The focus of this review paper is on cold spray metal matrix composites. In many situations, single-phase coatings may not be able to meet multiple requirements imposed in practice. For example, while Al coatings can provide excellent sacrificial protection, they can be relatively easily scratched. Combining the properties of their constituents, metal matrix composites can offer a 
combination of properties that could be otherwise challenging to achieve or even mutually exclusive, from strength to toughness to high wear and corrosion resistance and high-temperature stability. From the processing perspective, cold spray offers a unique space compared to more traditional composite fabrication technologies. Unlike powder metallurgy processing, spark plasma spraying, pressure infiltration, and thermal spraying, there is considerably lower applied heat in cold spray to induce liquid phase formation and/or to activate sintering. As a result, one can not only avoid oxidation and deleterious matrix-reinforcement interfacial reactions, but also preserve the microstructure of feedstock materials.

To deposit metal matrix composite via cold spray, one can prepare a batch of composite powders before spraying, or co-deposit two separate batches of matrix and reinforcement powders. Different techniques, including mechanical blending (Ref 31, 32), ball milling (Ref 33), spray drying (Ref 34, 35), agglomeration and sintering (Ref $34,36-42$ ), and coating powder particles to form a coreshell arrangement (Ref 43) can be used to prepare powder feedstocks. Different methods provide various levels of control over composition, particle size, shape, and distribution of the two phases, but all together enable a vast design space for deposition of metal matrix composites. For a detailed discussion on the advantages of each of the above powder preparation techniques and a material-based classification of metal matrix composites, we refer the readers to a recent review paper on the topic (Ref 26).

The purpose of this paper is to present an overview of the mechanical and tribological properties of cold spray metal matrix composites with a particular emphasis on the underlying fundamentals and predictive frameworks where possible. This class of cold spray materials comprises a metallic matrix phase together with a reinforcement phase, which could be ceramic, metallic, or intermetallic. In this paper, we discuss the influence of the reinforcement phase on the deposition process, coating microstructures, and coating properties. We start the review with a discussion on bonding mechanisms. We highlight how the differences between deposition of a single-phase material and co-deposition of two phases can influence the deposition efficiency and porosity in cold spray metal matrix composites. We will then discuss elasticity, hardness, ultimate tensile strength, ductility, adhesive and cohesive failures, wear rate and mechanisms, as well as the frictional response of cold spray metal matrix composites. While reviewing the literature in these sections, we emphasize predictive understanding and compare experimental findings with the theoretical prediction of the properties as a function of reinforcement content when possible. We include discussions on how cold spray process parameters and post-spray thermal and mechanical treatments can be exploited to design microstructure and improve properties of metal matrix composites. We end the review with a discussion on several important unresolved issues for the field and propose new avenues for further research and developments.

\section{Bonding Mechanism}

Impact-induced bonding in cold spraying of metallic materials can be broadly classified into metallurgical bonding and mechanical interlocking. For metallurgical bonding to occur, clean metallic contact at the atomic level is required. This condition can be met by the large interfacial strain during jetting - an intense outward ejection of material at the interface between particle and substrate. Whether triggered by adiabatic shear instability mechanism (Ref 44-47) or shock wave release mechanism (Ref 48-50), there exists a consensus that jetting can disrupt and displace the native oxide layer, create fresh metallic surfaces, and thus, significantly facilitates metallurgical bonding (Ref 46, 47, 51-59). Mechanical interlocking, on the other hand, occurs when impacting particles anchored or embedded into substrates (Ref 60-63). These conditions are most likely to prevail when particles are much harder and heavier than substrates. Mechanical interlocking can significantly contribute to bonding, in addition to chemical interaction, when different classes of materials are used as powder particles and substrates, e.g., ceramics particles on metallic substrates (Ref 64) or metallic particles on polymeric substrates (Ref 65). Interfacial gaps can be present in the case of mechanically interlocked interfaces, whereas the continuity of material has been confirmed for the metallurgically bonded cold spray interfaces. Impact-induced bonding has been studied empirically through postspray microstructural characterizations (Ref 23, 27). Recently, in situ observations of a single-particle impacting onto a substrate (Ref 40,49, 52, 66-68) have also provided a complementary approach to further understand impact bonding. However, there are many interesting material phenomena that are still challenging to study empirically at the length scales and timescales amenable to cold spray. Computational approaches, both atomistic and continuum, have contributed significantly to the current understanding of this multifaceted phenomena at different scales. Examples include resolving adiabatic softening (Ref 45-47), jetting (Ref 50) and pressure shock waves (Ref 48, 50, 69), native oxide fracture (Ref 70,71 ), dislocation activities, and microstructural evolution (Ref 72, 73) with molecular dynamics and finite element simulations.

While bonding and material buildup in metal matrix composites are also achieved by the general mechanisms discussed above, there can exist an additional synergistic effect when two phases are co-deposited. Such effect is of 


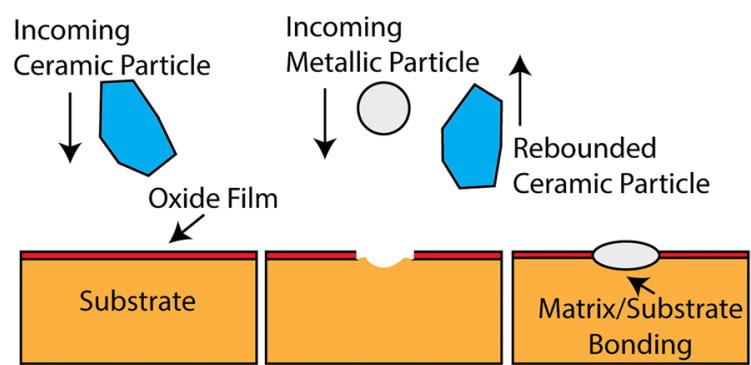

(a)

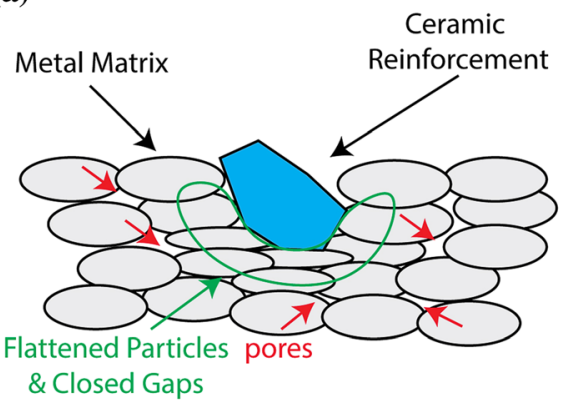

(c)
Incoming Reinforcement

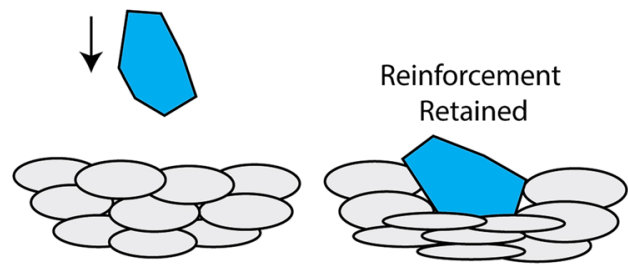

(b)

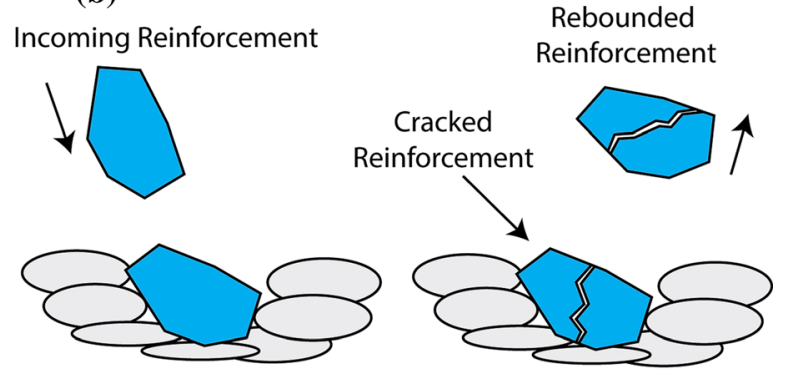

(d)

Fig. 1 Schematics showing (a) surface activation, (b) cushioning effect of the matrix, (c) tamping effect of ceramic reinforcement, and (d) erosion in CS MMCs

particular dominance when one phase is metal, and the other is ceramic (Ref 74). In this case, impact of ceramic particles provides the so-called "surface activation" effect through (i) increasing substrate roughness by creating impressions and craters and (ii) disrupting native oxide layers and exposing clean metallic surfaces with higher metallurgical activity to subsequent impacts (Ref $25,31,39,75-78)$. A schematic illustration of surface activation with ceramic particle impacts can be seen in Fig. 1(a). Both mechanisms enhance bonding between metallic particles. Metallic particles, on the other hand, can effectively dissipate the impact energy of ceramic particles by accommodating a significant amount of plastic deformation, shown in Fig. 1(b). They can, therefore, act as cushions for hard and non-deforming ceramic particles and provide an embedment mechanism (Ref 74). As the coating builds up, the impact of ceramic particles also provides a tamping or peening effect, which can lead to defect closure as well as enhanced metallurgical bonding in metallic phases and metal/ceramic interfaces (Ref 31, 78-81) as illustrated in Fig. 1(c). As will be discussed in the next section, there exists an optimum balance in the co-deposition of ceramic and metallic particles. A very small volume fraction of reinforcements may not fully activate the above reciprocal synergy. In contrast, too large contents of ceramic reinforcement can give rise to erosion, adversely affecting material deposition (Ref 76). Erosion, in the latter case, is activated due to an increased probability of ceramic particles impacting on ceramic particles (Ref 82-86). A schematic depicting the fracture of ceramic particles is shown in Fig. 1(d). In CS MMCs with metallic reinforcements, the surface activation, tamping, and cushion effects (Ref 87) may or may not be present depending on the difference in mechanical properties of the two phases. If the two phases have significantly different properties, such as hardness and density, one can expect a similar synergy. The deposition behavior of CS MMCs with intermetallic reinforcement is similar to the one with metallic reinforcements as intermetallic phases are often formed during post-deposition heat treatments (Ref 88-90). In these latter cases where metallic interfaces interact with each other, chemical-physical factors can play an important role in bonding.

\section{Deposition Efficiency and Porosity}

The amount of reinforcement can significantly change the deposition efficiency and the porosity in CS MMCs. The addition of reinforcement produces a tamping/peening (Ref 91) effect on the matrix and substrate and helps retaining soft matrix particles as well as closing existing interfacial gaps and pores. As a result, an increase in reinforcement content, particularly when relatively small amounts of reinforcement are added (Ref 92), can increase deposition efficiency of the soft phase and reduce porosity. In general, the overall deposition efficiency is measured by measuring the weight of the substrate before and after the spraying process and comparing it with the weight of the powder used. Phase-specific deposition efficiencies are measured 


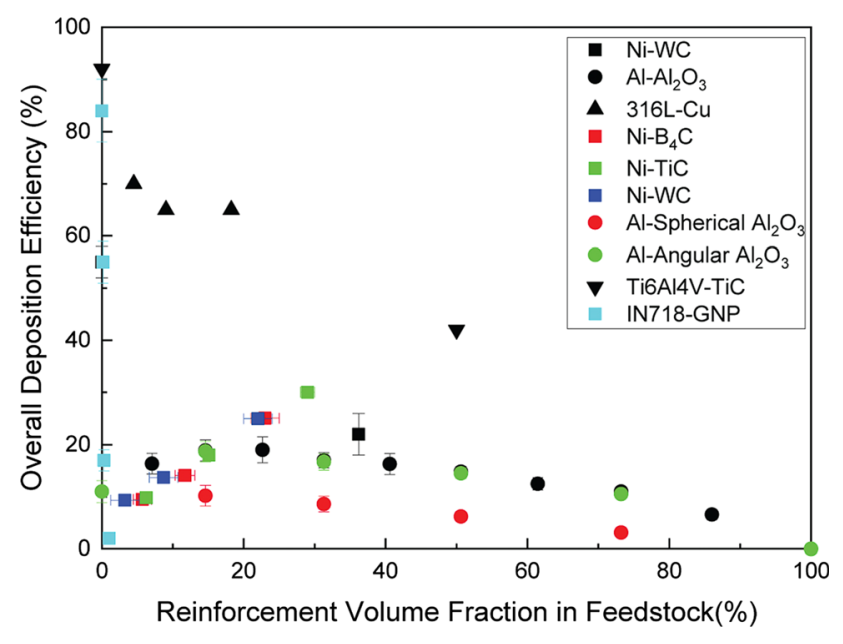

Fig. 2 Deposition efficiencies of the metal-ceramic powder mixture versus nominal reinforcement volume fraction of various material combinations indicating an optimum reinforcement volume fraction in the range of $20-40 \%(\operatorname{Ref} 93,103,106,107,148,174)$

by obtaining the volume or weight fraction of a specific phase, usually through composite coating images analysis. We have gathered the reinforcement volume fractions in powder feedstock for a variety of CS MMCs from the literature and the corresponding deposition efficiencies of the cold spray process. Figure 2 shows how deposition efficiency varies as a function of the nominal reinforcement content. The trend suggests that there exists an optimum reinforcement volume fraction $(\sim 30 \%)$ to achieve the maximum overall deposition efficiency. The initial increase in the deposition efficiency with increasing reinforcement content is attributed to surface activation and micro-asperities caused by the impact of ceramic particles. The micro-asperities facilitate the bonding of subsequent incoming particles (Ref 36). At higher reinforcement content, however, the impact of ceramic particles onto already deposited ceramics particles becomes predominant, and as a result, the overall deposition efficiency decreases. In fact, Fig. 2 shows that the deposition efficiency can be zero with a ceramic powder feedstock. Figure 2 also shows that the increasing-decreasing trend is not necessarily the case when non-ceramic reinforcement is added to metallic particles. The addition of a slight amount of graphene nanoplates (GNPs), for example, results in a significant reduction of the deposition efficiency in IN718-GNP coatings. The decrease in the overall deposition efficiency of 316L composite coating with the addition of $\mathrm{Cu}$ as reinforcement can be attributed to the metallic reinforcement being softer than the metallic matrix.

Figure 3(a) shows a cross-sectional micrograph of $\mathrm{Al}$ CS coating onto an $\mathrm{Al} 7075$ substrate where a large number of pores denoted with the arrows can be seen. Addition of 7 wt. $\% \mathrm{Al}_{2} \mathrm{O}_{3}$ particles in the feedstock as reinforcement can significantly reduce the porosity, as shown with Fig. 3(b). The same phenomena can be observed in pure Al CS coating where porosity in the single-phase coating (Fig. 3c) is significantly decreased by the addition of 20 vol. $\% \mathrm{~B}_{4} \mathrm{C}$ reinforcing particles in the feedstock (Fig. 3d). It is also interesting to note that the addition of reinforcing particles that are nominally softer than the matrix material could reduce the porosity level in CS MMCs. This is shown in Fig. 3(e) and (f), where the addition of 5\% Cu particles in the feedstock as reinforcement can effectively reduce the porosity level in 316L CS coating where the gaps between the harder, less deformed $316 \mathrm{~L}$ matrix can be filled in by the softer, highly deformed $\mathrm{Cu}$ phase. The three examples also show that both metallic and ceramic reinforcement can reduce the level of porosity in CS MMCs. However, at higher concentrations of reinforcement, incoming reinforcing particles will have higher probabilities of colliding with pre-deposited hard particles, resulting in an increased amount of rebounding as well as fracture, thereby reducing deposition efficiency and increasing the amount of porosity and defects (Ref 83, 93).

\section{Effect of Reinforcement Content on Deposition Efficiency and Porosity}

In Al-based CS metal matrix composites (MMCs), it was found that the addition of relatively small amounts of a variety of reinforcing particles, e.g., $\mathrm{Al}_{2} \mathrm{O}_{3}$ ( $\mathrm{Ref} 79,91,94-$ 96), Al-Si (Ref 97), SiC (Ref 83), and TiN (Ref 98) resulted in a significant decrease in porosity of the composite coatings and at the same time increased the deposition efficiency (Ref 83, 93). Such an increase was attributed to the dramatic tamping effect of ceramic particles on the pre-deposited Al splats (Ref 79) signified by increased flattening ratios of the splats (Ref 97). However, with a further increase in the reinforcement content to 40 vol.\% and higher in the feedstock, the porosity of $\mathrm{Al}$ 2024- $\mathrm{Al}_{2} \mathrm{O}_{3}$ coating increased (Ref 94). The deposition efficiency of $\mathrm{Al}$ 5056-SiC and $\mathrm{Al}-\mathrm{Al}_{2} \mathrm{O}_{3}$ coating decreased (Ref 83, 93) with increasing reinforcement contents due to increased interactions between hard particles, which also created increased amounts of pores and cracks.

In Cu-based CS MMCs, effects of reinforcements such as $\mathrm{Al}_{2} \mathrm{O}_{3}, \mathrm{SiC}$, and $\mathrm{AlCuFeB}$ quasicrystal were studied. An increase in the volume fraction of $\mathrm{Al}_{2} \mathrm{O}_{3}$ in the powder feedstock resulted in an increase in the deposition efficiency of coatings sprayed at $0.8 \mathrm{MPa}$ (Ref 99) and $3 \mathrm{MPa}$ (Ref 100), and a decrease in the porosity in both low- and high-pressure cold-sprayed coatings with working pressure from 0.6 to $4 \mathrm{MPa}$ (Ref 96, 99). Composite CuSn8 coatings reinforced with $\mathrm{AlCuFeB}$ quasicrystal (QC) presented much denser microstructures than the pure CuSn8 coating due to the tamping effect from the QC reinforcement. The 

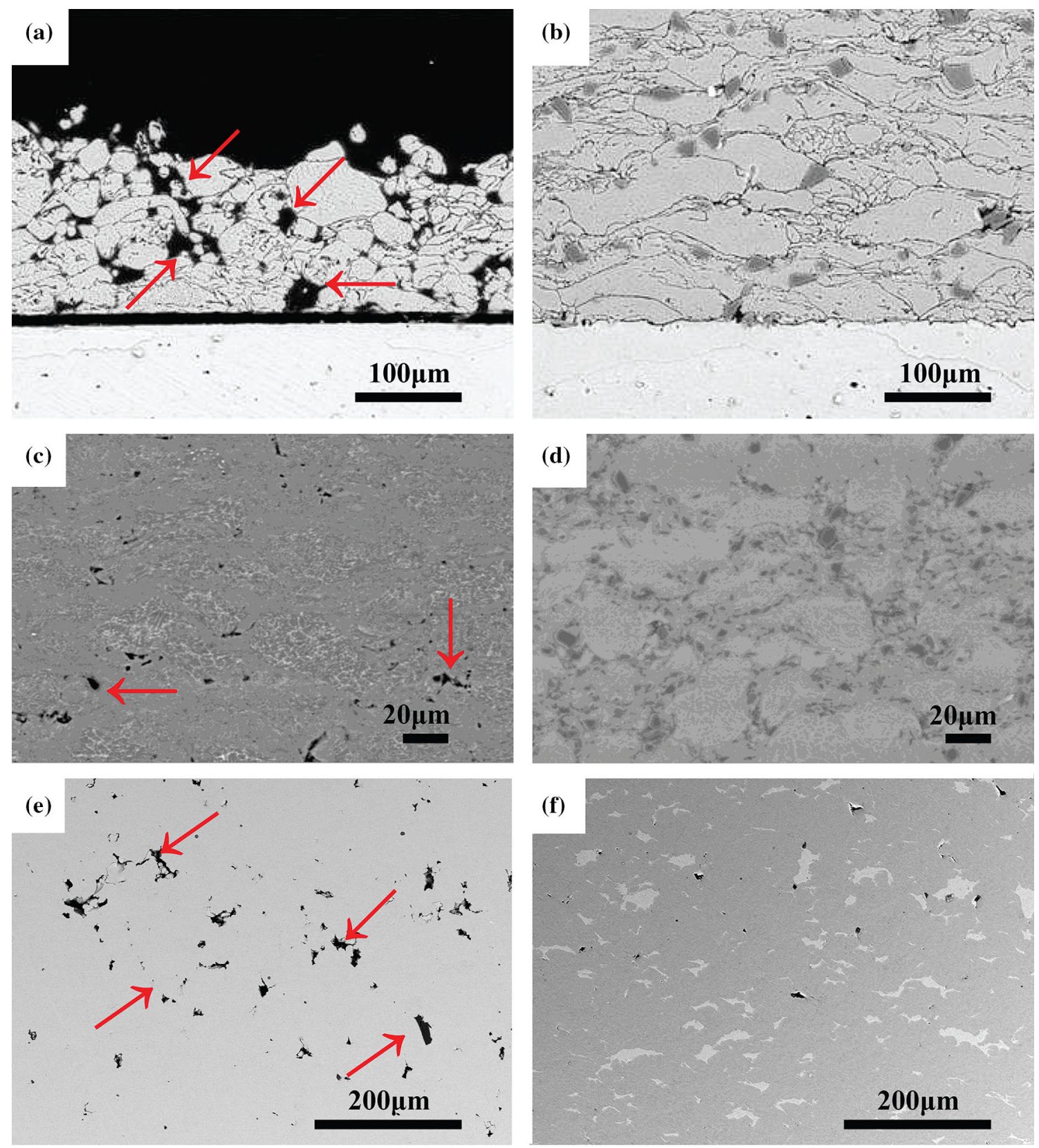

Fig. 3 A reduction of porosity can be achieved with the addition of reinforcing particles in CS MMCs. Figures on the left have higher porosity. Selected pores are shown with arrows. In (a) and (b), the addition of $\mathrm{Al}_{2} \mathrm{O}_{3}$ particles in $\mathrm{Al}-\mathrm{Al}_{2} \mathrm{O}_{3}$ composite coating significantly reduced porosity (Ref 82$)$; In (c) and (d), it can be seen that

$\mathrm{B}_{4} \mathrm{C}$ reinforcement reduced $\mathrm{CS} \mathrm{Al}$ coating significantly as well (Ref $150)$; in (e) and (f), it can be seen that addition of $5 \% \mathrm{Cu}$ particles in CS 316L coating resulted in a reduction of porosity from $3.2 \pm 1.1 \%$ to $0.9 \pm 0.3 \%$ (Ref 107). Images are reproduced with permissions from Springer and Elsevier

porosity level of the CuSn8-based composite coatings decreases from $\sim 2.6$ to below $0.25 \%$ with increasing the content of the QC phase from 19.5 to 57.6 vol.\% in the feedstock (Ref 101). The deposition efficiency of the $\mathrm{Cu}$ CNT-SiC composite coatings was shown to decrease from 20 to $12 \%$ when 5 vol. $\%$ of CNT was added to pure $\mathrm{Cu}$. The deposition efficiency continued to decrease to $4 \%$ when 10 vol.\% $\mathrm{SiC}$ was added but increased to $19 \%$ as $\mathrm{SiC}$

content was increased from 10 to $20 \mathrm{vol} . \%$ in the feedstock (Ref 102).

An opposite trend, i.e., a decrease in deposition efficiency from 55 to $22 \%$ and a decrease in porosity from 3.8 to $1.1 \%$ with an increase in reinforcement content from 0 to 36.2 vol.\% in the feedstock, has been reported in the case of Ni-based coatings reinforced with tungsten carbide (WC) particles in high-pressure cold spray at $4 \mathrm{MPa}$. That 
was attributed to the impact-induced fragments of WC particles found in the coating, which was shown to prevent intimate contact between $\mathrm{Ni}$ particles (Ref 103, 104). However, a recent study with low-pressure cold spray showed reduced porosity with increased WC content in Ni$\mathrm{CrC}$ coatings (Ref 105). Similar to Ni-WC in high-pressure cold spray, it was found that the deposition efficiency of the IN718-GNPs composite coatings decreased from 84 to $2 \%$ with the increase in the GNP content from none to $1 \%$. The authors argued that the presence of the GNPs prevented the occurrence of adiabatic shear instability and particle bonding (Ref 106). The addition of BN particles to $\mathrm{Ni}$, similar to $\mathrm{WC}$, was shown to be effective in decreasing the porosity level (Ref 96).

In CS MMCs made of stainless steel, $\mathrm{Cu}$, and Tribaloy powders, highly deformed $\mathrm{Cu}$ particles were shown to fill the gaps between the less deformed stainless steel and Tribaloy particles, resulting in lower porosities in the composite coatings compared to the single-phase stainless steel coating (Ref 107). The compositions of the deposits significantly differed from the initial mixtures, which could be explained by differences between deposition efficiencies of each phase. $\mathrm{Cu}$ had higher phase-specific deposition efficiency than stainless steel, resulting in an increased $\mathrm{Cu}$ content in the coating. However, the overall deposition efficiency of the coating decreased as higher amounts of $\mathrm{Cu}$ were added. The deposition efficiency of the Tribaloy particles was shown to depend on the particle type they impacted strongly. The probability of retaining Tribaloy particles on copper or steel particles was significantly higher than on Tribaloy particles (Ref 107).

In other material classes such as magnesium and cobalt, studies of porosity and deposition efficiency have been conducted too, but to a lesser extent compared to the typical matrix materials in CS MMCs (Ref 96, 108). In Mgbased coating (AZ91D reinforced with $\mathrm{SiC}$ ), the reinforcement content in the coating was shown to increase up to $51 \mathrm{vol} . \%$ as the content in the feedstock powder was increased to $60 \mathrm{vol} . \%$ (Ref 108). The same increasing trend was found for the deposition efficiency, albeit only up to 30 vol.\% $\mathrm{SiC}$ in the powder feedstock. Beyond 30 vol.\% SiC, the deposition efficiency started to decrease as the probability of rebounding of incoming particles increased with the number of hard particles increasing in pre-deposited layers (Ref 108).

\section{Effect of Heat Treatment on Porosity}

Heat treatment (HT) can significantly change the coating microstructure by recovery, grain growth, recrystallization, and formation of intermetallic phases. It can be an effective method to improve bonding and decrease porosity (Ref 90). In $\mathrm{B}_{4} \mathrm{C}$-reinforced $\mathrm{Al}$ coatings deposited on 6061-T6 substrates and heat-treated under high-purity Ar environment for $4 \mathrm{~h}, \mathrm{HT}$ at $400^{\circ} \mathrm{C}$ resulted in a decrease in porosity from $3.9 \%$ in the as-sprayed condition to $1.9 \%$ (Ref 109). Further increase in HT temperature to $500^{\circ} \mathrm{C}$ did not yield further decrease in porosity since inter-splat crevices and triple junctions/pores were either completely healed out or reduced in size (Ref 109). For $\mathrm{Al}_{2} \mathrm{O}_{3}$-reinforced A380 coating, on the other hand, a slight increase in porosity was reported after heat treatment (Ref 110). The increase in porosity was attributed to spheroidization and augmentation of the smaller pores and formation of relatively large pores during the heat treatment.

The in situ reaction of metallic phases during heat treatment is a processing strategy broadly adopted for the syntheses of metallic/intermetallic CS coatings, particularly for Ni-Al (Ref 87), Ti-Al (Ref 111), Fe-Al (Ref 90, 112), and Ni-Ti (Ref 89). In CS Ni-Ti composite coating, vacuum annealing at 700,800 , and $900^{\circ} \mathrm{C}$ for $2 \mathrm{~h}$ was used to produce a uniform distribution of intermetallic phases. However, coating porosity increased rapidly at elevated temperatures due to the Kirkendall effect (Ref 89). Formation of intermetallic phases was also reported in CS $\mathrm{TiAl}_{3}-\mathrm{Al}$ coating, along with an increase in porosity, since the formation of $\mathrm{TiAl}_{3}$ intermetallics was accompanied by volume expansion (Ref 111).

\section{Effect of Processing Parameters on Deposition Efficiency and Porosity}

In addition to powder feedstock-related parameters such as the reinforcement material, content, size, and morphology, cold spray processing parameters such as gas temperature, pressure, propelling gas type, standoff distance, as well as spraying nozzle type, material, and scan speed provides an additional space for the design of CS MMCs with desired performance. Higher propelling gas and preheating temperatures lead to increased deposition efficiencies and reduced porosities in CS MMCs by inducing thermal softening, particularly in metallic particles, and/or by enabling higher impact velocities (Ref 11, 113). What is more, higher gas temperatures were shown to improve the retention of the reinforcement in the coatings due to greater deformation of metallic particles and enhanced metallic bonding between the deformed splats (Ref 114).

It is well established that higher propelling gas pressure leads to elevated impact velocity and momentum of the particles (Ref 114). A series of studies on different material systems have found that increased propelling gas pressures lead to an increase in deposition efficiency, a decrease in porosity, more retention of reinforcing particles, and an increase in bonding strength. In particular, reinforcement retention can be improved due to increased particle momentum that helps embedment. In CS Ti/TiC coating, 
deposition efficiency and homogeneity of the coating were found to increase with increasing deposition pressure from 3.5 to $4 \mathrm{MPa}$ (Ref 115). In CS Maraging steel 300 (MS300) reinforced with $\mathrm{WC}$, the retainability of $\mathrm{WC}$ particles increased from 78 to $85 \%$ with an increase in propelling gas pressure from $4 \mathrm{MPa}$ to $5 \mathrm{MPa}$ (Ref 116). Increasing impact velocity was also shown to lead to lower porosity levels in $\mathrm{Al}_{2} \mathrm{O}_{3}$-reinforced $\mathrm{Cu}$ and $\mathrm{Al}$ MMCs (Ref 96, 117).

In summary, there exists a general trend that smaller amounts of reinforcement tend to increase the overall deposition efficiency of the powder blend, while larger amounts of reinforcement present a detrimental effect. Porosity and defects tend to decrease with the initial increase in the reinforcement content. However, at higher reinforcement contents, the benefit can be reduced due to fractured reinforcement particles resulted from impacts between the hard particles. Post-spray treatments such as heat treatment and friction stir processing can alter coating porosity and microstructure, often leading to a reduction in the number of defects, the formation of intermetallic compounds, and a more uniform microstructure through diffusion or mechanical blending.

\section{Elastic Deformation}

In general, cold spray coatings exhibit an anisotropic microstructure. The deposition process involves the highspeed impact of the particles onto a substrate or a predeposited layer, resulting in flattening of the particles, as well as compaction and tamping of the pre-deposited layer. As a result, the microstructure of CS coatings in the plane parallel to the substrate surface is different from that in the plane normal to it where higher densities of dislocations and grain boundaries are formed (Ref 118). In addition, due to influences of later arriving particles on the pre-deposited layers, differences in microstructure can occur at various depths. The degree to which such anisotropic microstructure could lead to elastic anisotropy has been the subject of a few studies (Ref 119-122). Resonant ultrasound spectroscopy (Ref 119) and depth-sensing indentation (Ref 120) measurements on $\mathrm{Al}, \mathrm{Cu}, \mathrm{Ni}, \mathrm{Ti}$, and $\mathrm{Ta}$ coatings have shown only a slight deviation from perfect elastic isotropy in contrast to thermal spray counterparts (Ref 121, 122). The same approximately isotropic behavior, albeit to a lesser degree compared to the single-phase counterpart, was reported for CS MMC coatings (Ref 118). This can be regarded as an advantage of cold spray MMC materials over fiber or laminate-reinforced composites that show strong anisotropic behavior.

Elastic deformation of CS MMC deposits occurs when the constituent phases are proportionally sharing the load, without plastic deformation or decohesion that can lead to load transfer and permanent damage of the coating. The elastic modulus of composite coatings depends on the volume fraction of the reinforcing particles. There are a few theoretical frameworks developed to predict the elastic modulus of composites with the rule of mixture (ROM) being the simplest one. Using an iso-strain (Voigt) model that assumes that reinforcement and matrix were fibers aligned along the loading direction subject to the same strain, an upper bound estimate of the elastic modulus is given by $\mathrm{Eq} 1$ :

$E_{\text {upper }}=\left(1-V_{P}\right) E_{M}+V_{P} E_{P}$

where $V_{P}$ is the volume fraction of the reinforcing particles, and $E_{P}$ and $E_{M}$ are elastic moduli of the particle and the matrix, respectively.

To account for the particulate-reinforced nature of CS MMCs, one of the most widely used models is the HashinShtrikman (H-S) model (Ref 123). The H-S model (Eq 26) assumes an isotropic aggregate based on the variational principle of linear elasticity:

$K_{\mathrm{upper}}=K_{P}+\left(1-V_{P}\right)\left[\frac{1}{K_{M}-K_{P}}+\frac{3 V_{P}}{3 K_{P}+4 G_{P}}\right]^{-1}$

$K_{\text {lower }}=K_{M}+V_{P}\left[\frac{1}{K_{P}-K_{M}}+\frac{3\left(1-V_{P}\right)}{3 K_{M}+4 G_{M}}\right]^{-1}$

$G_{\text {upper }}=G_{P}+\left(1-V_{P}\right)\left[\frac{1}{G_{M}-G_{P}}+\frac{6 V_{P}\left(K_{P}+2 G_{P}\right)}{5 G_{P}\left(3 K_{P}+4 G_{P}\right)}\right]^{-1}$

$G_{\text {lower }}=G_{M}+V_{P}\left[\frac{1}{G_{P}-G_{M}}+\frac{6\left(1-V_{P}\right)\left(K_{M}+2 G_{M}\right)}{5 G_{M}\left(3 K_{M}+4 G_{M}\right)}\right]^{-1}$

$E=\frac{9 K}{1+\left(\frac{3 K}{G}\right)}$

where $K$ and $G$ are the bulk and shear moduli of the composite. The subscripts "upper" and "lower" refer to the upper and lower bound estimates, and "M" and "P" refer to matrix and particle, respectively.

Mura's model (Ref 124), described with Eq 7-8, has also been proposed to estimate the elastic modulus of composite materials. In Mura's model, reinforcement geometry is assumed to be spherical, and only a relatively small volume fraction $(<25 \%)$ of reinforcement is considered:

$K=K_{M}\left[1+\frac{V_{P}\left(K_{M}-K_{R}\right)}{K_{M}+\frac{1}{3}\left(K_{R}-K_{M}\right) \frac{1+v_{M}}{1-v_{M}}}\right]^{-1}$ 
$G=G_{M}\left[1+\frac{V_{P}\left(G_{M}-G_{R}\right)}{G_{M}+2\left(G_{R}-G_{M}\right) \frac{4-5 v_{M}}{15\left(1-v_{M}\right)}}\right]^{-1}$

where $v$ is the Poisson's Ratio, and $K$ and $G$ can then be used in Eq 6 to calculate the elastic modulus of the composite material. In order to address Mura's model's deficiency in calculating the elastic modulus of the material at higher volume fractions of reinforcement $(>50 \%)$, the model proposed by Kroner (Ref 125) and Budiansky (Ref 126) yields to Eq 9-11 that when solved together, can be used to determine the elastic modulus:

$K=K_{M}+\frac{V_{P} K\left(K_{R}-K_{M}\right)}{K+\frac{1}{3}\left(K_{R}-K\right) \frac{1+v}{1-v}}$

$G=G_{M}+\frac{V_{P} G\left(G_{R}-G_{M}\right)}{G+2\left(G_{R}-G\right) \frac{4-5 v}{15(1-v)}}$

$v=\frac{3 K-2 G}{2(G+3 K)}$

Again, elastic modulus can be obtained using Eq 6 once Eq 9-11 are solved for $K$ and $G$.

It is also worth noting that in addition to the theoretical models described above, finite element simulations can be used to predict the elastic modulus of the composite material (Ref 127) by a proper choice of representative volume elements. However, both theoretical and simulation models fail to account for defects such as pores, fractured particles, and poor bonding, as well as possible anisotropy within cold-sprayed MMCs.

To assess the applicability of these models, measured elastic moduli for Al-SiC cold-sprayed coatings were collected from the literature (Ref 128) and plotted as a function of the $\mathrm{SiC}$ content. Theoretical predictions described

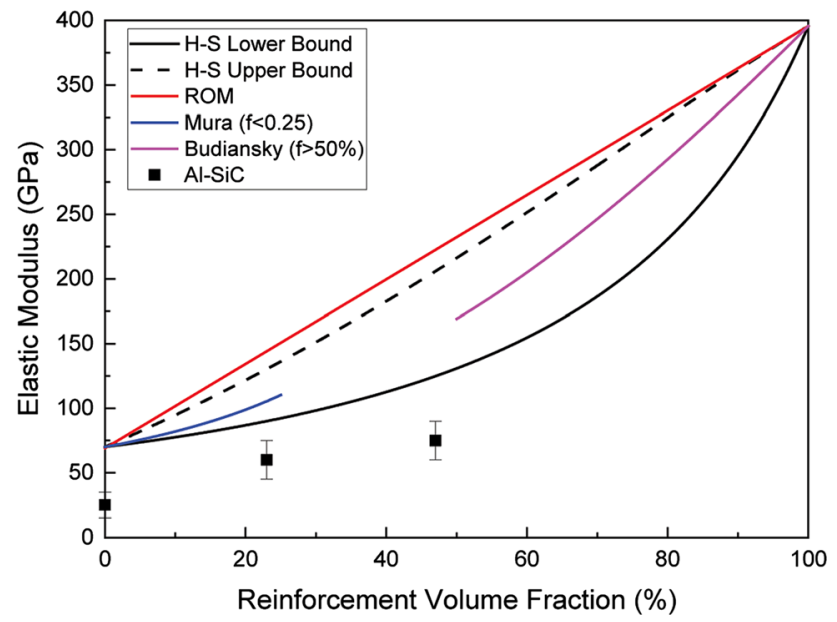

Fig. 4 Predicted and measured elastic moduli of Al-SiC CS composite coatings as a function of reinforcement volume fraction (Ref 128) above were superimposed on the same plot. Figure 4 shows that the elastic modulus of CS MMC increases with an increase in the reinforcement volume fraction, but the ROM significantly overestimates the increase in the case of Al-SiC MMCs. A similar increase in elastic modulus at higher volume fractions of reinforcement was also noticed in $\mathrm{Al}-\mathrm{Cu}$ (Ref 129) composite coatings. We also note that the experimental measurements are below the lower bound to all theoretical predictions, including the lower bound of the H-S model. This can be attributed to the presence of poorly bounded interfaces and porosity that influenced the stiffness of the composite material.

In addition to the reinforcement content, particle size and shape can also affect elastic moduli of MMC coatings. Particle size and shape can influence the reinforcement content in the coating even when all other spraying conditions are the same (Ref 130). Concerning particle size, cold-sprayed $\mathrm{Ni}-\mathrm{Ni}_{3} \mathrm{Al}$ deposited with the $\mathrm{Ni}_{3} \mathrm{Al}$ particle size less than $45 \mu \mathrm{m}$ was found to show a $12 \%$ higher elastic modulus as compared to the same material deposited with $\mathrm{Ni}_{3} \mathrm{Al}$ particles larger than $45 \mu \mathrm{m}$ (Ref 131). A decrease in mechanical properties with an increase in particle size is attributed to lower impact velocities achieved during spraying of larger particles, which in turn results in weaker interlocking/bonding between deformed particles (Ref 131). However, in another study of a CS NiFeSiAl soft magnetic composite coating, a 10-15\% increase in elastic modulus of the composite coating was obtained by increasing reinforcing particle size from $d_{0.5}=40$ to $56 \mu \mathrm{m}$ ( $\operatorname{Ref} 132$ ). The improvement was attributed to the enhanced peening effect of the rebounded large particles during deposition.

Regarding reinforcing particle shape, indentation measurements on $\mathrm{A} 380 / \mathrm{Al}_{2} \mathrm{O}_{3}$ composite coating with different $\mathrm{Al}_{2} \mathrm{O}_{3}$ powder morphologies (Ref 133), showed the composite with irregular $\mathrm{Al}_{2} \mathrm{O}_{3}$ to have higher hardness/elastic modulus, compared to the composite with spherical $\mathrm{Al}_{2} \mathrm{O}_{3}$ reinforcements. The elastic modulus of the composite made with a mixture of spherical and irregular reinforcements was shown to lie in between the two. The difference in elastic modulus due to reinforcement shapes was attributed to a higher amount of reinforcement content that was retained during the spraying process. The irregular-shaped reinforcing particles were found to impose higher constraints against the deformation of neighboring splats.

In conclusion, theoretical predictions can be used to estimate the elastic modulus of cold-sprayed MMCs. However, due to the shortcoming of not accounting for defects and porosities, predicted moduli are in general higher than the actual ones. Predictions do not account for anisotropy of CS MMC coatings which leads to a higher elastic modulus on the cross-sectional plane. Predictions 
also do not account for particle size and shape which have case-specific effects on coating elastic properties.

\section{Plastic Deformation}

\section{Indentation Hardness}

It is well established that the hardness of cold spray coatings is generally higher than those of both powder feedstock materials and bulk counterparts (Ref 112, 134-136). This is rooted in the work hardening phenomenon as a result of severe plastic deformation of powder particles during deposition. The high-velocity impact of powder particles generates large plastic strains of the order of $\sim 1$ (up to 10) and strain rates up to $10^{9} \mathrm{~s}^{-1}$, particularly in the interfacial regions, in a short period $(\sim 10$ to $\sim 100 \mathrm{~ns})$ (Ref 47, 48). A large density of dislocations is generated to accommodate plasticity which can organize themselves into subgrains. The adiabatic nature of the rapid deformation causes local temperature rise, which in turn gives rise to dynamic recrystallization (Ref 137-141). If the plastic strain and temperature exceed critical values, the subgrains rotate and recrystallize into refined grains (Ref 142), which are harder than the original grains due to the Hall-Petch effect (Ref 143). A combination of dislocation-based activities (Ref 98, 102, 144) and grain refinement (Ref $114,118,144)$ is responsible for the higher hardness of cold spray coatings compared to the original powder feedstock. Repeated impacts of the reinforcing (usually harder) particles further promote plastic deformation of the matrix metallic material through the tamping effect and provide extra work hardening. Figure 5(a) shows a transmission electron microscope (TEM) image of the interface between an $\mathrm{Al}$ particle and an $\mathrm{Al}_{2} \mathrm{O}_{3}$ particle in a cold spray composite (Ref 118). Nanocrystalline grains observed at the $\mathrm{Al}$ side near the interface indicate a significant level of plastic deformation in the metallic phase as a result of being impacted by the ceramic neighbor which does not show any evidence of plasticity. The resultant increase in dislocation density in the metallic phase and possible grain refinement such as shown in Fig. 5(b) can contribute to the overall hardening of the material.

In addition to grain-refinement-related strengthening mechanism, uniform distribution of the reinforcements in the coating constrains the deformation of the metallic particles and contributes to the hardening through a dispersion strengthening mechanism. Figure 5(b) shows an example of a uniform dispersion of $\mathrm{BN}$ particles in a $\mathrm{NiCrAl}$ alloy matrix processed via cold spray (Ref 145). The BN particles which are in intimate contact with the matrix do not deform when the material is loaded. BN particles provide hardening since a larger stress is necessary to expand a loop of dislocation between them. The sub-micron distance between $\mathrm{BN}$ particles, in this case, is beneficial as the flow stress is inversely related to the reinforcing particle distance. A comparison of the hardness of A15356/TiN composites in the as-sprayed and heattreated conditions suggests that the contribution of dispersion strengthening mechanism to the overall hardening is greater than that of tamping effect (Ref 146).

Hardness, along with other mechanical properties of MMCs such as strength and Young's modulus, can be, to the first order, predicted using ROM with two generalized

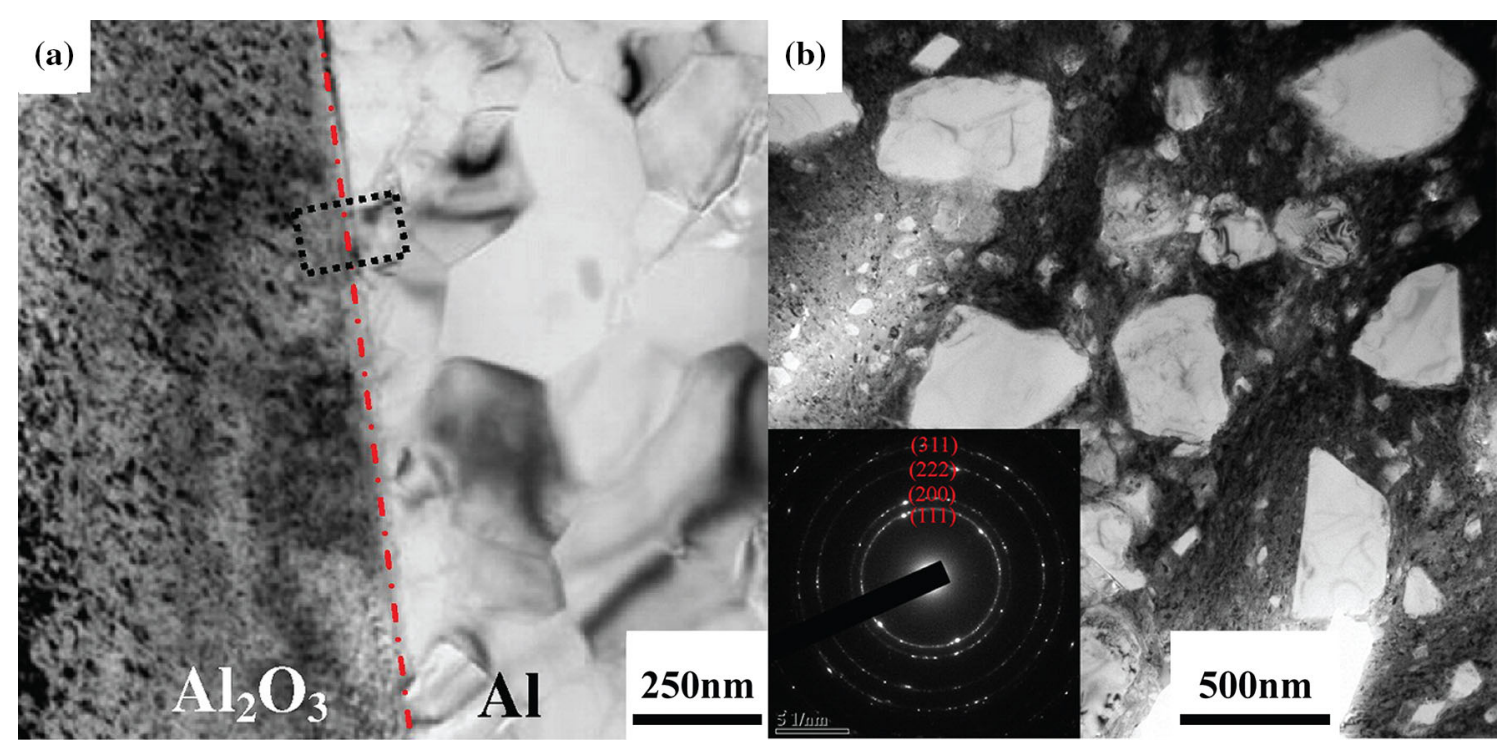

Fig. 5 TEM image of (a) metal-ceramic interface in $\mathrm{Al}_{-}-\mathrm{Al}_{2} \mathrm{O}_{3}$ composite coating and (b) cross-section of $\mathrm{BN}$-reinforced NiCrAl composite coating (Ref 118, 145). Images are reproduced with permission from Elsevier 
assumptions of iso-strain and iso-stress conditions (Ref 147). Iso-strain (Voigt) model assumes that reinforcement and matrix are subjected to the same strain, and thus yield to an upper bound for hardness in Eq 12. Iso-stress (Reuss) model assumes that stress in the reinforcement is equal to the stress in the matrix and yields to a lower bound for hardness of the composite as shown with the inverse ROM in $\mathrm{Eq} 13$ :

$$
\begin{aligned}
& H_{\text {upper }}=V_{P} H_{P}+V_{M} H_{M} \\
& H_{\text {lower }}=\left(V_{P} / H_{P}+V_{M} / H_{M}\right)^{-1}
\end{aligned}
$$

where $V_{P}$ and $V_{M}$ represent volume fractions of reinforcement and matrix, while $H_{P}$ and $H_{M}$ are hardnesses of the constituent phases, respectively. However, it is worth noting that the above equations only account for load sharing in fiber-reinforced composites arranged in axial or transverse loading directions and does not represent the particulate nature of reinforcements in CS MMCs. The effects of pores and defects on the load-bearing capacity of the MMC are not accounted for in Eq 12-13 either.

Figure 6 shows the lower bound and upper bound estimations of the hardness for $\mathrm{Al}-\mathrm{Al}_{2} \mathrm{O}_{3}$ composite coatings, along with the experimental measurements from literature (Ref 93, 148). We highlight that the hardness of bulk pure $\mathrm{Al}(\sim 15 \mathrm{HV})$ is lower than the hardness of pure $\mathrm{Al}$ coating $(\sim 40 \mathrm{HV})$, due to intensive work hardening during the spraying process. We have used the latter for the theoretical predictions. In Fig. 6, both theory and experiment show that the addition of reinforcement results in an increase in the hardness of CS MMCs. Reinforcement volume fractions in the coating are limited to $\sim 45 \%$ in this case due to the relatively lower deposition efficiency of ceramic particles during the spraying process. We note that measured hardness values are all within the region defined

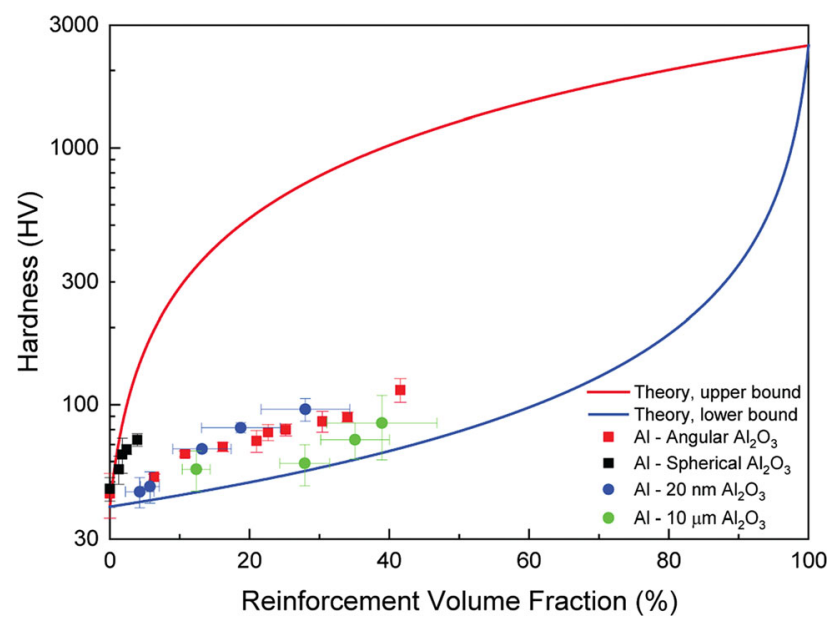

Fig. 6 Predicted and measured $\mathrm{CS} A \mathrm{Al}-\mathrm{Al}_{2} \mathrm{O}_{3}$ composite coating hardness as a function of reinforcement volume fraction (Ref $38,93,148)$ by the upper and lower bounds. The hardness values measured for $\mathrm{Al}$ coatings reinforced with angular $\mathrm{Al}_{2} \mathrm{O}_{3}$ reinforcement are closely following the trend predicted by the lower bound. The lower bound prediction, however, underestimates the hardness of the composite coating, as it does not take into account the work hardening of metallic phases during cold spray deposition. The hardness values for $\mathrm{Al}$ coatings reinforced with spherical $\mathrm{Al}_{2} \mathrm{O}_{3}$ are closer to the upper bound prediction. This is due to lower deposition efficiency in the latter case which led to a higher number of impacts and reboundings of ceramic particles and consequently a higher level of plastic deformation in the Al phase (Ref 93, 148). It is also interesting to note that the addition of nanoscale $\mathrm{Al}_{2} \mathrm{O}_{3}$ as reinforcement results in higher hardness of the composite coating as compared to the addition of microscale $\mathrm{Al}_{2} \mathrm{O}_{3} \cdot \mathrm{Al}_{2} \mathrm{O}_{3}$ nanoparticles, initially in the form of agglomerated powder in the feedstock, were shown to get effectively dispersed in the matrix during deposition. It is their decreased interparticle distances, compared to the microscale counterpart, that provides the composite coating with higher hardness through the dispersion strengthening mechanism (Ref 38).

\section{Effect of Reinforcement Content on Hardness of CS MMCs}

In Al-based composite coatings, the aforementioned general trends have been widely reported with various types of ceramic reinforcements. Hardness of $\mathrm{Al}-\mathrm{Al}_{2} \mathrm{O}_{3}$ composite coatings increased from $\sim 45 \mathrm{HV}$ to $\sim 110 \mathrm{HV}$ with increasing the $\mathrm{Al}_{2} \mathrm{O}_{3}$ content in the feedstock from 0 to 100 wt.\% (Ref 93). However, the hardness of $\mathrm{A} 380 / \mathrm{Al}_{2} \mathrm{O}_{3}$ coating first increased from $105 \mathrm{HV}$ to $\sim 140 \mathrm{HV}$ as ceramic content increased from 0 to $30 \mathrm{wt} \%$ and then decreased to $\sim 125 \mathrm{HV}$ with $40 \mathrm{wt}$.\% reinforcement in the feedstock (Ref 95). The degree of fragmentation of the $\mathrm{Al}_{2} \mathrm{O}_{3}$ particles in the latter case increased with the increase in $\mathrm{Al}_{2} \mathrm{O}_{3}$ content and resulted in higher porosity and consequently lower hardness of the composites with high ceramic contents (Ref 95). A general increase in hardness with the addition of a variety of reinforcements including $\mathrm{Al}_{2} \mathrm{O}_{3}$ (Ref 91, 149), Al-Si (Ref 97), Cu (Ref 129), $\mathrm{B}_{4} \mathrm{C}$ (Ref 130, 150), SiC (Ref 84, 128, 150, 151), TiN (Ref 98), and $\mathrm{TiB}_{2}$ (Ref 114) particles has been reported with various Al-alloy compositions.

Similar trends have also been reported in Ni-based coatings. Effect of various types of reinforcement including $\mathrm{Ni}_{3} \mathrm{Al}$ (Ref 88), WC (Ref 103, 104, 152), Co (Ref 152), and IN718 (Ref 153) has been studied. In all these cases, the addition of reinforcing particles led to an increase in the hardness of composite coatings. The largest gain in the hardness of Ni-based coatings was achieved with the addition of $\mathrm{WC}$ reinforcements. One special case was that 
the microhardness of the graphene nanoplate (GNP)-reinforced IN718 composite coatings was measured to be $14 \%$ lower than that of the pure IN718 coatings (Ref 106). The reduction in hardness was attributed to the poor bonding between GNP and IN718 particles.

In Cu-based coatings, it was reported that the addition of $\mathrm{Al}_{2} \mathrm{O}_{3}$ (Ref 99, 100, 154), carbon nanotubes (CNT) (Ref 102), SiC (Ref 102) (Ref 154), AlCuFeB quasicrystal (QC) (Ref 101), Cr (Ref 155), Ni (Ref 156, 157), Zn (Ref 157), and WC (Ref 158) reinforcing particles leads to an increase in hardness. However, $\mathrm{Cu}-\mathrm{MoS}_{2}$ (Ref 158, 159) composite coating presented a lower hardness than pure $\mathrm{Cu}$ coatings, due to $\mathrm{MoS}_{2}$ being softer than $\mathrm{Cu}$.

In Ti-based composite coatings, it was found that the hardness increased in Ti-13.8 vol.\% TiC compared to pure $\mathrm{Ti}$ due to relatively uniform dispersion of the hard $\mathrm{TiC}$ particles (Ref 160). However, the addition of more TiC particles in Ti-33.4 vol.\% TiC did not further improve the hardness due to decreased bonding between Ti particles as well as fragmented and cracked TiC particles (Ref 160). Hardness of the Ti6Al4V-23 vol.\% TiC composite coating also increased to $273 \pm 19 \mathrm{HV}$ compared to the unreinforced Ti6Al4V coating with a hardness of $191 \pm 12 \mathrm{HV}$ (Ref 161).

In Fe-based composite coatings, addition of $20 \mathrm{wt} . \% \mathrm{Ni}$ coated $\mathrm{SiC}$ particles resulted in a $17.8 \%$ increase in the microhardness of 316L CS MMCs compared to the unreinforced coating (Ref 162). In CS MMCs deposited with mixtures of stainless steel 316L, 10 wt.\% copper, and Tribaloy T-700 powders, increasing Tribaloy particles content to 10,30 , and $60 \mathrm{wt} . \%$ resulted in increase of the coating hardness by 8,24 , and $28 \%$ compared to the $316 \mathrm{~L}$ $10 \% \mathrm{Cu}$ coatings. The addition of the copper particles to the powder feedstock, on the other hand, resulted in a lower hardness of the CS composite due to copper being the softest of the three phases (Ref 107).

The hardness gain in other types of composite coating based on magnesium and ceramic matrices has been studied as well. In SiC-reinforced AZ91D coating (Ref 108), the microhardness of the composite coating increased from 150 to $\sim 200 \mathrm{HV}_{0.3}$ as the volume fraction of $\mathrm{SiC}$ increased from 19 to $51 \%$. In $\mathrm{Al}_{2} \mathrm{O}_{3}$-CNT composite coatings, well-dispersed 2 wt.\% CNTs within the $\mathrm{Al}_{2} \mathrm{O}_{3}$ matrix led to a significant fourfold increase in hardness of the composite coating compared to pure $\mathrm{Al}_{2} \mathrm{O}_{3}$. Further increase in CNT to 4 wt.\% did not result in significant improvement. The improvement in hardness in $\mathrm{Al}_{2} \mathrm{O}_{3}-\mathrm{CNT}$ composite coating is due to a load sharing phenomenon that is activated by the CNTs bridging the crack surfaces (Ref 163).

We have gathered indentation hardness and reinforcement volume fraction measurements for different CS MMCs from the literature and populate them in the plot shown in Fig. 7. We highlight that the reinforcement volume fraction in this plot is measured from CS coatings, not from powder feedstocks. Al-based, Cu-based and Ni-based CS MMCs are the widely studied material systems compared to $\mathrm{Mg}_{-}$, Ti-, and $\mathrm{Fe}$-based systems. We note an overall increasing trend in the hardness of CS MMCs with an increase in the reinforcement volume fraction. To the first order, the trend can be approximated as a liner increase, but with different rates depending on the material system and possibly spraying conditions. Among the widely studied material systems, Ni-based composite coatings present significantly higher hardness values compared to $\mathrm{Cu}$ - and Al-based MMCs. Covering a wider range of hardness and reinforcement volume fraction, $\mathrm{Ni}$ based coatings also offer more flexibility in terms of CS MMC design for a desired hardness. Cu-based coatings offer an intermediate hardness level but with the reinforcement volume fractions mainly limited to the lower end. While the hardness of Al-based CS MMCs is lower than the $\mathrm{Cu}$-counterparts at similar reinforcement contents, their ability to accommodate higher reinforcement volume fractions can be exploited to achieve comparable hardness values to the $\mathrm{Cu}$-based MMCs. The few data points for other material systems indicate that the hardness of $\mathrm{Mg}$ based coatings is close to that of Al-based ones, while the hardness of Fe-based and Ti-based coatings is more similar to that of Ni-based coatings. We also note that $\mathrm{Cu}$-reinforced SS $316 \mathrm{~L}$ coating is an exception to the general trend of Fig. 7. The decrease in hardness with an increase in the volume fraction of $\mathrm{Cu}$ in this latter case is attributed to the reinforcement being softer than the matrix.

\section{Effect of Particle Size and Morphology on Hardness of CS MMCs}

In addition to the volume fraction of reinforcing particles, it has been shown that particle size and morphology can also influence the hardness. Microhardness tests on A380/ $\mathrm{Al}_{2} \mathrm{O}_{3}$ composite coating showed that the coating with irregular $\mathrm{Al}_{2} \mathrm{O}_{3}$ has a higher hardness $\left(\sim 145 \mathrm{HV}_{0.3}\right)$, compared to the hardness of the composite reinforced with spherical $\mathrm{Al}_{2} \mathrm{O}_{3}\left(\sim 127 \mathrm{HV}_{0.3}\right)$. However, both composite coatings have higher hardness than pure A380 coating $\left(\sim 119 \mathrm{HV}_{0.3}\right)$, which lacks the tamping effect from ceramic particles (Ref 133). The composite made with a mixture of spherical and irregular reinforcements was shown to have intermediate hardness of $\sim 137 \mathrm{HV}_{0.3}$. The reason that irregular $\mathrm{Al}_{2} \mathrm{O}_{3}$ particles resulted in significantly higher hardness than the spherical counterpart is due to a large amount of retained irregular $\mathrm{Al}_{2} \mathrm{O}_{3}$ particles in the coating. WC powders with plasma spheroidized cast and agglomerated and sintered morphologies were used to produce Ni-WC MMCs (Ref 37). Higher hardness in Ni- 


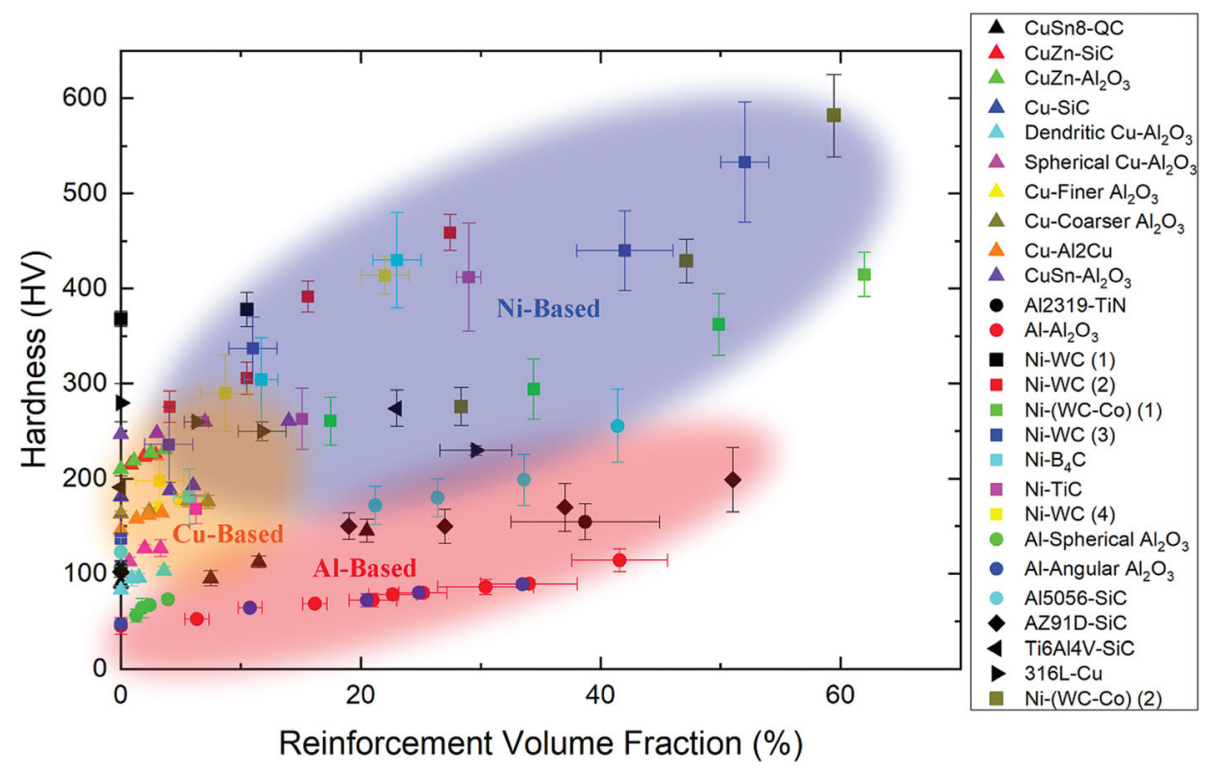

Fig. 7 Hardness of CS MMCs versus reinforcement volume fraction in the coatings classified based on the matrix material. Generally, an increase in hardness can be seen with an increase in reinforcement

cast WC was found compared to Ni-aggregate WC coatings. This was attributed to significantly lower mean free paths between WC particles in Ni-cast WC. As in Ni-cast WC, ultrafine $(<1 \mu \mathrm{m})$ WC fragments caused by severe fragmentation upon impact were dispersed in the coating (Ref 37). Besides, the hardness of the cast WC particles is also higher than that of aggregate WC, contributing to the overall higher hardness. From the above-mentioned examples, it is important to realize that details of manufacturing processes can influence various material properties. As a result, for CS MMCs reinforced with irregular particles, one needs to consider additional aspects that can influence mechanical performances of the coating.

In terms of particle size, in CS Ni-FeSiAl soft magnetic composite coating, higher deformation of FeSiAl particles and higher microhardness (10-15\%) of the composite were obtained by powders with a larger size $\left(d_{0.5}=56 \mu \mathrm{m}\right.$ compared to $40 \mu \mathrm{m}$ ) due to the enhanced peening effect of the rebounded large particles (Ref 132). In another study, however, $\sim 2.5 \%$ higher hardness for the coatings deposited with $\mathrm{Ni}_{3} \mathrm{Al}$ particles smaller than $45 \mu \mathrm{m}$ was obtained as compared to the coating sprayed with particles larger than $45 \mu \mathrm{m}$ (Ref 131). The decrease in hardness with an increase in particle size was attributed to lower velocity during spraying of the larger particles, resulting in a weaker mechanical interlocking between deformed particles. It was also reported that microhardness values were independent of the $\mathrm{Al}_{2} \mathrm{O}_{3}$ particle size in $\mathrm{Cu}-\mathrm{Al}_{2} \mathrm{O}_{3}$ composite coating (Ref 100). content (Ref 36, 37, 42, 83, 98, 100, 101, 106$108,148,152,154,174,213-216)$

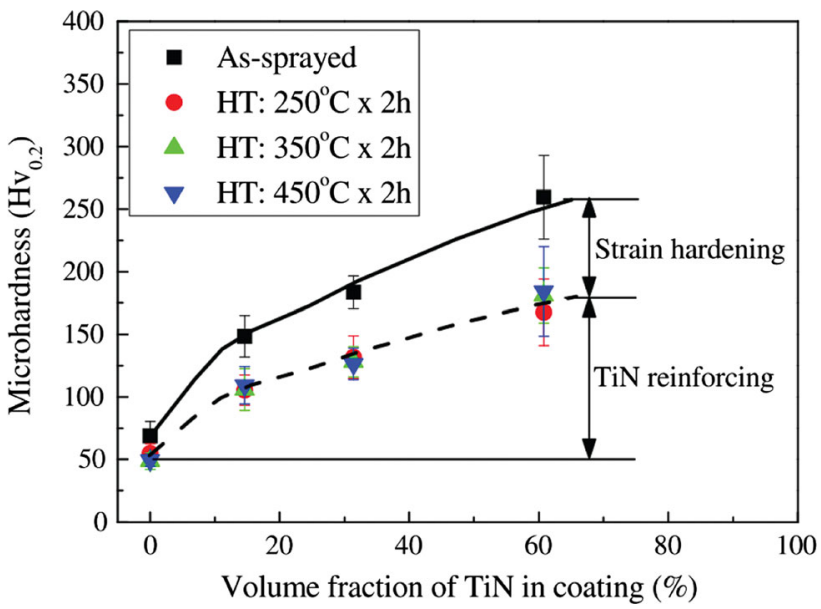

Fig. 8 Heat treatments lead to reduced hardness in Al-TiN MMC coating (Ref 146). The comparison shows that in this case, the hardness gain by dispersion strengthening is greater than that by work hardening. Image is reproduced with permission from Elsevier

\section{Effect of Post-spray Heat and Mechanical Treatments on Hardness of CS MMCs}

While the gain in hardness due to work hardening can be completely relieved by heat treatment, the gain in hardness due to dispersion strengthening is maintained in CS MMCs. This has been confirmed by comparing the microhardness of the TiN-reinforced A15356 coating before and after heat treatment at various temperatures with the hardness of the unreinforced coating in Fig. 8 (Ref 146). It is interesting to note the contribution of dispersion 
strengthening to the overall hardening of CS MMC, in this case, is larger than the contribution of work hardening.

Several studies reported a decrease in the hardness of CS MMC coatings after heat treatment due to the removal of the cold work effect and grain growth (Ref $39,109,128,164)$. Grain growth occurs due to the existence of a thermodynamic driving force to reduce the internal energy of the material, which can be achieved by reducing the total area of grain boundary while heat treatment is applied. However, due to a reduction of grain boundary in the coating, the effect of Hall-Petch strengthening is reduced (Ref 143). In $\mathrm{B}_{4} \mathrm{C} / \mathrm{Al}$ coatings heat-treated at $200,300,400$ and $500^{\circ} \mathrm{C}$ under high-purity Ar environment for $4 \mathrm{~h}$, increase in HT temperature up to $500^{\circ} \mathrm{C}$ resulted in a continuous decrease in coating hardness from $58 \pm 2.8$ in the as-sprayed condition to $35 \pm 1.3$ $\mathrm{HV}_{0.2}$ (Ref 109). The same trend was found in the $20 \mathrm{vol} . \%$ cBN-NiCrAl coatings where the hardness decreased from $\sim 1063 \pm 67 \mathrm{HV}$ in the as-sprayed condition to $997 \pm 43 \mathrm{HV}$ after heat treatment at $750^{\circ} \mathrm{C}$ for $5 \mathrm{~h}$ (Ref 164). In heterogeneously structured WC-10Co coatings, no significant change in the hardness of WC reinforcing particles was noticed after annealing at $900^{\circ} \mathrm{C}$ for $5 \mathrm{~h}$. However, a slight decrease in the overall hardness of the coating was observed and attributed to recovery, recrystallization, and grain growth of the Co phase (Ref 43). Heat treatment of $\mathrm{Al}-\mathrm{SiC} \mathrm{CS}$ MMCs in vacuum and air at $400^{\circ} \mathrm{C}$ for $4 \mathrm{~h}$ resulted in a 20 to $50 \%$ decrease in hardness, respectively (Ref 128). Heat treatment in air leads to oxidation at the inter-splat boundary region which may have hindered the complete bonding of the splats.

An increase in hardness after heat treatment at moderate temperatures can also be achieved as a result of enhanced inter-splat bonding and metallurgical bonding, e.g., formations of intermetallics, in CS MMC coatings (Ref 90, 111). However, in most cases, it was shown that excessive annealing temperatures result in a decline in hardness due to grain growth and removal of the cold work effect (Ref 90, 116). In CS $\mathrm{TiAl}_{3}-\mathrm{Al}$ composite coatings, while the average microhardness of the $\mathrm{Al}$ and $\mathrm{Ti}$ phases was 69 and $154 \mathrm{HV}$ in the as-sprayed condition, respectively, the in situ reaction of $\mathrm{Al}$ and $\mathrm{Ti}$ during heat treatment led to a significant increase in the hardness to $525 \mathrm{HV}$ in the intermetallic phase (Ref 111). The as-sprayed FeAl/ $\mathrm{Al}_{2} \mathrm{O}_{3}$ coating exhibited a hardness of about $600 \mathrm{HV}_{0.1}$, which slightly increased after annealing between 300 and $500^{\circ} \mathrm{C}$ for $5 \mathrm{~h}$ (Ref 90). The microhardness, however, decreased with annealing temperature further increasing beyond $500^{\circ} \mathrm{C}$ where phase transformation and recrystallization were activated. The microhardness of the deposit annealed at a temperature of $1100^{\circ} \mathrm{C}$ was only two-third of the microhardness in the as-sprayed condition (Ref 90). Increased microhardness is also achieved after the solution and age hardening treatments in CS WC-MS300 coating (Ref 116). However, samples with higher treatment temperatures achieved lower hardness due to coarsened grain size offsetting precipitation hardening (Ref 116). The microhardness of oxidized CS Ni- $\mathrm{Al}_{2} \mathrm{O}_{3}$ coatings after vacuum heat treatment at a range of temperatures (650$850^{\circ} \mathrm{C}$ ) was found to be comparable to the as-received condition (Ref 165). In this case, the oxidation process relaxed compressive stresses, and the formation of $\mathrm{NiO}$ in the coating counteracted the reduction in hardness.

In contrast to the initial increase in hardness followed by a later decline with increasing annealing temperature discussed above, heat-treated $\mathrm{Ag} / \mathrm{SnO}_{2} \mathrm{CS}$ MMCs showed an opposite trend. The hardness decreased from $112 \pm 3 \mathrm{HV}$ in the as-sprayed condition to $76 \pm 2 \mathrm{HV}$ after annealing at $600^{\circ} \mathrm{C}$, followed by an increase to $110 \pm 3 \mathrm{HV}$ after annealing at $850^{\circ} \mathrm{C}$. In this case, the initial decline in the hardness was attributed to the release of residual stresses and recrystallization of silver particles as well as the transverse cracks in the coating-substrate interface. The increase in hardness at higher annealing temperature, on the other hand, was attributed to residual stress relaxation and simultaneously densification of the coating (Ref 166).

A common post-spray mechanical treatment for cold spray coating is friction stir processing (FSP) (Ref 167170). During FSP, the frictional heat causes the materials to soften without melting and thus accommodate a high level of plastic deformation and mixing (Ref 169, 170). FSP of CS AA2024/ $/ \mathrm{Al}_{2} \mathrm{O}_{3}$ was shown to break the $\mathrm{Al}_{2} \mathrm{O}_{3}$ reinforcing particles into smaller particles and improve reinforcement dispersion in the AA2024 matrix (Ref 171). As the severity of the FSP process increases with increasing tool rotation speed, from Fig. 9(a), (b), (c) and (d), it is noticed that the $\mathrm{Al}_{2} \mathrm{O}_{3}$ fragments get finer and their distance decreases. Meanwhile, the dissolution of the Guinier-Preston Bagaryatskii (GPB) zone and the formation and coarsening of the high-temperature metastable $S\left(S^{\prime}\right)$ phase were shown to occur during FSP. FSP was shown to transform a two-phase microstructure in CS Ni-Ti composite coating in the as-sprayed condition (see the SEM micrograph and the corresponding EDS maps in Fig. 9e and f) into severely deformed and alloyed microstructure, shown in the SEM/ESD images in Fig. 9(g) and (h) (Ref 89). Ni-Ti intermetallic compounds were found in the alloyed layer, on the top surface. Cross-sectional observation of the coating after FSP (Fig. 9i) shows that a deformed layer, shown with the black arrow, exists beneath the alloyed top surface. While the alloyed layer on the top is homogenous, the deformed layer is characterized by heavily elongated particles along the rotation direction of the tool (Ref 89).

As a post-spray treatment to CS MMCs, FSP can lead to a significant increase in coating hardness due to 
Fig. 9 AA2024/ $\mathrm{Al}_{2} \mathrm{O}_{3} \mathrm{CS}$

$\mathrm{MMC}$ in as-sprayed condition

(a) and friction stir-processed

(b-d). Friction stir tool rotation

speed was increased from (b) to

(d) where changes in the particle

refinement degree, particle

dispersion as well as

interparticle spacing can be observed (Ref 209). SEM micrograph (e) and EDS maps

(f) show the surface of assprayed Ni-Ti coating, where large $\mathrm{Ni}$ and $\mathrm{Ti}$ particles are present. After FSP, an alloyed layer of $\mathrm{Ni}-\mathrm{Ti}$, along with elemental mixture, and intermetallic formation occurred as shown in the SEM micrograph (g) and EDS map (h). A cross-sectional micrograph of the FSPed coating (i) shows an alloyed layer on the top and a deformed layer on the bottom. The former is characterized by the homogeneous layer on the top, while the latter presents heavily elongated particles along the rotation direction of the tool, as marked by the arrow (Ref 89). Images are reproduced with permission from Elsevier
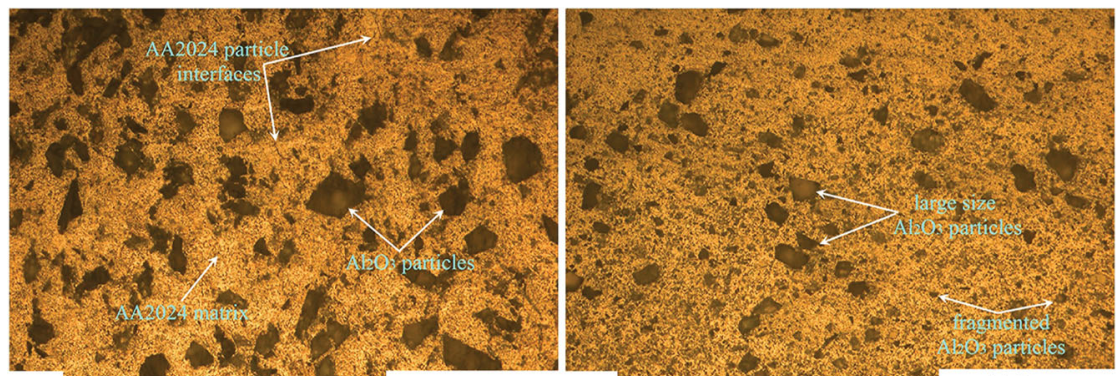

(a)

$100 \mu \mathrm{m}$

(b)
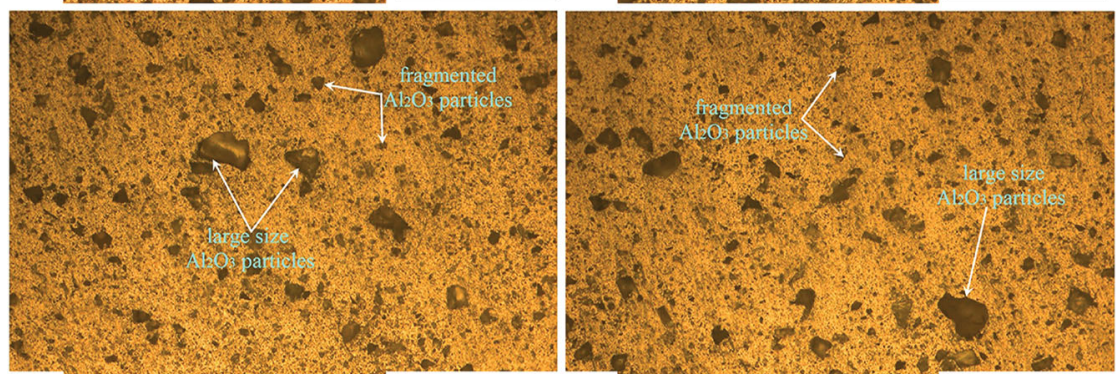

(c)

$100 \mu \mathrm{m}$

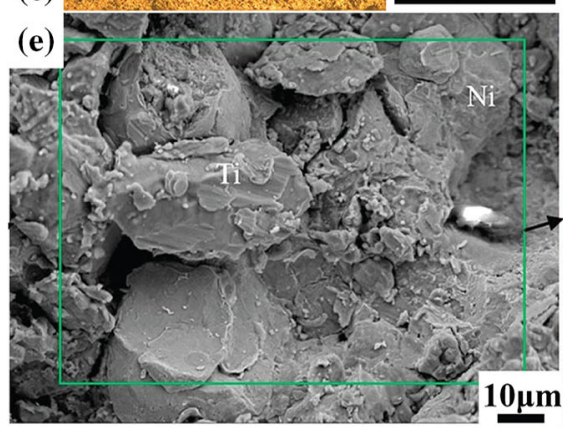

(d)

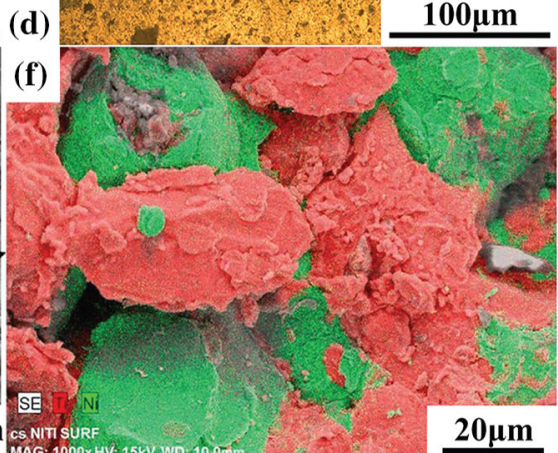

\section{(g)}

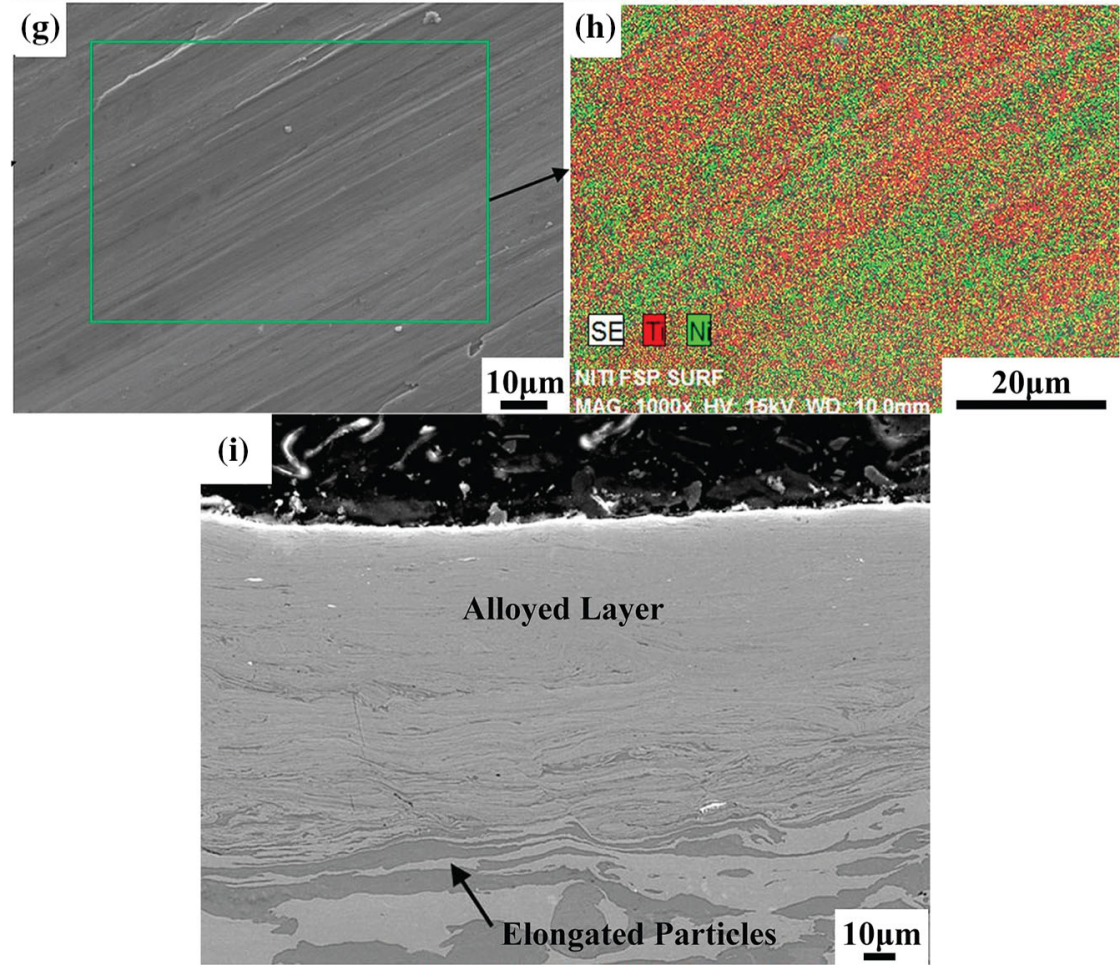

(h)

$20 \mu \mathrm{m}$ 
microstructural and morphological refinement as well as improved mixing and bonding. After FSP, the hardness of AA2024/ $\mathrm{Al}_{2} \mathrm{O}_{3}$ MMCs increases from $\sim 125$ to $145 \mathrm{HV}$ due to the refinement of $\mathrm{Al}_{2} \mathrm{O}_{3}$ particles (Ref 171). The microhardness of the FSPed Ni-Ti coating significantly increased to $1003 \pm 65 \mathrm{HV}$, about 4.5 times compared to the as-sprayed coating. For WC-CoCr MMC, post-spray FSP has resulted in a $\sim 120 \%$ increase in the average hardness compared to the as-deposited coating. This increase is attributed to the WC particle refinement and the reduction in the reinforcing interparticle distance (Ref 172).

\section{Effect of Processing Parameters on Hardness of CS MMCs}

In general, higher deposition/preheating temperatures result in lower hardness for the CS MMC coatings. The microhardness of Al5056-SiC composite coatings was shown to slightly decrease with the gas temperature increasing from 400 to $600^{\circ} \mathrm{C}$ ( $\operatorname{Ref} 83$ ). The trend was found to be persistent in a wide range of reinforcement content from 0 to $60 \mathrm{vol} . \%$. As particle preheating temperature increased from 25 to $500^{\circ} \mathrm{C}$, the microhardness of $\mathrm{Ni}-\mathrm{FeSiAl}$ composite coating decreased from $\sim 330$ to $\sim 240 \mathrm{HV}_{0.3}$ due to thermal softening (Ref 173). Thermal softening in this case reduced the hardness of the matrix more significantly than the hardness of the reinforcement. As a result, flattening of reinforcing particles was reduced.

Higher propelling gas pressure, unlike temperature, usually leads to increased hardness in CS MMCs due to a stronger work hardening effect during the deposition process. As an example, about a twofold increase in particle velocity resulted in about the same twofold increase in the microhardness of NiCrAl-BN and $\mathrm{Ti}^{-\mathrm{TiAl}_{3}} \mathrm{CS}$ MMCs (Ref $174,175)$. In addition, the effect of higher momentum on the hardness of the MMC coatings can be high enough to compensate for the lower hardness of the initial powder feedstock, as exemplified by a comparison of $\mathrm{B}_{4} \mathrm{C}$ and $\mathrm{WC}$ as reinforcement added to $\mathrm{Ni}$ coatings. While $\mathrm{B}_{4} \mathrm{C}$ reinforcing particles are much harder than $\mathrm{WC}, \mathrm{Ni}-\mathrm{WC}$ coating showed similar hardness to $\mathrm{Ni}-\mathrm{B}_{4} \mathrm{C}$ coating due to higher momentum and tamping effect of WC particles (Ref 174).

In summary, hardness, as a widely studied material property, can be predicted with the rule of mixtures to a relatively better accuracy when compared with elastic modulus with the same framework. An increase in reinforcement content generally leads to an overall increase in coating hardness as long as the reinforcement is harder than the matrix. Particle size and shape can have dual effects on coating hardness and should be studied on a case by case basis. Heat treatment, while relaxing the intense cold work effect, preserves the dispersion strengthening in CS MMCs and can lead to the formation of intermetallic compounds with certain material systems. As a result, it is often found that heat treatment can slightly decrease or even increase coating hardness. However, treatment conditions such as temperature and time should be carefully studied on a case by case basis to achieve optimal results for a particular coating. Post-spray mechanical treatment such as friction stir processing can significantly increase coating hardness by refining the reinforcing particles and matrix grain size as well as enhancing the dispersion strengthening effect.

\section{Yield Strength, Tensile Strength, and Ductility}

In addition to being a potent coating technology, cold spray can be used for near-net-shape and additive manufacturing (Ref 109, 154, 176, 177). Cold spray demonstrates a lower tendency of delamination compared to thermal counterparts, and as a result, can be used to manufacture bulk materials and components. The demand in free-standing CS materials motivates understanding and measuring mechanical properties such as yield strength, ultimate tensile strength (UTS), and ductility at the macroscales.

A recent study (Ref 105) on CS WC-reinforced Ni composite coatings has proposed a unified scaling law between the tensile strength and the characteristics of coldsprayed composite materials:

$\mathrm{UTS} \propto \frac{\psi}{\sqrt{\phi} \times \sqrt{\lambda} \times \theta}$

where UTS represents the ultimate tensile strength of the MMC coating, $\psi$ represents the total interfacial area between the metallic matrix and ceramic reinforcements, $\lambda$ represents the mean free path between the reinforcing particles, $\phi$ represents the average particle size, and $\theta$ represents the porosity of the coating (Ref 105). From the proposed model, the tensile strength of the coating will increase as the reinforcement content increases due to larger interfacial areas available to transfer and share the load. Larger reinforcement contents will also lead to a reduced mean free path between the particles and thus present greater constraints on the plastic deformation of the coating. An increase in the average size of reinforcing particles, however, will result in a decrease in tensile strengths, as larger particles result in larger mean free paths, adversely affecting the load-bearing capacity of the MMC (Ref 105, 178). Besides, increasing porosity will result in an inversely proportional reduction of the tensile strength. These effects are interconnected since changing reinforcement content can change all four variables in the equation. The scaling described above can be observed in Fig. 10, where the scaling between UTS and $\psi, \phi, \lambda$, and $\theta$ are shown for Ni-WC composite coatings in (a)-(d), respectively (Ref 105). 

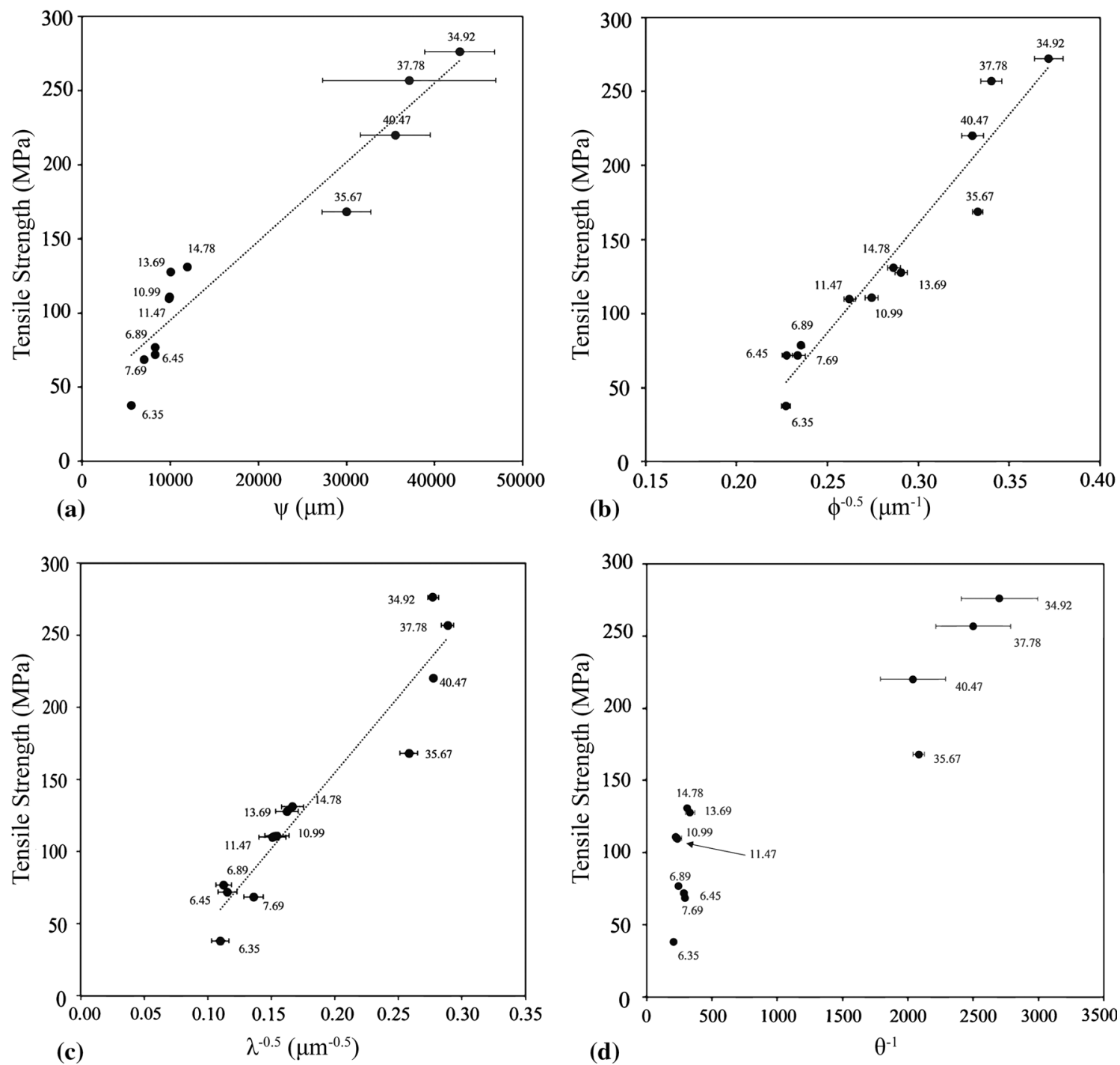

Fig. 10 Effect of (a) total interfacial area between the metallic matrix and ceramic reinforcements, $\psi$, (b) mean free path between the reinforcing particles, $\lambda$, (c) the average particle size, $\phi$, and

There is a relatively limited amount of studies that investigated the effect of reinforcement content on the tensile properties of free-standing CS MMCs. Consistent with the indentation hardness results, the addition of reinforcing particles improves the UTS of free-standing MS300/WC (Ref 116), A380/Si (Ref 179), Al-B 4 C (Ref 176, 180) composites compared to unreinforced ones. However, the effect of the amount of reinforcement on the ductility of CS MMCs is more limited with the brittleness in the as-sprayed condition; all the above-mentioned coatings have shown ductility in the range of $0-1 \%$ without post-spray treatments (Ref 116, 176, 179, 180). Brittle nature of CS MMCs is due to a large amount of inter-splat defects and intensive cold working effect (Ref 109). Pores, defects, and interfaces with a lack of metallurgical bonding are favorable locations for crack initiation. Heat treatments

(d) porosity, $\theta$, on ultimate tensile strength of Ni-WC composite coatings (Ref 105). Images are reproduced with permission from Elsevier

such as annealing and solution aging, and mechanical treatments such as hot rolling, or a combination of the two will be required to promote metallurgical bonding and to enhance the ductility of CS MMCs.

Although limited, there are some reports on the effect of reinforcement content on the strength and ductility of various $\mathrm{CS}$ MMC coatings. In $\mathrm{Al}_{2} \mathrm{O}_{3}$-reinforced $\mathrm{Al} \mathrm{CS}$ MMC, the UTS of the coating increased from 61 to 88 and $98 \mathrm{MPa}$ as the reinforcement content increased from 0 to 25 and 50 vol.\%. (Ref 79). The addition of $\mathrm{SiC}$ also led to a higher strength in Al coating, with the UTS increasing from 40 to $\sim 60$ and $95 \mathrm{MPa}$ with an increase in $\mathrm{SiC}$ content from 0 to 23 and 47 vol.\% (Ref 128). Such increase in strength can be due to the tamping and depression strengthening effects (Ref 79, 100). Ductility, however, decreased from $0.5 \%$ in the pure material to $\sim 0.2 \%$ in the 
composite reinforced with 23 and 47 vol.\% of SiC (Ref 128). In Cu-metallic glass (MG) CS MMCs, the strength increased $14 \%$ and the ductility was also improved from $3.0 \%$ (pure $\mathrm{Cu}$ ) to $6.6 \%$ by the addition of 4 wt.\% MG particles. Ductility, however, remained relatively low compared to heat-treated samples $(\sim 20 \%)$ due to the cold work effect (Ref 181).

In terms of the effect of powder morphology, it was found that in $\mathrm{Al}_{2} \mathrm{O}_{3}$-reinforced $\mathrm{A} 380$ coating (Ref 110), the addition of 20 vol.\% spherical and irregular ceramic particles in the feedstock resulted in a $70 \%$ and $40 \%$ increase in the UTS respectively. Ductility improved from $\sim 3 \%$ in the as-sprayed condition to $4 \%$ and $4.5 \%$ for irregular and spherical reinforcements, respectively. The enhanced performance found with the spherical particles is due to a stronger tamping effect resulted from spherical particles' tendency to rebound when they impact upon the substrate to a depth that is not significantly greater than their radius. In contrast, irregular particles were easier to embed and had a smaller probability to rebound during the deposition process, producing a less compact deposit.

Heat treatment can have profound impacts on the tensile properties of CS MMCs. It can lead to a significant increase in ductility by improving inter-splat bonding as well as the recovery and recrystallization in the cold worked regions. However, the typical strength-ductility tradeoff is observed in this class of materials. A comparison of engineering stress-strain curves in Fig. 11 shows that the strength and ductility of CS MMCs can be adjusted by applications of heat treatment. While the $\mathrm{Cu}-\mathrm{MG}$ coating showed relatively lower ductility in the as-sprayed condition (Ref 181), an increase in ductility of the composite coating was obtained by increasing temperatures up to $300^{\circ} \mathrm{C}$ in a $1-\mathrm{h}$ annealing treatment. Elongation was improved from $6.6 \%$ in the as-sprayed conditions to $26.1 \%$, in exchange for the

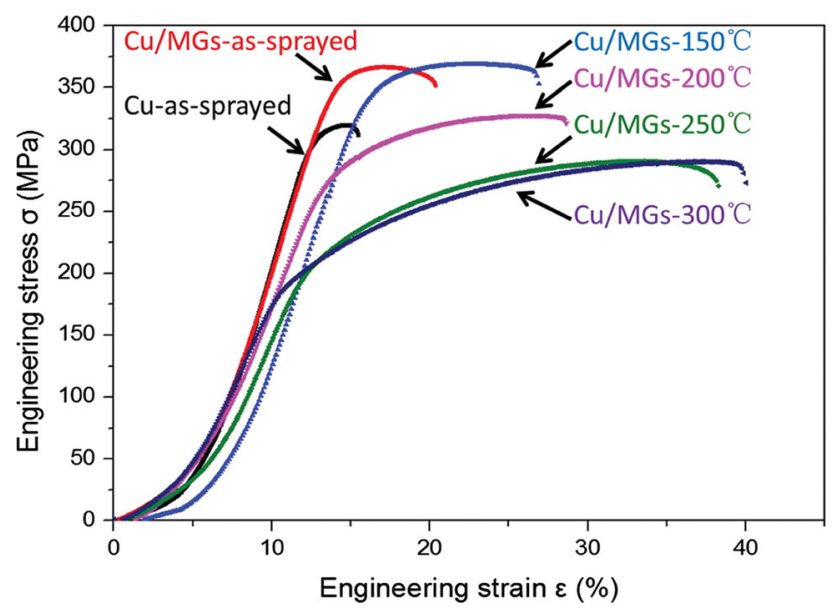

Fig. 11 Heat treatments lead to enhanced ductility in CS Cu-MG MMCs (Ref 181). Image is reproduced with permission from Elsevier reduction of tensile strength from $366 \pm 10 \mathrm{MPa}$ to $290 \pm 10 \mathrm{MPa}$. The significant increase in ductility was attributed to the recrystallization of the $\mathrm{Cu}$ matrix, which reduced the density of dislocations and the work hardening effect produced during the cold spray process. In $\mathrm{Al}_{2} \mathrm{O}_{3^{-}}$ reinforced A380 coating (Ref 110), post-spray heat treatment at $350^{\circ} \mathrm{C}$ for $4 \mathrm{~h}$ was shown to fuse splat boundaries and increase ductility by a factor of two compared to the as-sprayed condition. In $\mathrm{B}_{4} \mathrm{C} / \mathrm{Al}$ composite coating, assprayed and heat-treated coating at $200^{\circ} \mathrm{C}$ showed entirely brittle behavior due to large amounts of inter-splat defects and intensive cold working effect (Ref 109). An increase in both ductility and strength was achieved with increasing annealing temperature to $500^{\circ} \mathrm{C}$. The tensile strength reached $60 \mathrm{MPa}$ compared to $38 \mathrm{MPa}$ in the as-sprayed condition and the ductility increased from 0.3 to $1.4 \%$ (Ref 109). In solution-aged CS WC-reinforced MS 300 coating, the tensile strength of the coating processed with two different sets of processing parameters significantly increased from $147 \mathrm{MPa} / 308 \mathrm{MPa}$ in the as-sprayed condition to $744 \mathrm{MPa} / 821 \mathrm{MPa}$, and the ductility improved from $0.6 \%$ / $0.96 \%$ to $2.53 \% / 3.06 \%$ with solution treatment at $800 / 1000^{\circ} \mathrm{C}$ for $1 \mathrm{~h}$ and aging at $480^{\circ} \mathrm{C}$ for $6 \mathrm{~h}$ (Ref 116).

Hot rolling, as a post-spray treatment to cold spray, was shown to increase both strength and ductility of Si-reinforced A380 composite coatings (Ref 179). A thickness reduction of $40 \%$ at $500^{\circ} \mathrm{C}$ led to a significant increase in UTS, from $100 \pm 13.4 \mathrm{MPa}$ in the as-sprayed condition to $420 \pm 2.1 \mathrm{MPa}$ after hot rolling. This was accompanied by a concurrent increase in ductility from none to $5 \pm 2.3 \%$ elongation. The improvement in strength and ductility was found to be due to various forms of strengthening from grain boundary to solid solution to precipitation strengthening to dispersion as well as enhanced inter-splat bonding (Ref 179). Hot rolling was also found to be more effective than annealing at $300^{\circ} \mathrm{C}$ for $10 \mathrm{~h}$ which resulted in a moderate increase in strength to $186 \pm 17 \mathrm{MPa}$ and ductility to $0.93 \pm 0.05 \%$.

Similar hot rolling with various thickness reductions $(20 \%, 40 \%$, and $60 \%)$ was performed on CS Al-B ${ }_{4} \mathrm{C}$ composite coating as part of a thermomechanical treatment with consecutive heating and rolling steps (Ref 180). The resultant UTS and elongation were found to increase with higher levels of thickness reduction. The strength and ductility of the as-sprayed coatings $(\sim 37 \mathrm{MPa}$ and $\sim$ $0.3 \%$ elongation) significantly increased after $60 \%$ thickness reduction to $131 \mathrm{MPa}$ and $\sim 5.2 \%$ elongation. Fracture surface analysis of the as-sprayed coatings showed debonding of mechanically interlocked $\mathrm{Al}$ splats at $\mathrm{B}_{4} \mathrm{C} / \mathrm{Al}$ interfaces. Al splat boundaries were partially healed out after $20 \%$ thickness reduction, while the bonding between $\mathrm{B}_{4} \mathrm{C}$ and $\mathrm{Al}$ was found to be still too weak to transmit the load. In the case of $40 \%$ and $60 \%$ thickness reductions, on 
the other hand, uniform dimple morphologies were found on the fracture surface indicating the homogeneity of the microstructure composed of uniformly distributed refined $\mathrm{Al}$ grains and $\mathrm{B}_{4} \mathrm{C}$ particles (Ref 180). A one-step 30\% thickness reduction at $500^{\circ} \mathrm{C}$ and a hybrid hot compression and hot rolling with a total thickness reduction of $70 \%$ were both found to be effective with a concurrent increase in strength and ductility. In contrast to an isothermal heat treatment at $500^{\circ} \mathrm{C}$ for $4 \mathrm{~h}$, the hybrid treatment resulted in about threefold higher strength and fourfold higher elongation (Ref 176).

The tensile properties of CS AA2024/ $\mathrm{Al}_{2} \mathrm{O}_{3}$ MMCs are significantly enhanced after FSP, showing a $20 \%$ concurrent increase in both UTS and ductility. The improved interparticle bonding decreased reinforcing particle spacing, and their refinement was the main strengthening mechanism, while removal of weak interfaces was the origin of the improved tensile ductility (Ref 171).

From the various studies above, it can be seen that interparticle bonding quality is an important factor affecting the tensile strength of CS MMCs. To provide a better prediction of the tensile strength, numerical studies on the load-bearing behavior of CS MMCs are required. Although not specifically modeling CS MMCs, several finite element simulations on the particulate-reinforced materials (Ref 182-187) in general show that interfacial bonding strength and interfacial fracture energy dictate the overall strength of particulate-reinforced MMCs. Also, the morphology and volume fraction of the reinforcements can influence the overall stress-strain response (Ref 187). Due to the differences between CS MMCs and other types of particulatereinforced materials, additional studies using finite element methods on the CS MMCs, in particular, are required to provide a more comprehensive understanding of the loadbearing behavior of CS MMCs.

In summary, while the tensile strength of CS MMCs is higher than the unreinforced counterparts, their ductility can be relatively low in the as-sprayed condition due to a large number of defects and lack of metallurgical bonding. Heat treatment can lead to a significant increase in the ductility, albeit with a typical compromise in the tensile strength. A concurrent increase in ductility and strength can be achieved by applying thermo-mechanical treatments such as hot rolling and friction stir post-processing. In general, higher reinforcement contents lead to a higher tensile strength. Spherical reinforcing particles have been shown to result in higher tensile strength and ductility of the composite compared to irregular reinforcements.
Fig. 12 SEM micrographs and EDS mapping of failed coatingsubstrate interfaces after adhesion tests. Here the coating is $\mathrm{Al}-\mathrm{Al}_{2} \mathrm{O}_{3}$ of varying $\mathrm{Al}_{2} \mathrm{O}_{3}$ contents and the substrate is $\mathrm{Mg}$. Effect of increasing reinforcing content from 0 to 25,50 , and $75 \mathrm{vol} \%$ in powder feedstock is shown in the SEM micrographs (a-d) and corresponding EDS maps (e-h) (Ref 31). Images are reproduced with permission from Elsevier

\section{Failures}

Understating adhesive and cohesive failures of CS MMCs is of particular importance due to the widespread application of such materials as protective, structural, and functional coatings. The addition of reinforcing particles has shown both positive (Ref 31, 93) and negative (Ref 84) effects on the coating's adhesion to the substrate. A relatively small amount of reinforcing particles can produce a strong activation effect on the substrate surface and thus improve adhesion strength of CS MMC by (1) roughening of the substrate surface and (2) cleaning the oxide film off the substrate surface (Ref 25). Both effects facilitate the formation of metallurgical bonds between the substrate and the matrix. It is also suggested that the removal of oxide film from metallic particles can happen by the impact of ceramic particles during the spraying process, increasing chemical/metallurgical activity and as a result the strength of the coating (Ref 25).

The effects of reinforcing particles on matrix and substrate can be seen in the SEM micrographs and energydispersive $\mathrm{x}$-ray spectroscopy (EDS) maps shown in Fig. 12, where the surfaces of the $\mathrm{Mg}$ substrate underneath an $\mathrm{Al}-\mathrm{Al}_{2} \mathrm{O}_{3}$ coating was characterized after adhesive failure. Figure 12(a) shows the failed interface for the case of unreinforced coating. Figure 12(b), (c) and (d), on the other hand, shows the failed interfaces for MMCs reinforced with 25,50 , and $75 \mathrm{vol} . \% \mathrm{Al}_{2} \mathrm{O}_{3}$, respectively. The corresponding EDS maps are shown in Fig. 12(e), (f) and (h) where green areas show the $\mathrm{Al}$ residue on the $\mathrm{Mg}$ substrate (red) after the adhesive failure. It can be seen that the addition of $\mathrm{Al}_{2} \mathrm{O}_{3}$ reinforcement significantly improved $\mathrm{Al}$ adhesion onto the $\mathrm{Mg}$ surface and changed the failure mode from adhesive to cohesive, demonstrated by the increase in aluminum adhering to the magnesium substrate. The enhanced adhesion is attributed to the above-mentioned roughening effect as well as the removal of oxides from the surface. Bonding strength increased from $\sim 15$ $\mathrm{MPa}$ at no reinforcement to $\sim 45 \mathrm{MPa}$ at 50 vol. $\% \mathrm{Al}_{2} \mathrm{O}_{3}$ with the failure mode being adhesive. However, the bonding strength decreased to $\sim 30 \mathrm{MPa}$ with an increase in the $\mathrm{Al}_{2} \mathrm{O}_{3}$ content to 75 vol.\% where the failure mode was changed to cohesive (Ref 31$)$.

In AZ91D-SiC composite coating, 15 vol.\% addition of $\mathrm{SiC}$ particles resulted in an increase in the adhesion 

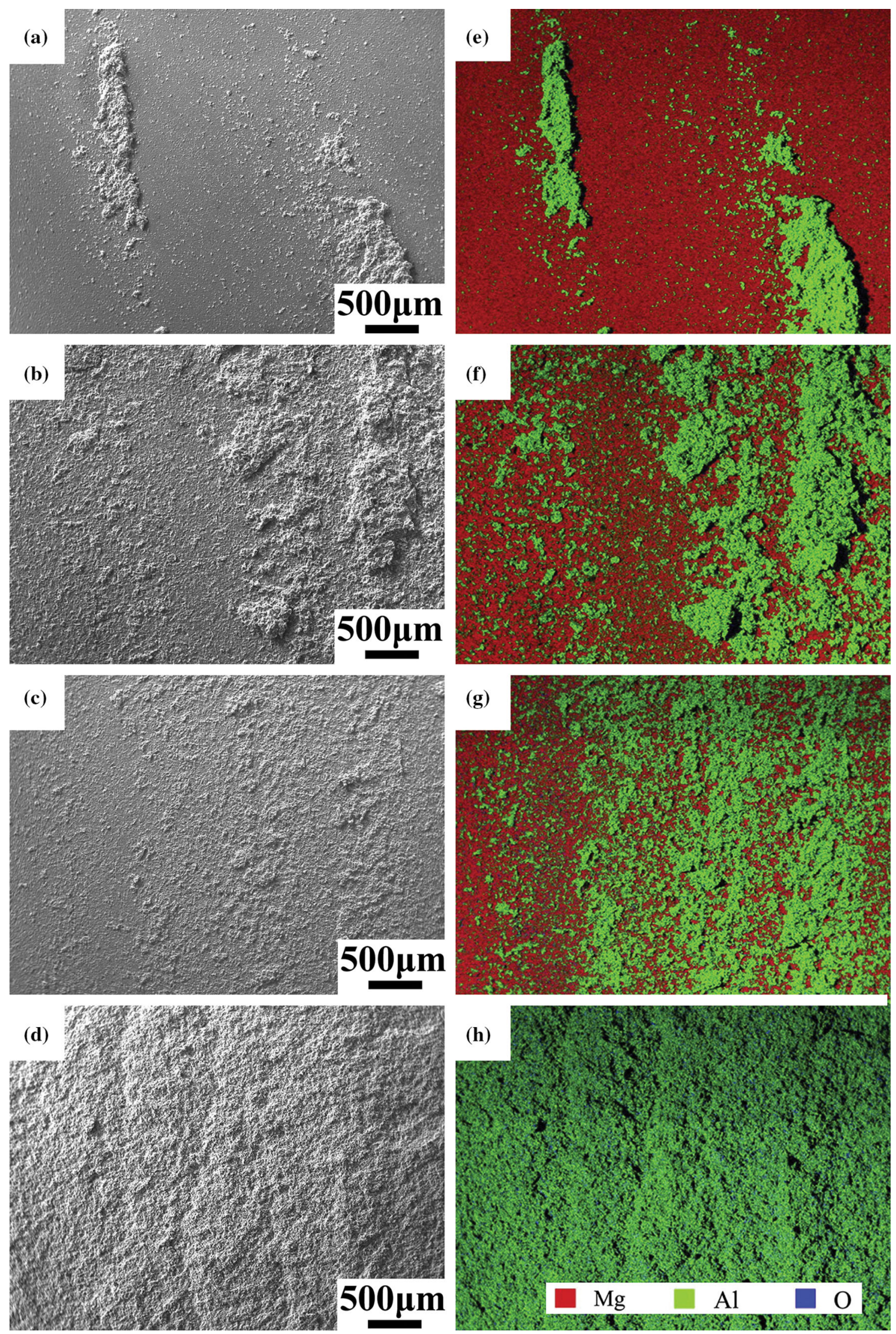
strength from $\sim 12 \mathrm{MPa}$ in the unreinforced condition to $\sim 22 \mathrm{MPa}$ (Ref 108). The improvement was attributed to the tamping effect of the $\mathrm{SiC}$ particles on the first layer coating. In $\mathrm{Al}-\mathrm{Al}_{2} \mathrm{O}_{3}$ composite coating on $\mathrm{Al} 6061$ substrate, adhesion strength increased with the addition of 70 wt.\% of ceramic particles to the feedstock powder, reaching the adhesion strength of the glue used to conduct the test (70 MPa) (Ref 93). The significant increase in the adhesion from the coating devoid of reinforcement at below $20 \mathrm{MPa}$ was due to the roughening effect of ceramic particles and micro-asperities promoting mechanical interlocking at the coating-substrate interface. Oxide removal is also potentially increasing the adhesion strength by promoting metallurgical bonding between the particles and the substrate. The effect of oxide removal was studied by depositing a single layer of coating with different feedstock powders and observing an increase in oxides on the surface after $72 \mathrm{~h}$. Also, the effect of asperity was decoupled from oxide removal by calculating the singlelayer deposition efficiency (Ref 93).

It is worth noting that at a relatively higher amount of reinforcement, reduction of adhesion strength can happen due to reduced effective contact area between the metal matrix and the substrate surface. What is more, higher contents of defects and pores, usually found at larger volume fractions of reinforcement, negatively affect the adhesion strength. In $\mathrm{Al} 2024-\mathrm{Al}_{2} \mathrm{O}_{3}$ composite coatings on AA 2024-T3 substrate, for example, while the addition of $20 \mathrm{wt} . \% \mathrm{Al}_{2} \mathrm{O}_{3}$ particles resulted in an increase of adhesion strength from $20 \mathrm{MPa}$ to $50.68 \mathrm{MPa}$, further increase in $\mathrm{Al}_{2} \mathrm{O}_{3}$ from 20 to $60 \%$ did not result in a significant further increase in adhesion strength (Ref 94). The initial increase was attributed to the indented substrate surface by reinforcing particles which enhanced mechanical interlocking. Coating adhesion strength also decreased slightly with increasing the amount of $\mathrm{SiC}$ reinforcements from 0 to 15 vol.\% in Al-12Si coating on the 6061-T6 substrate (Ref 84). The presence of $\mathrm{SiC}$ particles at the substrate-coating interface by large amounts was shown to reduce the number of anchoring sites between the coating and the substrate. For Co-WC coating on $\mathrm{Al}$ substrate, increase in Co content from 12 to $17 \mathrm{wt} . \%$ resulted in a higher adhesion strength of $26 \pm 10 \mathrm{MPa}$ compared to $19 \pm 1 \mathrm{MPa}$ (Ref 113).

In addition to improvement in strength in the normal direction, the addition of particle reinforcement restricts deformation within the MMCs and thereby can influence the shear strength of the CS coating as well. In CS Al composite coating onto $\mathrm{Mg}$ substrate, a 25 vol.\% addition of $\mathrm{Al}_{2} \mathrm{O}_{3}$ particle reinforcement improved adhesion strength in shear mode by $50 \%$ compared to pure $\mathrm{Al}$ coating (Ref 91). The shear strength of $\mathrm{B}_{4} \mathrm{C}$-reinforced $\mathrm{Al}$ 12Si coating deposited with cryomilled powder feedstock onto $\mathrm{Al} 6061$ substrates showed a higher value of $22.6 \pm 5.6 \mathrm{MPa}$ compared to $17.6 \pm 3.8 \mathrm{MPa}$ obtained without reinforcement. However, the coating produced with powders that were simply mechanically mixed had a shear strength of $16.1 \pm 2.2 \mathrm{MPa}$, lower than that without reinforcement (Ref 130). It was attributed to the fact that in cryomilled feedstock, ceramic particles are mostly submicron in size and are trapped inside the matrix particles. This prevents direct contact between reinforcing particles and the substrate and reduces the extent of impingement on the effective bonding area between the substrate and matrix.

While the tamping effect by a relatively small number of reinforcing particles can improve cohesion strength, larger amounts of ceramic particles can prevent intimate contact of metallic particles. Consequently, the effective load transfer between metallic particles is reduced, resulting in a lower cohesion strength (Ref 151). The cohesion strength of the $\mathrm{CuSn}_{5}-\mathrm{Al}_{2} \mathrm{O}_{3}$ coatings was shown to increase from 11.2 to $32.5 \mathrm{MPa}$ with an increase in $\mathrm{Al}_{2} \mathrm{O}_{3}$ content from 0 to $30 \mathrm{wt} . \%$ in the feedstock (Ref 99). The addition of $\mathrm{SiC}$ particles in the 316L matrix resulted in an increase in the cohesion strength from $48 \pm 7 \mathrm{MPa}$ to $53 \pm 9 \mathrm{MPa}$ (Ref 162). In Al5056/SiC coating, the cohesion strength of the coating increased from 107.1 to 146.9 $\mathrm{MPa}$ with an increase in the $\mathrm{SiC}$ content from 0 to 26.4 vol.\% (Ref 151). Further increase in the reinforcement content to $41.4 \mathrm{vol} . \%$, however, resulted in a decrease in the cohesion strength to $112.7 \mathrm{MPa}$.

Figure 13 shows a fracture surface analysis of Al5056SiC CS MMC failed in cohesion tests (Ref 151). Here the reinforcement content increases from top to bottom. Each row shows micrographs of the same fractured surface but at different magnifications. The first observation is that $\mathrm{SiC}$ particles significantly improve the deformation of Al5056 particles. While in the coating with no reinforcement, Al5056 particles are mainly spherical (shown by the green arrow in Fig. 13b), they are more flattened and transformed into oblate shapes when $\mathrm{SiC}$ reinforcing particles are present (shown by the yellow arrow in Fig. 13d). The second observation is that cracks between poorly bonded splats present in the coating with no reinforcement, shown by the red arrow in Fig. 13(b), are no longer present when ceramic reinforcement is added. Third, evidences of dimples and ductile fracture start to appear in the case of the coating reinforced with 21.1 vol.\% $\mathrm{SiC}$ (see the white arrow in Fig. 13b). These effects together contributed to the cohesion strength's increase from $107 \mathrm{MPa}$ for pure coating to $129 \mathrm{MPa}$ for the coating reinforced with $21.1 \mathrm{vol} \% \mathrm{SiC}$. Dimples in the fracture surfaces are more evident when the reinforcement content is increased to $26.4 \mathrm{vol} . \%$ (see white arrows in Fig. 13f), and the cohesion strength reached a peak of $147 \mathrm{MPa}$. Fourth, by further increasing the $\mathrm{SiC}$ content in the range of 33.6-41.4 vol.\%, it was found that 
Fig. 13 Effect of increasing reinforcement content in $\mathrm{Al}$ 5056-SiC CS MMC on fracture behavior (Ref 151). Images are reproduced with permission from Elsevier
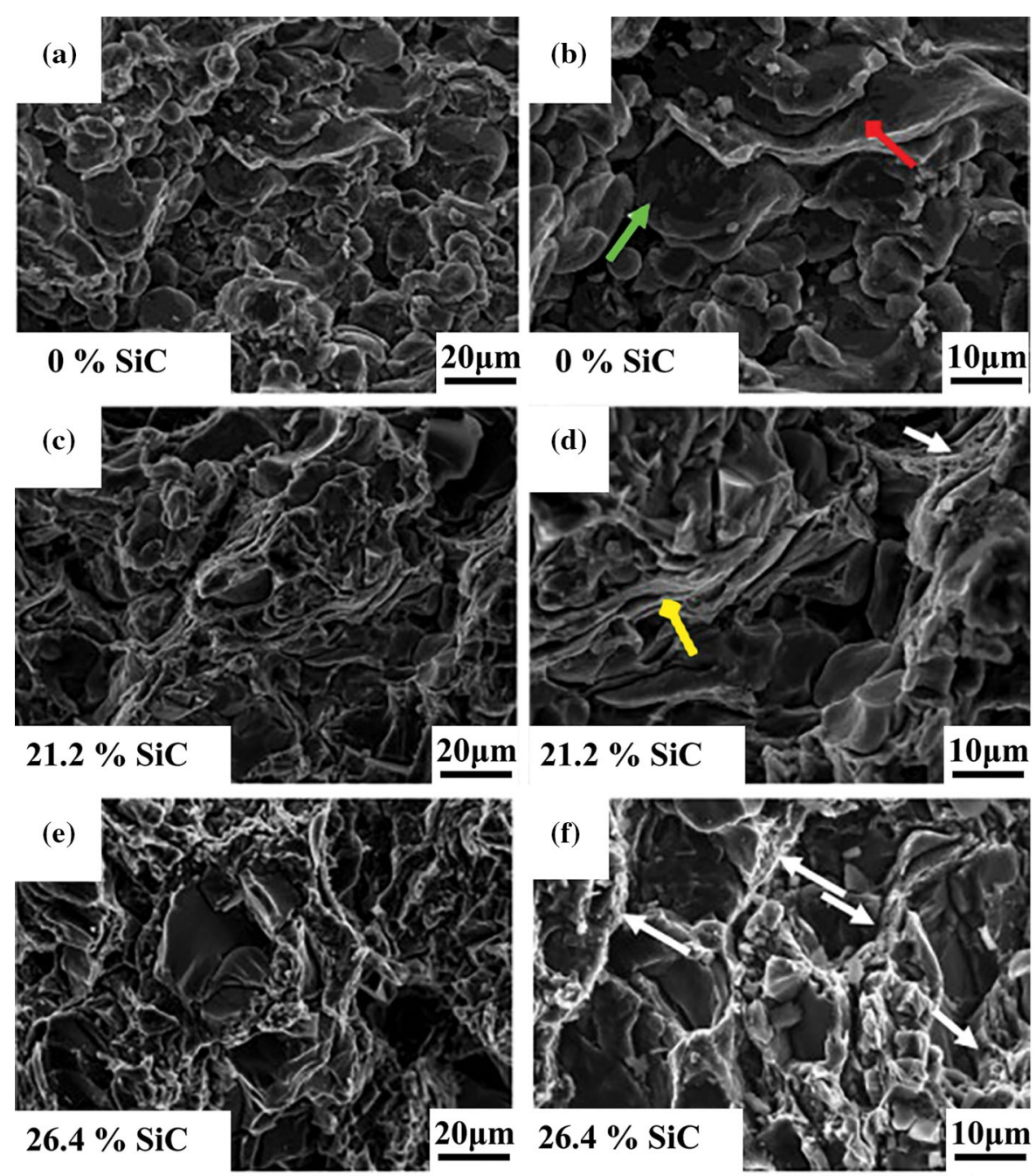

$21.2 \% \mathrm{SiC}$

$10 \mu \mathrm{m}$
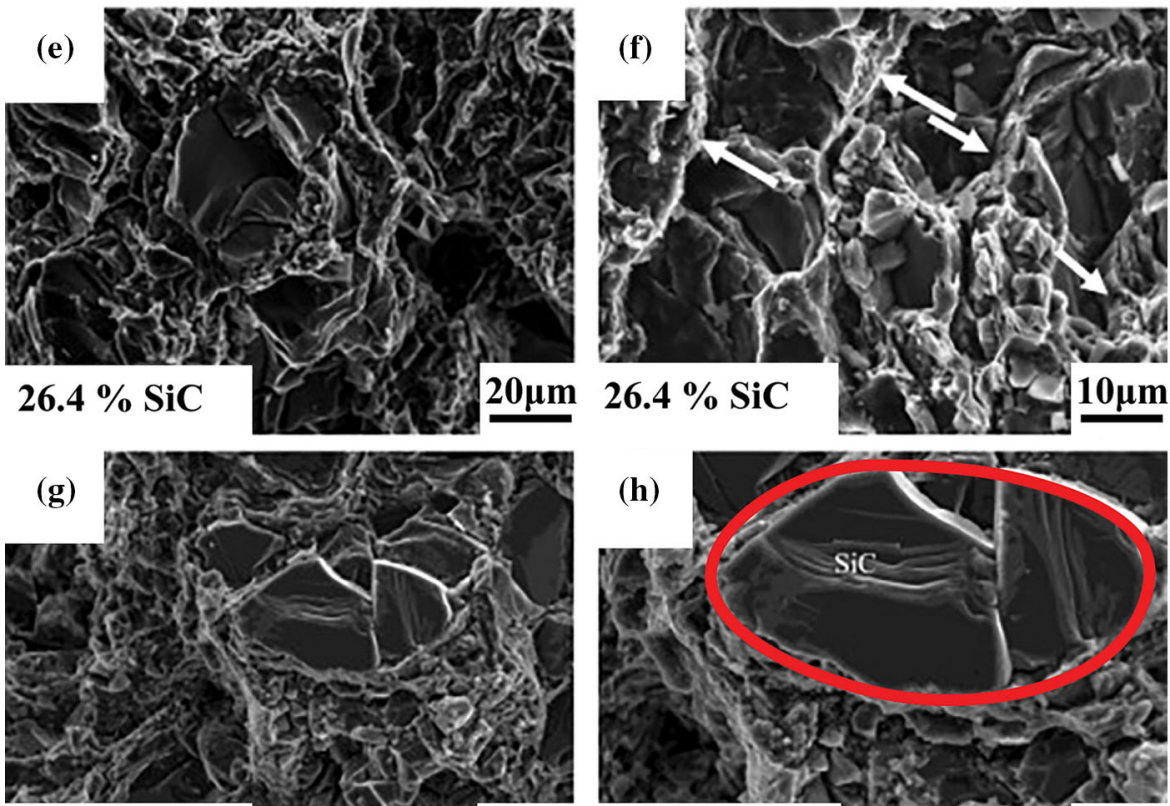

$33.6 \% \mathrm{SiC}$

$20 \mu \mathrm{m}$
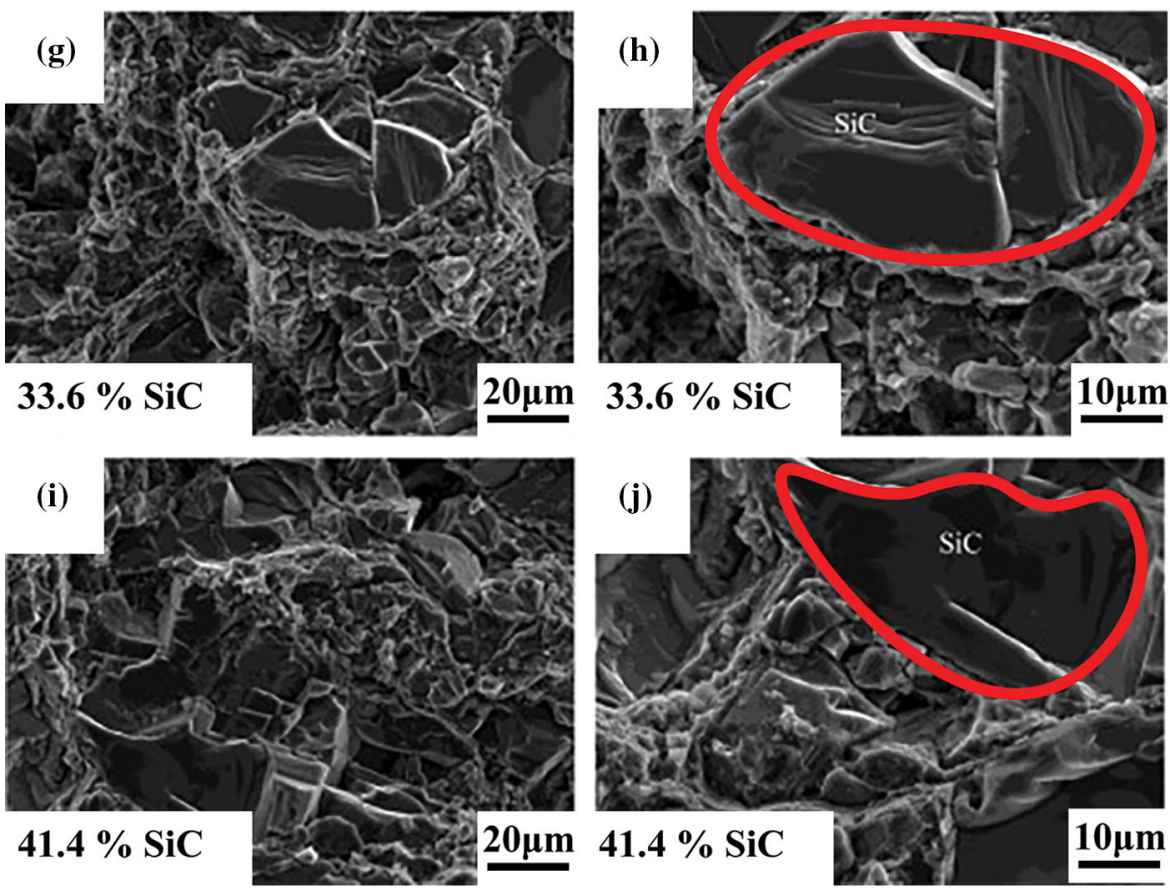
the reinforcing particles reduced the effective contact area between the Al5056 particles (see enclosed particles in Fig. $13 \mathrm{~h}$ and $\mathrm{j}$ ). The number of cracks was also found to increase in these latter cases. As a result, the cohesion strength decreased to $122 \mathrm{MPa}$ and $113 \mathrm{MPa}$ at 33.6 to 41.4 vol.\% SiC compared to the peak value of $147 \mathrm{MPa}$ (Ref 151).

Cohesive failure can also occur under shear condition, and in addition to the amount of particle reinforcement, particle morphology also influences the cohesive shear strength of CS MMC coatings. $\mathrm{Al}-\mathrm{Al}_{2} \mathrm{O}_{3}$ composite coatings with angular and spherical $\mathrm{Al}_{2} \mathrm{O}_{3}$ particles exhibited similar compressive stress-strain behaviors during pressure torsion test (Ref 9). However, a lower torque was needed to maintain shearing of the composite coating reinforced with angular particles as compared to the one with spherical particles, suggesting a lower shear strength in the former case. Stress concentrations at the sharp corners of the angular particles were found to promote the formation of microcrack in the matrix.

Fracture mechanisms can also change with the application of post-spray heat treatments. An example is given by the tensile tests conducted on $23 \mathrm{vol} . \% \mathrm{~B}_{4} \mathrm{C}$-reinforced Al CS MMCs after heat treating the specimens at 200, 300, $400 \& 500^{\circ} \mathrm{C}$ under high-purity $\mathrm{Ar}$ environment for $4 \mathrm{~h}$ (Ref 109). Ultimate tensile strength was $38 \mathrm{MPa}$ in the assprayed condition, which improved to $44,56,58$, and $60 \mathrm{MPa}$ after the above-mentioned heat treatments, respectively. Final fracture of the as-sprayed and heattreated specimens occurred in the coating. The fracture analysis of the as-sprayed coating shown in Fig. 14(a) and (b) revealed a large number of inter-splat crevices and weakly bonded splat boundaries which acted as crack initiation sites. After heat treatment at $200^{\circ} \mathrm{C}$, while some of the splats were found to be partially bonded, the same crack initiation mechanism as in the as-sprayed condition was found to be active due to the presence of significant amount of poorly bonded areas (Fig. $14 \mathrm{c}$ and d). More evidence of dimple-like features and ductile fracture were found for the samples heat-treated at $300^{\circ} \mathrm{C}$ as a result of stronger metallurgical bonding. However, inter-splat crevices/pores were still present, acting as crack initiation sites for premature fracture (Fig. 14 e and f). A complete departure from brittle fracture was found for the samples heat-treated at $400^{\circ} \mathrm{C}$ and $500^{\circ} \mathrm{C}$. In these latter cases, the entire fracture surfaces were characterized with ductile features signified by clear evidences of microvoid formation and coalescence (Fig. 14g, h, i and j). The observations of fracture mechanisms are in line with the increase in ductility from 0 in the as-sprayed and $200^{\circ} \mathrm{C}$-treated conditions to $0.7 \%, 1.1 \%$, and $1.4 \%$ when treated at 300,400 $\& 500^{\circ} \mathrm{C}(\operatorname{Ref} 109)$.
Figure 15 shows the fracture surfaces in the as-sprayed $7075 \mathrm{Al}$ reinforced with 4.2 vol.\% nano- $\mathrm{TiB}_{2}$ composite materials deposited with different processing conditions after cohesive failure (Ref 114). In this study, the carrier gas was systematically changed from air to nitrogen and helium, along with changes in gas temperature, pressure, and nozzle type. The corresponding fracture surfaces are shown in Fig. 15(a), (b) and (c), with the corresponding higher magnification images shown in Fig. 15(d),(e) and (f), respectively. Changes in processing conditions resulted in different levels of deformation during deposition. In Fig. 15(a), the fracture surface demonstrates a typical cleavage feature. Some dimples are found in the interparticle boundaries, where greater plastic deformation and recovery occurred. In Fig. 15(b), where nitrogen was used as the carrier gas, fracture took place along the splats interface rather than through them. Almost no dimples are observed on the fracture surface, displaying a brittle rupture. The fracture surface in Fig. 15(c), where helium was used as carrier gas, displays a curly structure with some fracture occurring through the deformed splats. Intra-splat fracture, observed in the latter case, confirms the stronger metallic bonding at the severely deformed interfacial regions due to the occurrence of material jetting and adiabatic shear instability. The change in failure mechanism is in line with the change in the degree of plastic deformation from Fig. 15(a), (b) and (c). It is also in line with the tensile strength values which changed from $\sim 325 \mathrm{MPa}$ to 280 and $350 \mathrm{MPa}$ and elongation which changed from 1.2 to $0.6 \%$ and $1.2 \%$ for the microstructures shown in Fig. 15(a), (b) and (c), respectively. In the closer views of the micrographs in Fig. 15(d) and (e), some interior defects and pores within the deposits can be observed which can in turn accelerate the failure during tensile tests and lower the strength and elongation (Ref 114). However, even for the helium sample (see Fig. 15c and f), the fracture morphologies and elongation of the composite displayed a brittle feature, which indicates limited metallurgical bonding at the deformed splats.

Compared to adhesive and cohesive failures, fracture toughness and fatigue behavior of CS MMCs are less studied (Ref 41, 43, 134, 188, 189). In an indentation approach to study the fracture of cubic BN-reinforced in $\mathrm{NiCrAl}$ coating, it was found that the crack propagates preferentially along the interface between the matrix and the large BN particles (Ref 134). As a result, fracture toughness of the coating was reported to decrease with increasing $\mathrm{BN}$ reinforcement content. The same trend was also reported for the increase of nano-WC-17Co powder from 10 to $50 \mathrm{wt} . \%$ in the nano-/micropowder blend to produce WC-17Co CS MMC (Ref 188). While the fatigue behavior of free-standing CS MMCs has not been studied to the best of our knowledge, improved fatigue 
Fig. 14 Change of fracture surface with heat treatment. From top to bottom is the assprayed (a, b) $200^{\circ} \mathrm{C}$-treated (c, d), $300^{\circ} \mathrm{C}$-treated $(\mathrm{e}, \mathrm{f}), 400^{\circ} \mathrm{C}$ treated $(\mathrm{g}, \mathrm{h})$, and $500^{\circ} \mathrm{C}$-treated $(i, j)$ conditions (Ref 109). Images are reproduced with permission from Elsevier
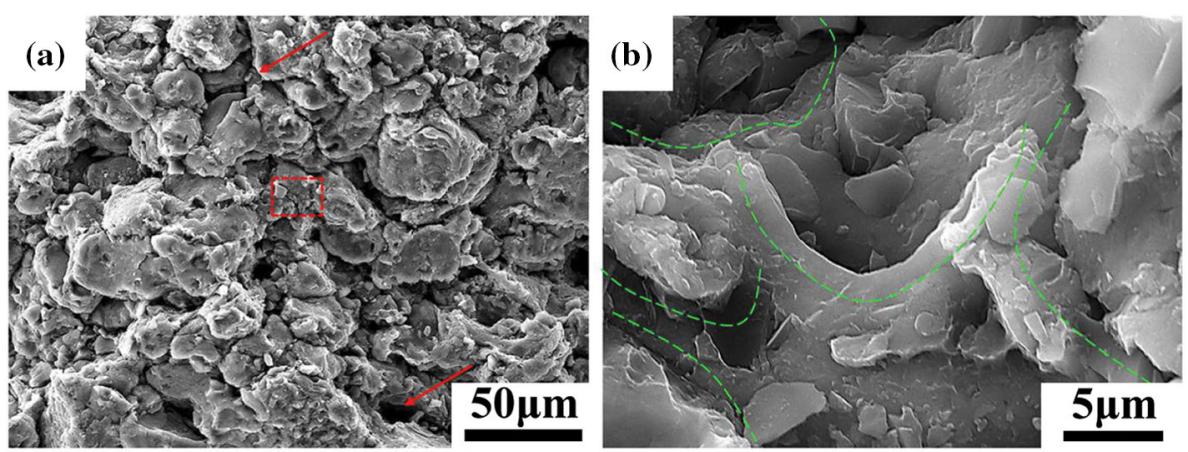

(c)
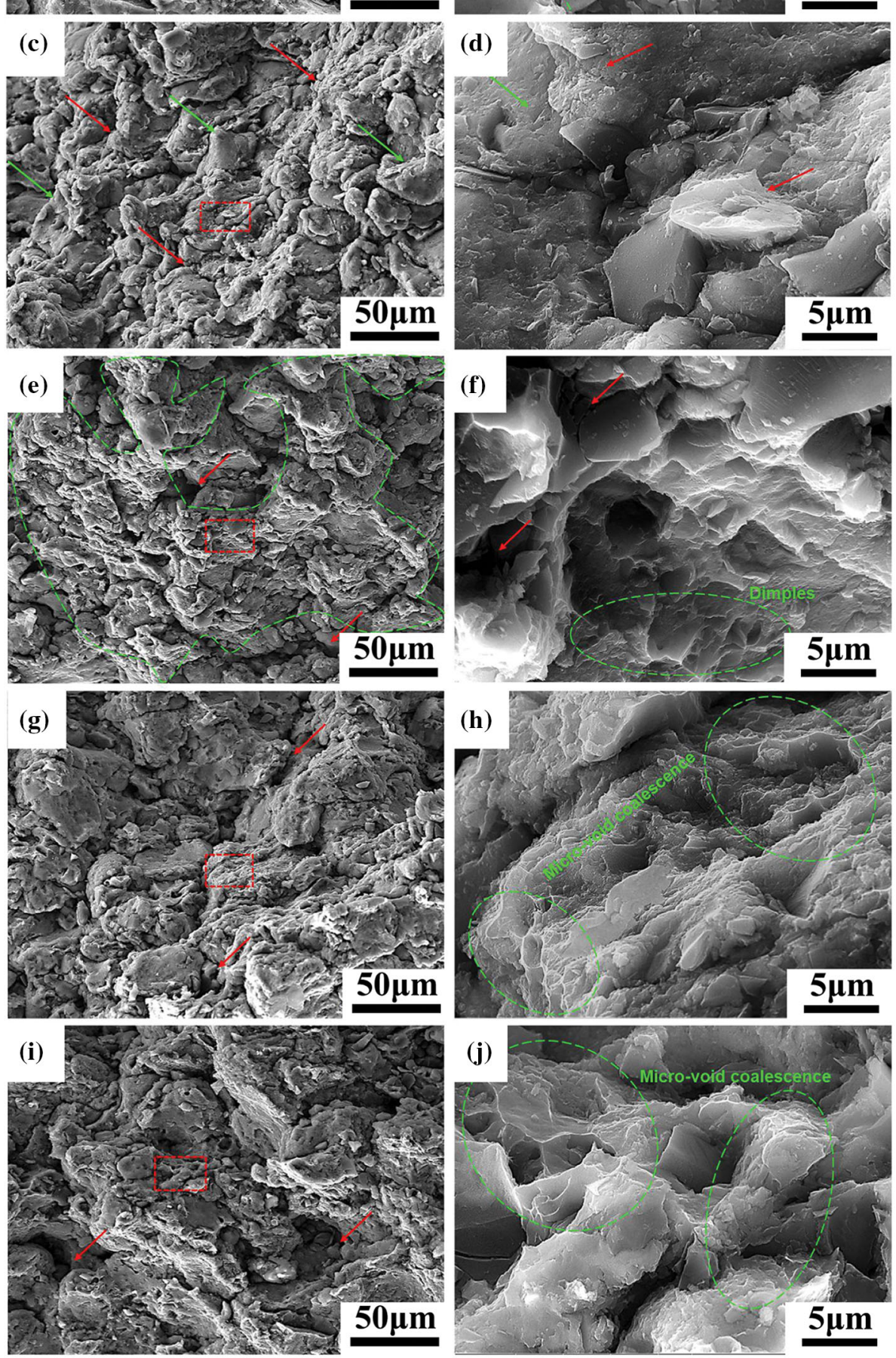

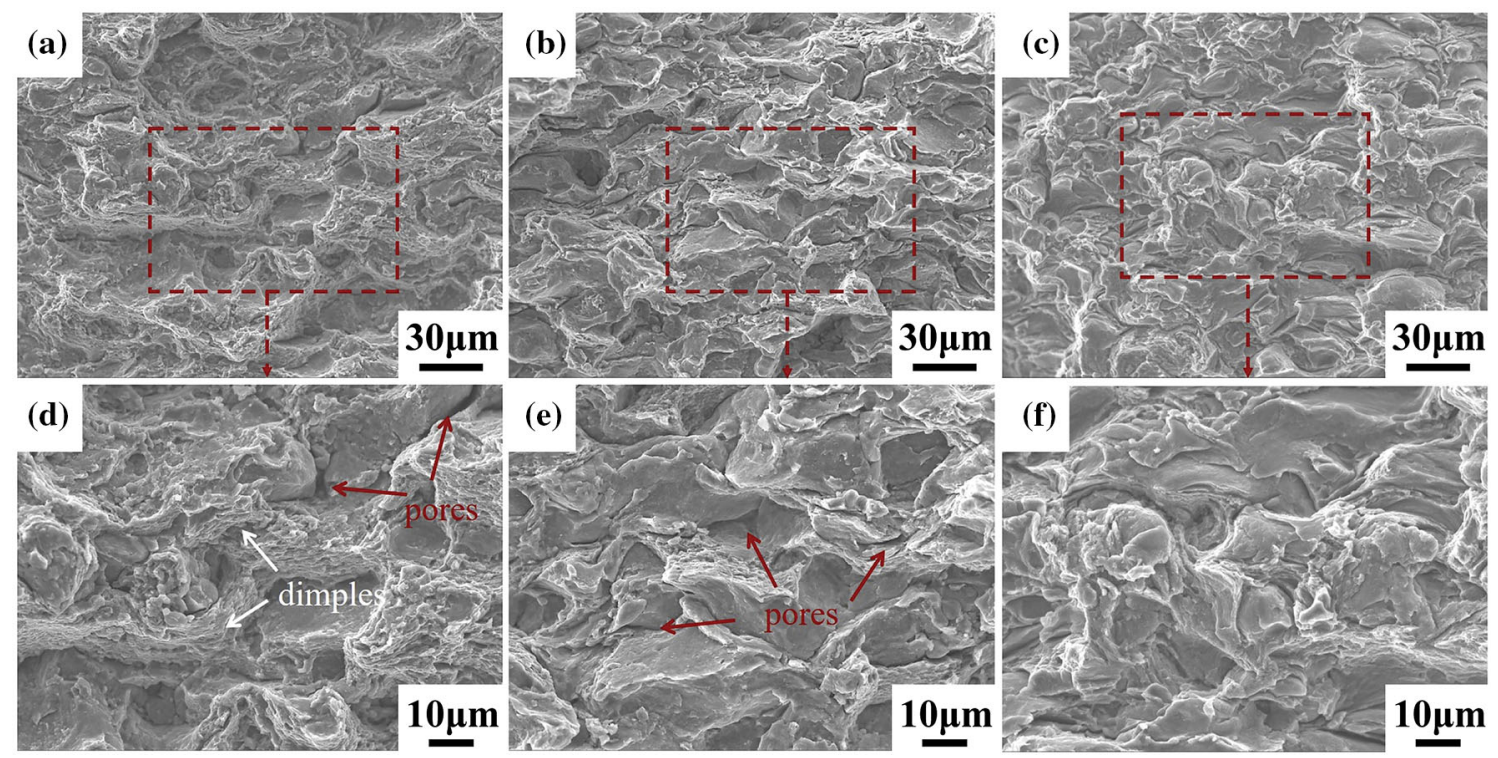

Fig. 15 Effect of processing conditions on fractured surfaces. The carrier gas use in cold spray is, from left to right, (a, d) air, (b, e) nitrogen, and $(\mathrm{c}, \mathrm{f})$ helium. (d, e, f) are higher magnifications of (a, b, c), respectively. (Ref 114). Images are reproduced with permission from Elsevier

characteristics of an additively manufactured $15 \mathrm{Cr}-5 \mathrm{Ni}$ stainless steel substrate were reported after being coated with $\mathrm{CS} \mathrm{Cr}_{3} \mathrm{C}_{2}$-Ni MMC coating (Ref 41). The improvement in fatigue crack growth rate, particularly in the Paris region (region II), was attributed due to a toughening mechanism provided by the reinforcing particles ahead of the crack tip.

In summary, coating/substrate adhesion strength is improved with increasing reinforcement content due to enhanced tamping effects, and such increase can lead to a change in failure mode from adhesive to cohesive. However, too much reinforcement can reduce the effective metallurgical bonding areas and results in reduced adhesion strength. A similar effect is also present for cohesion strength of the coating. Particle morphology can affect the coating cohesive strength. Coatings reinforced with spherical particles presented higher shear strength due to fewer stress concentrators compared to angular particles with sharp corners. Heat treatment can significantly improve bonding within the coating and as a result change the fracture mechanism of CS MMC coatings. With the limited reports available in the literature, fracture and fatigue of CS MMCs are areas that require future studies.

\section{Tribology of Metal Matrix Composites}

\section{Wear Mechanisms}

Wear is the process of material removal from surfaces that are in relative motion and is typically classified into low, mild, and severe regimes (Ref 190). In the low wear regime, material removal is governed by localized surface deformation and plowing mechanisms at the asperity level without significant formation of debris particles (Ref 190). The primary mechanism in the mild wear regime, where the contact is still at the asperity level, is surface microcracking. The localized fracture in this regime leads to the formation of powder-like debris with sizes on the same order of magnitude as of the contacting junctions (Ref 190). In the severe wear regime, on the other hand, large subsurface crack and macroscopic fracture occur eventually leading to the formation of flake-like debris with length scales corresponding to the apparent contact area (Ref 190).

It has been shown that plasticity and plowing in the matrix (see the Ni matrix in Fig. 16(a) and the $\mathrm{Al}$ matrix in Fig. 16c and d) and fracture in the reinforcement (see cracked WC particles in Fig. 16g) are among the important processes governing the wear behavior in MMC CS coatings, particularly those with ceramic reinforcements. As important is the behavior of metallic/ceramic interfaces (Ref 103, 151, 157, 162). If the interfacial bonding is strong, then reinforcing particles can significantly contribute to the load-bearing capacity of the composite and reduce the wear rate (Ref 104, 177, 191). Imperfect interfacial bonding, on the other hand, can lead to debonding (see the pulled-out WC particle in Fig. 16(b) and $\mathrm{Al}_{2} \mathrm{O}_{3}$ particle in Fig. 16d), fracture, and fragmentation of reinforcing particles which can, in turn, result in severe wear through a variety of mechanisms (Ref 104, 192). First, fractured particles lose their ability to carry the applied load. As a result, the amount of shear strains in the matrix material increases significantly leading to localization of 

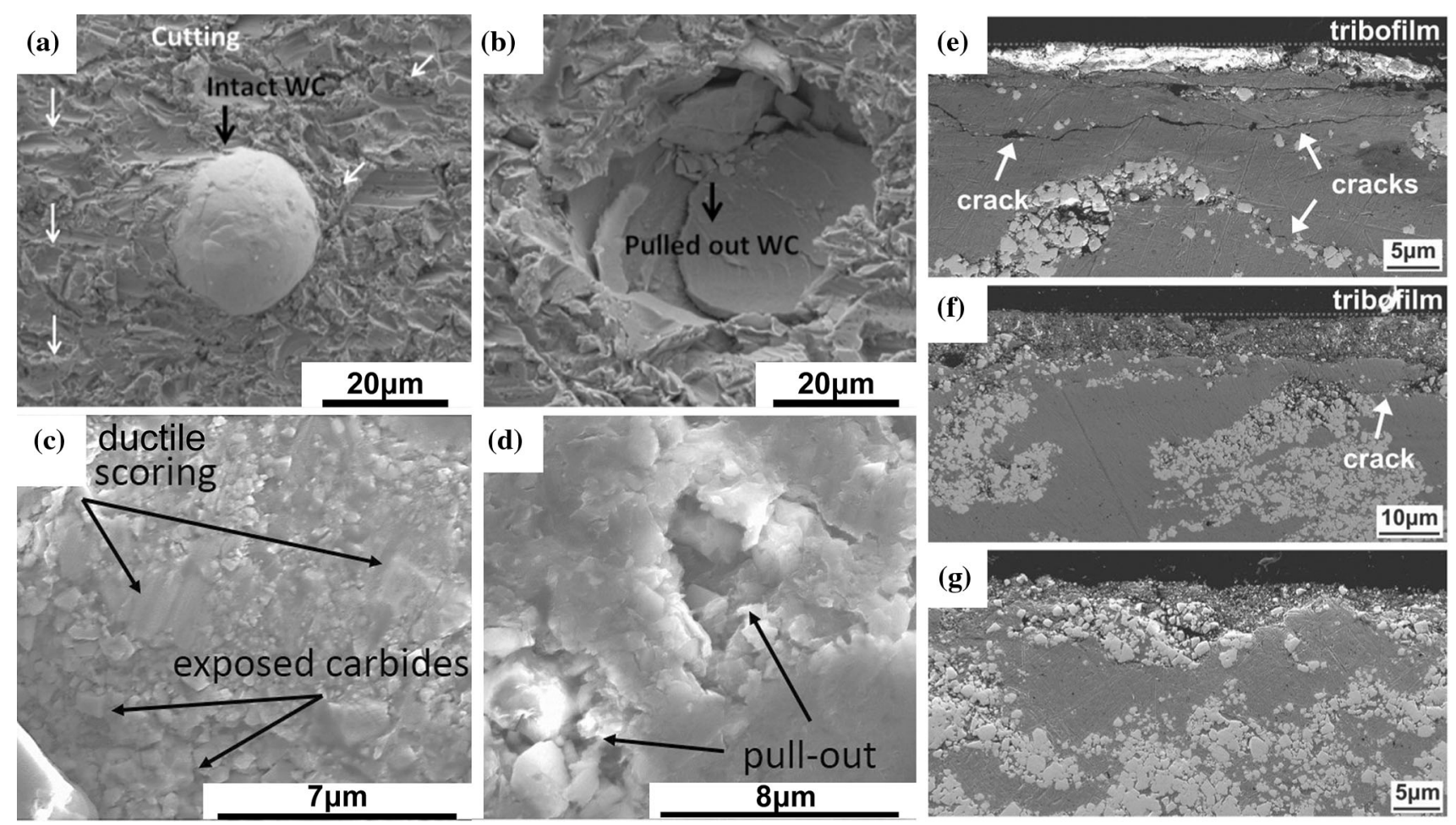

Fig. 16 (a) and (b) show a typical particle pull-out in worn CS NiWC MMC coatings (Ref 104). (c) and (d) show the damage to the Al matrix in the form of scoring and plowing where carbide reinforcement was exposed (Ref 192). (e), (f), and (g) are cross-sectional images of worn surface in $\mathrm{WC} * \mathrm{Co}-\mathrm{Ni}$ coating. In (e), a tribofilm was found on the surface of the coating. The tribofilm resulted from the detached plastic wear debris smearing onto the worn surface, having low toughness, and a tendency to crack. The cracks below the surface

deformation and delamination of the subsurface layers. Second, fractured or debonded reinforcing particles can promote the rate of delamination by creating additional crack growth paths through particle-matrix decohesion. Third, fractured particles and pulled-out particles can provide additional material removal mechanisms through third-body abrasion.

Plasticity in a typical sliding wear experiment can also modify the microstructure of metal matrix materials. For coarse-grained metals, there is often a refinement to nearsurface nanocrystalline structures, while grain growth can take place for an initially refined metallic microstructure (Ref 193). Both phenomena change the local mechanical properties in the so-called mechanically modified layer (MML). In addition to modified layers near the surface, adhesion between the coating and counterbody can initiate material transfer and removal leading to the formation of transfer film and wear debris (Ref 20).

Wear is a dynamic process where mechanisms can evolve as the microstructure of the coating changes during sliding. Using in situ tribometry, flows of third bodies (tribofilm, transfer film, and wear debris) were directly are within the Ni matrix and were initiated due to low-cycle surface fatigue, which was suggested to be the main material removal mechanism. (f) shows a coating with higher WC content than that in (e), but the wear behavior is similar to (e). (g) shows the coating with even higher reinforcement content and a different surface morphology where there is no tribofilm but a rough surface and cracked WC reinforcement can be found on the surface (Ref 152). Images are reproduced with permission from Elsevier

observed during sliding wear of CS Ti and Ti-TiC composite coatings and correlated with observed trends in friction and wear mechanism (Ref 160). The results revealed that the adhesion of $\mathrm{Ti}$ to the counterface was initiated during the initial stage of pure Ti coating sliding. At later cycles, the main wear mechanisms changed to cracking of transfer films and generation of oxidized debris that led to further wear by abrasive particles. Locally developed mechanically modified layers through compaction of oxidized debris on wear track were not found to be protective. Incorporation of $\mathrm{TiC}$ into $\mathrm{Ti}$ coating was found to significantly modify the friction behavior, due to a dual effect of TiC particles. First, transfer and adhesion of $\mathrm{Ti}$ to the counterface, in this case, was found to be due to the dislodging of $\mathrm{TiC}$ fragments leading to an initial rise in the CoF. Second, through third body flows (e.g., material transfer, detachment, and debris recirculation), the TiCcontaining coatings eventually formed compact, lubricating tribofilms that led to a stable, reduced friction at higher cycles (Ref 160).

In addition to being a dynamic process, wear and material removal mechanisms can vary significantly 
depending on material type, reinforcement content in the CS MMCs, as well as testing conditions. In WC-Co-Ni composite coating, material removal of the coatings with lower ceramic content was shown to be dominated by the low-cycle surface fatigue caused by the load beyond the yield strength of the Ni phase (see the subsurface cracks in Fig. 16e and f) (Ref 152). Also, on the worn surfaces of the coatings with lower ceramic content, tribofilm was generated due to the detached plastic wear debris smearing onto the wear track (Fig. 16e and f). The tribofilm was shown to play a beneficial role in improving the coating wear resistance, preventing further wearing of the coating by the counterpart. No tribofilm, however, was generated on the surface of the coating with the highest ceramic content of $\sim 62$ vol.\% (see Fig. 16g). The coating in the latter case was characterized by embossed WC reinforcements on the worn surface that effectively prevented the wear of the Ni matrix phase (Fig. 16g) (Ref 152). A comparison of solid-particle erosion in $\mathrm{Ni}$ and $\mathrm{Ni}-10.5 \mathrm{vol} . \%$ WC coatings revealed similar erosive wear resistance at a $30^{\circ}$ incident angle but a lower erosion rate for the composite coating at a normal incidence angle (Ref 104). Cutting and plowing were the main wear mechanisms at a $30^{\circ}$ angle, whereas $\mathrm{Ni}$ deformation localization and lip formation and WC fracture were observed at the normal impact angle. Embedment of the $\mathrm{Al}_{2} \mathrm{O}_{3}$ (counterbody) into the coating and subsequent formation of MML was found to be the reason for the high erosion resistance of both coatings at $90^{\circ}$. The presence of the WC particles in the composite coating, however, prevented the embedment of the $\mathrm{Al}_{2} \mathrm{O}_{3}$ particles and the MML formation, which contributed to the lower erosion resistance at a normal incident angle. At $30^{\circ}$, WC particles were able to protect $\mathrm{Ni}$ from erosion at some regions of the surface, as can be seen from the intact WC particle in Fig. 16(a). However, the content of WC was found to be too low for significant improvement (Ref 104).

The underlying principles of friction and wear modification involve reduction in contact area and reduction in interfacial shear strength between the coating and counterbody (Ref 194). One can achieve both in CS MMC coatings by incorporating reinforcing phases that can take form as a hard reinforcement, a solid lubricant, or both. $\mathrm{Cu}$ $\mathrm{MoS}_{2}$ and $\mathrm{Cu}-\mathrm{MoS}_{2}-\mathrm{WC}$ composite coatings and their sliding wear experiments are a good example to discuss the aforementioned general approaches in wear reduction (Ref 158). $\mathrm{MoS}_{2}$ is a typical solid lubricant (Ref 194), while WC is a hard reinforcement. A comparison of the wear track morphology in $\mathrm{Cu}-\mathrm{MoS}_{2}$ and $\mathrm{Cu}-\mathrm{MoS}_{2}-\mathrm{WC}$ showed a large scale of detachment in the former but a smooth track with only small detachments in the latter (Ref 158). The difference was attributed to the slightly higher hardness of $\mathrm{Cu}-\mathrm{MoS}_{2}-\mathrm{WC}$ coating that reduced contact area as well as the presence of WC particles that limited deformation by accumulating and storing dislocation during shearing (Ref 195). $\mathrm{MoS}_{2}$ redistribution exhibited a similar manner on the wear tracks for both coatings. However, more $\mathrm{MoS}_{2^{-}}$ containing debris attached to the $\mathrm{Cu}-\mathrm{MoS}_{2}-\mathrm{WC}$ counterface was found, forming a transfer film that separates the initial sliding contact, and therefore reduced the friction. The subsurface microstructure of the wear tracks revealed a contrast between two coatings and the influence of the WC particles (Ref 158). Major microstructural change, such as the formation of ultrafine grains, only occurred around WC particles showing the load-bearing capability of the reinforcing particles. In the $\mathrm{Cu}-\mathrm{MoS}_{2}$ coating, on the other hand, an ultrafine-grained region was only found on the top of the wear track. Ultrafine grain formation on the surface was observed to be minor in the case of unreinforced coating even after a longer sliding. For the $\mathrm{Cu}-\mathrm{MoS}_{2}$ coating, on the other hand, server plastic deformation and microstructural refinement occurred more extensively due to a higher likelihood of crack nucleation and propagation around work hardened UFGs, leading to a thick, unstable tribolayer. This produced a more active material transfer in the contact and contributed to cracking, detachment, and eventually high wear rate (Ref 158).

The fretting wear behavior of the same materials was studied under gross slip regime, with a focus on the influence of WC particles on third body rheology and wear resistance at different stages of the test (Ref 196). During running-in, even though the participation of WC particles and fragments in the contact could not prevent drastic detachment induced by the presence of $\mathrm{MoS}_{2}$, they promoted a more rapid formation of wear debris bed. The main velocity accommodation mechanisms took place through elastic and plastic deformation, as well as normal breaking within the first bodies. During early steady-state, WC fragments in the contact caused more material loss. However, during the following test, the presence of WC particles constrained velocity accommodation on the top of the wear scar. Such constraints contributed to the formation of continuous tribologically transformed structure (TTS) layers and transfer films in the contact. The presence of these structures resulted in a more stable and lower volume of third body flows, leading to significantly improved wear resistance of $\mathrm{Cu}-\mathrm{MoS}_{2}$-WC with a wear rate of $\sim 80 \times 10^{-6} \mathrm{~mm}^{3} / \mathrm{Nm}$, much lower than that of $\mathrm{Cu}-$ $\mathrm{MoS}_{2}$ at $\sim 210 \times 10^{-6} \mathrm{~mm}^{3} / \mathrm{Nm}$. The presence of $\mathrm{WC}$ fragments inside the TTS and transfer films was discussed to be the key to maintain the stable and low source wear flows through microwedging and pinning. In contrast, at the $\mathrm{Cu}-\mathrm{MoS}_{2}$ contact, the velocity was accommodated across a large volume of third bodies and first body (i.e., a thick transition layer). The presence of $\mathrm{MoS}_{2}$ led to frequent detachment from the TTS layer and transfer film, 
which caused consistently high third body flows, resulting in a high wear rate (Ref 196).

In summary, plasticity and plowing in the matrix and fracture in the reinforcement are the main wear mechanisms in CS MMCs. In addition, weak matrix/reinforcement interfacial bonding can lead to particle pull-outs. Wear is a dynamic process as the surface constantly evolves during the process through material removal and formation of tribolayers. Wear mechanisms and processes can significantly vary from one material system to another, as well as under different conditions, requiring case-bycase studies. Wear mechanisms can be modified to achieve lower wear loss through the addition of hard reinforcement that distributes the load and/or incorporation of solid lubricants to reduce the shear force.

\section{Wear Rate/Volume}

While in general, the addition of reinforcements reduces the wear rate in CS MMC coatings, higher reinforcement content does not necessarily lead to a greater wear resistance. The improvement in wear behavior of CS MMC coatings compared to that of single-phase metallic counterparts originates from the fact that hard reinforcing particles, besides resisting the wear, can help distribute the compressive and shear stresses throughout the material (Ref 93). For compositions with lower reinforcement content, this stress distribution does not occur efficiently as the particles are too spread throughout the coating (Ref 93). At low concentrations of reinforcement, the ductile matrix phase endures excessive deformation. The excessive plastic flow of the matrix can plow the reinforcing particles as the wear tip slides through the coating, resulting in the reinforcement not contributing to the wear resistance of the coating (Ref 93). This mechanism, however, changes at higher ceramic contents, as the compressive and shear stresses are distributed from the matrix to the reinforcing particles better. The metallic phase does not suffer as much deformation, letting the reinforcement act as a wear-resistant material, as deformation on the surface will be limited (Ref 93). As the amount of ceramic content further increases, deterioration of bonding can occur which adversely impacts wear resistance of the coating (Ref 101).

In Al-based CS MMCs, reduction of wear rate compared to pure $\mathrm{Al}$ coating was achieved with the addition of $\mathrm{B}_{4} \mathrm{C}$ (Ref 130, 150), SiC (Ref 128, 150, 151), and $\mathrm{Al}_{2} \mathrm{O}_{3}$ (Ref $86,93,95,118,148,149)$. While in general an improved wear resistance is expected with increasing ceramic content in Al-based coatings (Ref 118, 151), no significant dependence of wear rate on the reinforcement volume fraction (Ref 150) as well as its increase (Ref 93) at higher reinforcement contents was also reported. Increasing $\mathrm{Al}_{2} \mathrm{O}_{3}$ volume fraction in CS MMC was shown to gradually change the wear mechanism from adhesive to abrasive (Ref 149). This change in the mechanism is accompanied by an increased but more stable friction coefficient (Ref 149). Once the mechanism of wear becomes fully abrasive, the reinforcement was shown to significantly contribute to wear resistance and reduce the wear rate by several orders of magnitude (Ref 149). For 6061 alloy-based composite coatings, transition in wear mechanism occurs with a much lower $\mathrm{Al}_{2} \mathrm{O}_{3}$ content when compared with that in pure $\mathrm{Al}$ based coatings, due to the higher strength of the matrix that prevented pull-out of $\mathrm{Al}_{2} \mathrm{O}_{3}$ particles (Ref 149). In Al-AlSi composite coatings, the wear mechanism was found to be debonding between dissimilar splats of Al and AlSi (Ref 97). As a result, the composite coating showed a higher wear volume compared to pure $\mathrm{Al}$ coating despite being harder. A comparison of two carbide reinforcements, namely, $\mathrm{B}_{4} \mathrm{C}$ and $\mathrm{SiC}$, added to $\mathrm{Al} 7075 \mathrm{CS}$ showed a better wear performance for the former case (Ref 150) where the load distribution between the matrix and the reinforcement was found to be more efficient. For a constant volume fraction of ceramic particles, the number of ceramic particles dramatically increases by introducing smaller and lighter (low density) particles. $\mathrm{B}_{4} \mathrm{C}$ particles used in this study had four times smaller average particle size $\left(\mathrm{d}_{0.5}=7 \mu \mathrm{m}\right)$ as compared to that of SiC particles $\left(\mathrm{d}_{0.5}=28 \mu \mathrm{m}\right)$. Therefore, for similar amounts of ceramic particles in the composite coatings, higher contribution of $\mathrm{B}_{4} \mathrm{C}$ particles to wear resistance can be explained by the presence of more $\mathrm{B}_{4} \mathrm{C}$ particles which provides better load distribution between the reinforcing particles and the $\mathrm{Al}$ 7075 matrix (Ref 150).

In $\mathrm{Cu}$-based $\mathrm{CS}$ MMCs, the addition of $\mathrm{Al}_{2} \mathrm{O}_{3}$ (Ref 99, 100, 154), AlCuFeB quasicrystal (QC) (Ref 101), metallic glass (MG) (Ref 181), Zn (Ref 157), diamond (Ref 197) and W (Ref 198) particles were all effective and resulted in lower wear rates than pure $\mathrm{Cu}$ coating. However, additional improvement in wear resistance with increasing reinforcing particles was not significant (Ref 99, 100, 198), with higher reinforcement content resulting in higher wear rate in some cases (Ref 100, 101). The addition of $\mathrm{Ni}$ particles as reinforcement to $\mathrm{Cu}-\mathrm{Al}_{2} \mathrm{O}_{3}$ coatings did not result in significant improvement of the wear behavior since no change in wear mechanism took place (Ref 157). However, the addition of $\mathrm{Zn}$ in $\mathrm{Cu}-\mathrm{Al}_{2} \mathrm{O}_{3}$ resulted in the wear mechanism to change from adhesive to a combination of adhesive and abrasive (Ref 157). The improved wear resistance at lower particle concentration range (below 7.5 vol.\%) in QC-reinforced $\mathrm{Cu}$ coatings is mainly attributed to the reinforcing effect of the particles, which was shown to reduce plowing on the coating and also reduce the depth of the frictional layer (Ref 101). However, a higher concentration (11.5 and 20.5 vol.\%) of the reinforcing phase adversely aggravated the wear 
resistance of coatings due to debonded ceramic particles causing severe abrasion (Ref 101).

In Ni-based CS MMCs, the effect of WC, IN718, and graphene nanotube as reinforcement on wear performance was studied (Ref 103, 106, 153). The addition of WC resulted in a decrease in wear rate by a factor of seven in sliding wear tests, due to the formation of a stable and cohesive mechanical mixed layer (MML) on top of the wear track (Ref 103). The MML was formed due to the fine fragmented WC particles being redistributed on the surface during sliding. Fine-fragmented WC particles not only facilitated the fast development of the MML, but also improved its stability. In addition, they increased the hardness of the MML, which contributed to the superior wear resistance of the composite coating (Ref 103). Cavitation erosion test showed that Ni-IN718 composite coating is significantly more wear resistant than pure Ni coating in terms of both mass loss and the level of degradation (Ref 153). A $20 \%$ volume fraction of the IN718 particles resulted in an overall mass loss reduction by $80 \%$ compared to pure Ni coating (Ref 153). This can be attributed to different material removal mechanisms with the existence of IN718 particles impeding crater formations and detachment of the Ni matrix (Ref 153). Besides, the wear rate of graphene nanoplate-reinforced IN718 composite coating on IN718 substrates was found to be around half of the substrate and 29\% lower than pure IN718 coatings (Ref 106). GNPs reduce wear rate by working as a solid lubricant which greatly decreases the abrasion of the matrix. Following the initial dislodge, GNPs also distribute along the sliding direction and stack on the wear track surface to form a protective layer between the abrasive tip and the sample to prevent further wear. Also, GNPs process a flake-like structure, and surface fragments of GNPs adjacent to the IN718 matrix provide an additional sliding effect (Ref 106). A comparison of $\mathrm{WC}, \mathrm{TiC}$, and $\mathrm{B}_{4} \mathrm{C}$ as reinforcement to Ni-based MMC coatings showed that the lowest wear rate in similar testing conditions was achieved by WC (Ref 174). The highest wear resistance of the WCNi MMC coatings was shown to be attributed to the high fracture toughness of the WC particles, and the higher level of Ni matrix work hardening by WC particles achieved during deposition (Ref 174).

In other types of CS MMCs, the decrease in wear rate can also be observed when reinforcement is added. Higher contents of the reinforcement in WC-12Co coatings were shown to result in a $33 \%$ reduction in wear rate as compared to WC-17Co (Ref 113). An 80\% reduction in wear rate of Ti6Al4V CS coating was achieved by the addition of $23 \mathrm{vol} . \%$ of $\mathrm{TiC}$ (Ref 161). Abrasive grooves along the sliding direction were observed in Ti6Al4V coatings, whereas tribolayers were found on the wear tracks of the composite coating. Reinforced $\mathrm{TiC}$ ceramic particles favored the formation of tribolayers that was shown to resist localized deformation and result in low wear (Ref 161). In Ti-TiC composite coatings, higher TiC content led to a proportional reduction of wear rate (Ref 160). In $\mathrm{Al}_{2} \mathrm{O}_{3}$-CNT composite coating, a 2 wt. $\%$ CNT addition led to the nanoparticle acting as self-lubricant and providing improved wear resistance compared to monolithic $\mathrm{Al}_{2} \mathrm{O}_{3}$ coating. However, at $4 \mathrm{wt} \%$ of CNTs, deterioration of wear properties was noticed in the nanocomposite which was associated with the presence of voids and cracks in the latter case acting as a source of delamination (Ref 163).

Similar to mechanical properties such as hardness and elastic modulus, the wear rate can also be quantitatively predicted as a function of reinforcement content. Two basic models predicting the lower bound (Eq 15) (Ref 199) and upper bound (Eq 16) (Ref 200) to specific wear rate have been developed based on an inverse and a linear rule of mixture, respectively:

$$
\begin{aligned}
& \frac{1}{W_{\text {lower }}}=\frac{V_{M}}{W_{M}}+\frac{V_{P}}{W_{P}} \\
& W_{\text {upper }}=V_{M} W_{M}+V_{P} W_{P}
\end{aligned}
$$

where $V_{P}$ and $V_{M}$ are volume fraction of the reinforcement and the matrix, and $W_{P}$ and $W_{M}$ are specific wear rates of the two phases. $W_{\text {lower }}$ and $W_{\text {upper }}$ are the lower bound and upper bound to specific wear rates, respectively. For these models to be applicable, the two constituent phases are assumed to wear as bulk materials, not considering important factors such as interfacial bonding, relative sizes of the reinforcement and matrix, as well as fracture toughness of the phases, all of which may significantly influence abrasion behavior of the composite (Ref 201). While Eq 15 and 16 were expected to provide upper and lower limits of abrasive wear rate of a composite, there are instances where experimental results are not confined within these over-simplified bounds due to negative reinforcement effect (Ref 201). To address the shortcomings of these models, an improved physical model was proposed, where primary wear mechanisms, specifically, plowing, cracking at the matrix/reinforcement interface or in the reinforcement, and particle removal, were considered (Ref 201). These effects are all gathered in one additional parameter $C$ in Eq 17:

$\frac{1}{W}=\frac{V_{M}}{W_{M}}+C \frac{V_{P}}{W_{P}} \quad V_{P} \leq 0.5$

In this improved model, $C$ is the contribution coefficient of the reinforcement in which the relative contribution of cracking at the interface and cracking of the reinforcement was considered. Interfacial fracture toughness as well as the relative size of the wear-induced crack to the size of the reinforcement affects the magnitude of $C$, which varies 
from 0 to 1 (Ref 201). $C=1$ represents the case where there is no particle removal either because the interfacial fracture toughness is relatively high or because the penetration of the counterpart is small relative to the particle size. In this case, the model reproduces the lower bound to a specific wear rate (best performance) shown in Eq 15. As $C$ approaches 0, particle removal dominates the response of MMC such that the predicted wear rates increase to a higher value than the monolithic matrix, a regime that is not predicted by the basic linear rule of mixture.

Figure 17 shows the experimental measurements of specific wear rate as a function of reinforcement volume fraction for $\mathrm{Al}-\mathrm{Al}_{2} \mathrm{O}_{3}$ composite coatings. We have also superimposed the theoretical predictions of the specific wear rate on the same plot. The theoretical predictions are based on the specific wear rate of the matrix, $\mathrm{W}_{\mathrm{M} \text { - }}$ $=4.4 \mathrm{~mm}^{3} / \mathrm{Nm}$ from experimental measurements of wear rate of the pure $\mathrm{Al}$ coating (Ref 93, 148), and an order of magnitude estimate for the specific wear rate of $\mathrm{Al}_{2} \mathrm{O}_{3}$ to be $\sim 10^{-5} \mathrm{~mm}^{3} / \mathrm{Nm}$ (Ref 202). It can be suggested from the plot that relatively lower levels of $\mathrm{Al}_{2} \mathrm{O}_{3}$ reinforcement contributed little to improve the wear resistance of the coating due to large losses that happen when particle removal is experienced. However, at higher reinforcement contents, the effect of particle removal is reduced with an increased bonding strength between matrix and particle which in turn increases interfacial fracture toughness. An increase in fracture toughness is reflected by the fact that the specific wear rates at higher reinforcement volume fractions can be fitted by a larger $C(C=0.002)$ value compared to those at lower volume fractions $\left(C=10^{-5}\right)$. We note that these $C$ values are significantly smaller when compared to corresponding values for non-CS composites (Ref 201) which we attribute to the presence of defects and

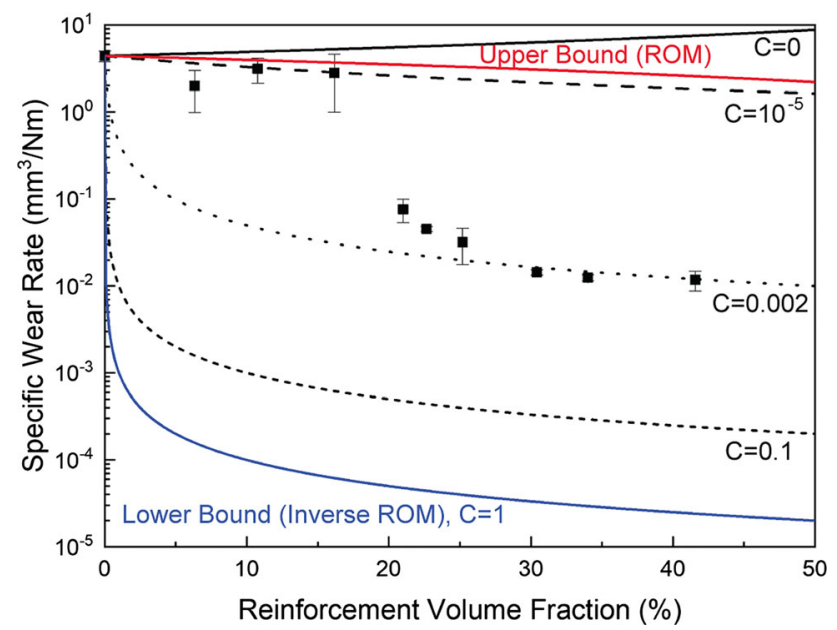

Fig. 17 Theoretical and experimental wear rates of CS $\mathrm{Al}^{-} \mathrm{Al}_{2} \mathrm{O}_{3}$ composite coating as a function of reinforcement volume fraction (Ref 93) imperfect bonded areas in cold spray deposits. The significant deviation of the experimental measurements from the lower bound prediction suggests that there is still room to improve wear behavior of $\mathrm{Al}-\mathrm{Al}_{2} \mathrm{O}_{3}$ composite coatings.

Figure 18 shows a compilation of specific wear rate and reinforcement volume fraction measurements for the material systems whose tribological behavior is widely studied in the literature, namely, Al-, $\mathrm{Cu}-$, and $\mathrm{Ni}$-based CS MMCs. It should be noted the counterpart materials, sliding speeds, as well as applied loads, are not the same for all these measurements. Therefore, instead of cross-comparing different material systems, we focus on the trend observed in a single material system with the same experimental conditions, i.e., the data points denoted with the same color in Fig. 18. We note that the reduction of wear rate by orders of magnitude can be achieved with an increasing amount of ceramic content in Al-based CS MMCs, shown by circles of different colors. However, in $\mathrm{Ni}-$ and $\mathrm{Cu}$ based coatings, shown by squares and triangles of various colors, respectively, improvement in wear resistance is less significant, and in some cases nonexisting with the addition of reinforcing particles to the coating. The success of the reinforcement strategy to improve the tribological performance of Al-based compared to $\mathrm{Cu}$ - and Ni-based coatings can be attributed to enhanced bonding resulting in a more significant load-bearing contribution of the ceramic reinforcement in the former case.

In addition to relating specific wear rate to the reinforcement content, one can also relate the specific wear rate to the hardness of CS MMCs in order to inform material design decisions. The Archard wear equation (Eq 18) states that the volume of material worn, $V$, is inversely proportional to hardness, $H$, for a given wear test conditions:

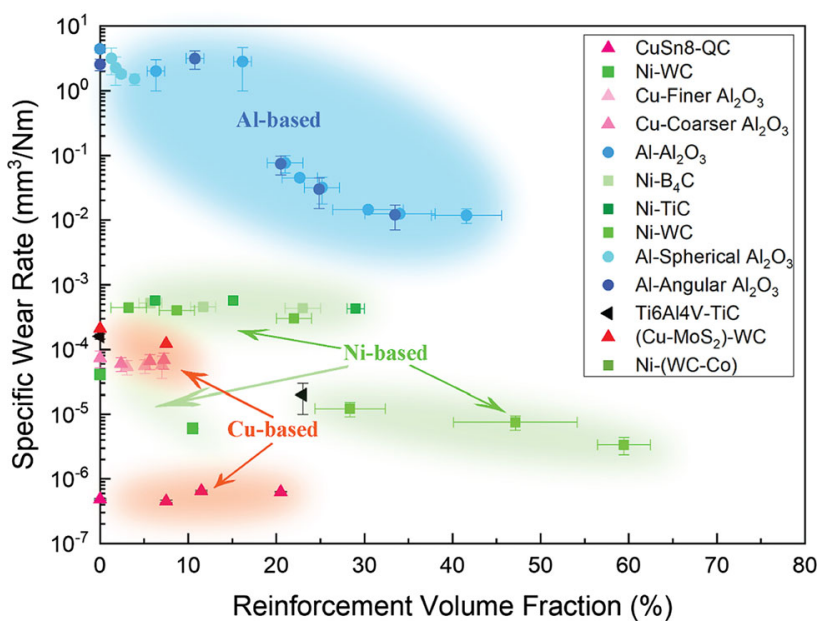

Fig. 18 Specific wear rate versus reinforcement volume fraction in CS MMC coatings (Ref 37, 100, 101, 106, 148, 152, 158, 174) 
$V=\frac{K L F}{H}$

where $K$ is the wear coefficient, $F$ is the normal load, $L$ is the sliding distance. The equation can be reorganized to:

Specific wear rate $=\frac{V}{F L}=\frac{K}{H}$

where it can be seen that there exists an inverse relationship between specific wear rate and the hardness with the wear coefficient as the numerator. We have collocated the specific wear rates of two types of $\mathrm{Al}-\mathrm{Al}_{2} \mathrm{O}_{3} \mathrm{MMC}$ coatings (reinforced with spherical and irregular particles) and plotted them as a function of the coating hardness in Fig. 19. We have also used the Archard scaling to fit the two sets of data points with the two lines in the log-log plot of Fig. 19. It can be observed that the wear rate of the $\mathrm{Al}$ coating reinforced with the spherical $\mathrm{Al}_{2} \mathrm{O}_{3}$ reasonably follows the Archard scaling. This is on the other hand only true up to a certain reinforcement volume fraction for the $\mathrm{Al}$ coatings reinforced with angular $\mathrm{Al}_{2} \mathrm{O}_{3}$; a significant deviation from the Archard scaling can be observed for the reinforcement volume fraction in the range of 20-50 vol. $\%$. The deviation coincides with the sharp reduction in specific wear rate which was attributed to the gradual change of wear mechanism from adhesive to abrasive due to an increased amount of reinforcement. This analysis highlights a potential limitation of Archard scaling in the context of CS MMCs where changes in the reinforcement content can result in not only the hardness of the composite coating but also the defect content, the microstructure, and the wear mechanism.

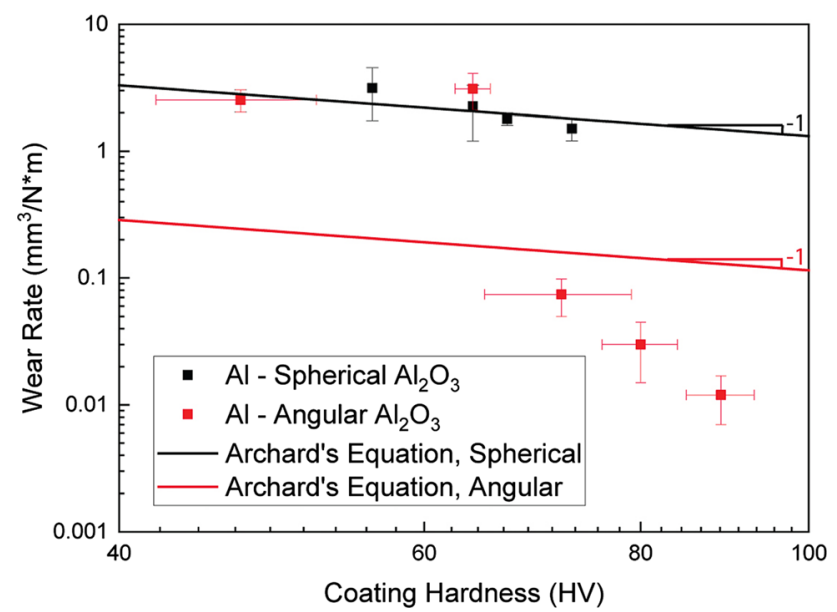

Fig. 19 Experimentally measured specific wear rate versus coating hardness of $\mathrm{CS} \mathrm{Al}-\mathrm{Al}_{2} \mathrm{O}_{3} \mathrm{MMC}$ and the Archard's scaling (Ref 148)

\section{Effect of Post-spray Treatment on Wear Rate of CS MMCs}

Heat treatment presents a dual effect on wear resistance of CS MMC coatings. On the one hand, bonding between the matrix and reinforcing particles can be improved, resulting in a reduction of wear rate. On the other hand, the reduction in hardness, especially at higher temperatures, leads to an increase in wear rate. Compared to the as-sprayed condition, a $33 \%$ decrease in wear rate was achieved in cBN$\mathrm{NiCrAl}$ nanocomposite coatings due to enhanced interparticle bonding after annealing at $750^{\circ} \mathrm{C}$ for $5 \mathrm{~h}$ (Ref 164). Heat treatment at $400^{\circ} \mathrm{C}$ in vacuum or air for $4 \mathrm{hr}$ also reduced the wear rate in $\mathrm{Al}-\mathrm{SiC}$ composite coatings to $30 \% \sim 70 \%$ of that of the as-sprayed coatings, depending on the volume fraction of $\mathrm{SiC}$ content. Vacuum heat treatment produced better wear resistance by reducing oxidation that impeded bonding in the inter-splat boundary (Ref 128). While moderate temperatures $\left(800^{\circ} \mathrm{C}\right)$ in solution aging treatment led to a decrease in wear rate of $\mathrm{CS}$ WC-MS 300 coating due to enhanced hardness and improved bonding, higher temperature $\left(1000^{\circ} \mathrm{C}\right)$ resulted in higher wear rates due to the reduction in the hardness of the coating (Ref 116). In MG-reinforced $\mathrm{Cu}$ MMC, the wear rate of the as-sprayed coating increased by a factor of 2.5 after heat treatment at $300^{\circ} \mathrm{C}$ for $1 \mathrm{hr}$, due to the thermal softening of the matrix (Ref 181).

Turning to post-spray mechanical treatments, FSP greatly improved the wear resistance of the $\mathrm{Ni}-\mathrm{Ti}$ composite coating by a factor of $\sim 2$ compared to the assprayed coating. The improved wear resistance was attributed to the enhancement of the microhardness and the formation of the dense intermetallic structures (Ref 89). Volumetric analysis of the as-deposited and FSPed coatings following solid-liquid impingement test also showed an improved performance of FSP MMC coatings under slurry erosion conditions. Poor erosion performance of the as-deposited MMC coatings was due to agglomerated WC particles within the matrix during CS. The FSP process, on the other hand, was shown to effectively break up and disperse the agglomerates resulting in a homogenous distribution of fine reinforcing WC particles. The primary erosion mechanism in the as-sprayed condition was found to be plowing in the softer matrix alloy which subsequently exposed carbide particles to the impinging slurry. The FSPed surfaces, on the other hand, presented a reduction in WC interparticle spacing. As a result, less of the matrix alloy was exposed to the impinging slurry. Consequently, the volume loss due to erosion was lower in the FSPed specimens when compared with the as-deposited coatings (Ref 172).

In summary, a significant reduction of the wear rate of pure coatings can be achieved through the addition of 
reinforcing particles. In most cases, reinforcements can provide load-bearing capacity and produce triboflims on the surface of the wear track, offering reduced depth of friction region and more stable wear surfaces. The addition of solid lubricants can provide additional wear resistance. However, it is also worth noting that very high reinforcement contents can lead to negative impacts on the wear performance of CS MMCs due to poor interfacial bonding and severe damage caused by loose reinforcing particles. Theoretical frameworks can be adopted for predictions of wear rates of CS MMCs. The predictions are sensitive to the degree of interfacial bonding between reinforcement and matrix and require calibrations for accurate prediction. Heat treatment can improve bonding and thus improve wear resistance of CS MMC coatings. However, excessive heat treatment can lead to negative effects due to reduced hardness. Post-spray mechanical treatments such as FSP can reduce interparticle spacings of hard reinforcements and thus provide better wear resistance through reduced matrix plowing.

\section{Coefficient of Friction}

In CS MMC coatings, the amount of particle reinforcement or solid lubricant in the coating can significantly affect frictional behavior and alter the coefficient of friction (CoF) of the coating. One of the important mechanisms by which the addition of hard reinforcement can reduce the $\mathrm{CoF}$ is through the reduction of contact area between the surface and the counterbody due to increased hardness of the coating ( $\operatorname{Ref} 101,203,204)$. However, the surface roughness of the composite coating, as well as the bonding between matrix and particles, can be affected by the addition of reinforcement too, both of which can adversely influence the $\mathrm{CoF}$ (Ref 95, 106). Another important mechanism that can be exploited to reduce $\mathrm{CoF}$ is selflubrication by adding solid lubricants as reinforcement to the matrix (Ref 20, 158, 159, 196, 204, 205). Application of solid lubricants, such as hexagonal boron nitride (h-BN) (Ref 205) and $\mathrm{MoS}_{2}$ (Ref 158, 159, 196), can decrease the coefficient of friction by introducing a layer of lubricating tribofilm.

In Al-based CS MMCs, lower CoF was achieved in both $\mathrm{CS}$ pure $\mathrm{Al}$ and $\mathrm{Al}-\mathrm{Al}_{2} \mathrm{O}_{3}$ composite coatings when compared with pure Al bulk metal (Ref 118). This can be due to the enhanced hardness of the CS coating compared to the bulk material. At microscales, coatings with 25 and 50 wt. $\%$ of $\mathrm{Al}_{2} \mathrm{O}_{3}$ showed comparable $\mathrm{CoF}$ to that of pure $\mathrm{Al}$ coating $(\sim 0.3)$, while coatings with 75 wt.\% $\mathrm{Al}_{2} \mathrm{O}_{3}$ provided a significant improvement in $\mathrm{CoF}$ (below 0.1). This can be attributed to higher hardness along with reduced plowing of the Al matrix at higher reinforcement content. Addition of $\sim 38$ vol.\% TiN into Al2319 coating resulted in $\mathrm{a} \sim 43 \%$ reduction in $\mathrm{CoF}$ and $\mathrm{a} \sim 15$ times smaller wear rate compared to that of pure coating (Ref 98). The adhesion between the coating and the 100Cr6 steel sliding ball was found to be the dominant wear mechanism in the case of pure Al2319 coating. In the composite coating, on the other hand, third-body abrasion by fine TiN particles between the sliding ball and the coating was shown to be responsible for lowering both the friction coefficient and the wear rate (Ref 98). CoF of the Al-AlSi composite coatings was also found to monotonically reduce from 0.80 to 0.23 with an increasing amount of AlSi alloy reinforcement from 0 to $100 \%$ (Ref 97). The addition of 10 wt. $\% \mathrm{Al}_{2} \mathrm{O}_{3}$ particles significantly reduced the $\mathrm{CoF}$ of the cold-sprayed A380 alloy coating from $\sim 0.5$ to $\sim 0.3$ (Ref 95). However, an increased amount of $\mathrm{Al}_{2} \mathrm{O}_{3}$ to 20, 30 , and 40 wt.\% increased $\mathrm{CoF}$ to around 0.4 (Ref 95). The reason was found to be an increase in the contact area between $\mathrm{Al}_{2} \mathrm{O}_{3}$ particulates and the counter tool due to the fragmentation of $\mathrm{Al}_{2} \mathrm{O}_{3}$ particles (Ref 95). CoF can also be sensitive to the applied load. In A15056/SiC coating, at a normal load of $2 \mathrm{~N}$, the $\mathrm{CoF}$ showed an initial increase from 0.72 to 0.96 followed by a decrease to 0.77 as the $\mathrm{SiC}$ content increased in the range of 0 to 41.4 vol.\% (Ref 151). At a higher normal load of $10 \mathrm{~N}$, however, an initial plateau at 0.52 was followed by an increase to 0.73 in the $\mathrm{CoF}$ in the same range of reinforcement content (Ref 151). The different trends were attributed to different wear mechanisms at different load levels. Since the amount of the contribution of the two phases to wear resistance is different, at the lower load Al matrix mainly resists wear, but at the higher load, participations from both phases occurred. Different reinforcement contents also contributed to the change in wear mechanism due to the change in interfacial bonding strength.

In $\mathrm{Cu}$-based coatings, effects of both hard reinforcements such as $\mathrm{W}, \mathrm{Al}_{2} \mathrm{O}_{3}$, and $\mathrm{AlCuFeB}$ quasicrystal as well as solid lubricants such as $\mathrm{MoS}_{2}$ on friction behavior of CS MMCs have been studied. In CuSn8-based composite coating, the $\mathrm{CoF}$ decreases slightly from $\sim 0.72$ to $\sim$ 0.65 with the increase of $\mathrm{AlCuFeB}$ quasicrystal (QC) phase from 0 to 57.6 vol.\% (Ref 101). The slight reduction in $\mathrm{COF}$ was attributed to the decreased adhesion between the sliding pairs with increasing QC particle fraction (Ref 101). The amount of $\mathrm{W}$ as reinforcement, however, did not change the $\mathrm{CoF}$ for $70 \mathrm{Cu}-30 \mathrm{~W}$ compared to $50 \mathrm{Cu}-50 \mathrm{~W}$ coatings, as there was not a major change in wear mechanism (Ref 198). CoF was found to slightly increase with the addition of 2.36 to 7.22 vol. $\% \mathrm{Al}_{2} \mathrm{O}_{3}$ to pure $\mathrm{Cu}$ coating due to more asperities exposed to the surface during the wear process at higher contents of reinforcement (Ref 100). A significant reduction of the $\mathrm{CoF}$ in $\mathrm{Cu}$ coating from 0.7 to $0.14-15$ was achieved with the addition of $1.8 \pm 0.99$ wt.\% $\mathrm{MoS}_{2}$ which acted as a solid lubricant (Ref 159). 
However, the CoF is not stable throughout the wear test, due to frequent detachment of $\mathrm{Cu}$ creating deep grooves along the wear track (Ref 158). It is through the addition of WC that $\mathrm{CoF}$ was stabilized since WC resisted detachment of $\mathrm{Cu}$ and $\mathrm{MoS}_{2}$ particles. For $\mathrm{Cu}-\mathrm{MoS}_{2}$ and $\mathrm{Cu}-\mathrm{MoS}_{2}-\mathrm{WC}$ composite coating, $\mathrm{CoF}$ of $\mathrm{Cu}-\mathrm{MoS}_{2}-\mathrm{WC}$ against alumina was lower than the composite without WC reinforcement (both lower than pure $\mathrm{Cu}$ coating). $\mathrm{CoF}$ was also more uniform throughout the wear track on $\mathrm{Cu}-\mathrm{MoS}_{2}-\mathrm{WC}$ composite (Ref 158).

The effect of reinforcement on $\mathrm{CoF}$ was also studied in Ni- and Fe-based coatings. The addition of 0.15 wt.\% graphene nanoplates (GNP) into IN718 composite coatings resulted in $16 \%$ and $13 \%$ lower CoFs than IN718 substrates and pure IN718 coatings, respectively. This was achieved due to sliding and lubricating effects activated by the exfoliation of the GNPs, increasing the wear resistance of the composite coatings (Ref 106). In CS-Ni-WC coatings, the presence of WC particles in the coating stabilized CoF, while fluctuations were noticed in the case of pure $\mathrm{Ni}$ coating. The fluctuations of $\mathrm{CoF}$ in pure Ni coating were attributed to material removal which was significantly reduced with the addition of WC reinforcements (Ref 103). In CS 316L-Ni/SiC coating, only a slight reduction of $\mathrm{CoF}$ was observed with the addition of $30 \mathrm{wt} . \% \mathrm{Ni} / \mathrm{SiC}$ particle reinforcement in 316L matrix (Ref 162).

Mechanisms discussed above strongly depend on matrix/reinforcement material types, presence and density of defects, surface distribution of reinforcements, as well as experimental conditions. The strong dependency could be the reason why a clear trend may not be easily discerned when comparing the $\mathrm{CoF}$ values that we have gathered from across the literature and plotted as a function of reinforcement content in Fig. 20. We highlight that the test conditions, such as counterpart material, load, sliding distance, speed, and the length scale (micro/macro), are different from one study to another causing significant scattering in the plot. The emphasis here is the general $\mathrm{CoF}$ trend for each material system represented by the same symbol and color rather than cross-comparison of the $\mathrm{CoF}$ values from different studies. The beneficial effects of

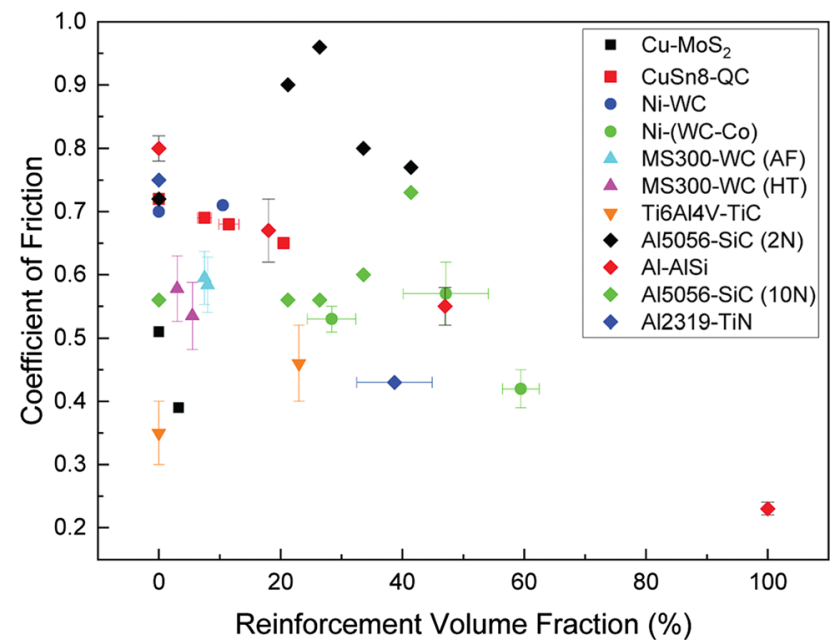

Fig. 20 Coefficient of friction $(\mathrm{CoF})$ of select MMC coatings as a function of reinforcement volume fraction (Ref $37,97,98,101,116,151,152,158,161)$

reinforcing particles in the reduction of the $\mathrm{CoF}$ appear to be the more dominant trend in Fig. 20. It is also interesting to note that the steepest decrease in $\mathrm{CoF}$ among all of the composite coatings shown in Fig. 20 is related to the addition of self-lubricating particles as reinforcement.

In summary, the addition of hard reinforcements that can reduce the contact area between the surface of the coating and counterbody, as well as incorporation of solid lubricants can effectively decrease the coefficient of friction in CS MMC coatings. In some cases, significantly reduced coefficients of friction can be found. However, there also exist cases where reduction of $\mathrm{CoF}$ is less obvious or nonexistent. Large reductions of coating $\mathrm{CoF}$ are usually achieved by significant shifts in the underlying wear mechanisms.

\section{Conclusions and Future Research Directions}

In this review article, we have discussed various aspects of cold spray metal matrix composites from processing science to mechanical and tribological properties. We started 
the review with a discussion on bonding mechanisms and highlighted the surface activation and tamping effects of ceramic particles combined with the cushion effect of the metallic particles in a co-deposition scenario. The tamping effect is an efficient mechanism in closing defects and reducing the porosity of the deposited layers. While deposition efficiency increases with increasing the reinforcement content, impacts of ceramic particles onto ceramics become more probable at a relatively larger volume fractions of reinforcement which in turn reduces the deposition efficiency. A maximum deposition efficiency can be generally achieved with a volume fraction of ceramic particles in the range of $20-40 \%$.

The rate of increase in elastic modulus of CS MMCs with the addition of the reinforcing particles is not constant as suggested by the rule of mixture. The rate, instead, increases as reinforcement content increases. Tamping effect and dispersion strengthening are the origins of the enhanced hardness of CS MMCs when compared to monolithic CS deposits. Experimental measurements of hardness as a function of reinforcement content generally lie in the space confined with the inverse rules of mixture (lower bound) and the rule of mixture (upper bound). Surface activation, tamping, and roughening effects of ceramic particles are also effective in improving the cohesion and adhesion strengths in CS MMCs. At a relatively high amount of reinforcement, the cohesion and adhesion strengths can be adversely affected due to reduced effective contact area between metallic particles in the coating or between metallic matrix and substrate surface. Plasticity and plowing in the matrix and fracture in the reinforcement combined with interfacial fracture are the important mechanisms governing the wear behavior of MMC CS coatings. The positive effects of reinforcing particles on wear resistance at lower contents and the deteriorating effects at higher contents are likely due to the load sharing of the particles in the former and the higher probability of particle debonding in the latter. Our theoretical treatment of specific wear rate in CS MMCs compared with the experimental measurements suggests that there is significant room to improve the tribological properties of CS MMCs. Reinforcement of CS matrix can be exploited as an effective strategy to reduce the coefficient of friction directly through self-lubricating reinforcements or indirectly through the reduction of the contact area between the surface and a counterbody due to increased hardness. In general, the flexibility in matrix/reinforcement material selection combined with a wide range of possible reinforcement contents can be exploited to span orders of magnitude for wear rate, a wide range of coefficient of friction, and hardness.

The effect of cold spray processing parameters on deposition efficiency and porosity of CS MMCs is similar to that of monolithic CS coatings. The higher levels of plastic deformation due to thermal softening and increased impact velocities result in higher deposition efficiencies and lower porosities. Post-spray treatments can be exploited to modify the microstructure and properties of CS MMCs. Post-spray heat treatments can reduce the defect content and significantly enhance the ductility by improving inter-splat bonding, recovery, grain growth, and recrystallization. It can be also used as a processing strategy to form intermetallic reinforcement post-deposition in which case the hardness of the coating can be increased as well. Post-spray mechanical treatments are also very effective in increasing coating hardness due to microstructural and morphological refinement as well as improved material mixing and bonding.

In writing this review, we have also emphasized on a predictive understanding of the mechanical and tribological properties of CS MMCs as a function of the corresponding properties of the constituent phases. Despite our general ability, as a community, to explain and rationalize experimental measurements, some pieces are yet missing for a comprehensive predictive understanding. In our view, this is a critical step toward a theory-driven optimization of CS MMCs in terms of mechanical and tribological properties. In preparing this review, we have identified a few areas with pressing research needs that we offer as future directions of research for the field of CS MMCs.

Perhaps the largest outstanding question about the mechanical properties of CS MMCs is the extent to which each phase contributes to the overall load-bearing capacity of the material. While the collective response of CS MMCs to external load has been widely investigated in the field, the phase-specific response of these materials is much less understood. With the recent advances in cold spray processing as an additive manufacturing technique and the possibility of making bulk free-standing MMC deposits, the phase-specific mechanical response is becoming a 
pressing question. Load-bearing behavior of the composite coatings is fundamentally dictated by the load partitioning between the two, often soft and hard, phases. The state of stress and strain in each phase can be dramatically different from what is measured at the macroscopic level. Advanced characterization techniques, e.g., in situ x-ray diffraction, are needed to resolve the phase-specific response and enable bridging the underlying microscale mechanisms and phase interactions to the continuum level behavior of MMCs.

The interfacial fracture toughness was discussed to be an important parameter governing the wear mechanism and rate. Low interfacial fracture toughness can result in particle removal, whereas high interfacial fracture toughness can favor other mechanisms such as plowing of the matrix material or fracture of the particle to be the dominant wear mechanisms. Despite its importance, interfacial fracture toughness in CS MMCs is an area that is yet to be investigated. Small-scale mechanical testing such as in-situ nanoindentation and microcantilever beam fracture can be employed to study the fracture toughness of metal-ceramic interfaces. Of particular interest to the cold spray community is to understand how interfacial fracture toughness is related to the characteristics of the reinforcement (material, size, volume fraction) and cold spray process parameters.

Computational efforts, both atomistic and continuum, can be extremely helpful to further understand deposition mechanisms and mechanical performance of CS MMCs. In terms of deposition behavior and bonding, it is highly desirable to understand the details of surface activation, tamping, and cushion effects in the co-deposition of CS MMCs. Is there a threshold velocity for ceramic particles impact to activate metallic surfaces? How can we quantify the extent of tamping and cushion effects? Systematic finite element simulations can be developed to tackle these questions. Molecular dynamic simulations can be also used to understand the state of interfaces, e.g., the nature of metal-ceramic bonding in CS MMCs. In terms of mechanical performance, finite element simulations can be used to predict the collective behavior of the composite material from the known properties of the constituent phases. Dispersion strengthening and its correlations with reinforcing particle spacing, size, morphology, volume fraction can be further understood.

As a solid-state process, cold spray is offering a unique space in the areas of composite fabrication and additive manufacturing of structural materials. A widespread deployment of CS MMCs as load-bearing components would not be possible before a comprehensive understanding of the bulk failure modes including fatigue. There are several important questions regarding the fatigue behavior of CS MMCs that need thorough understanding. For instance, among various types of defects (pores, interfacial cracks or particle cracks, etc.) that could be present with various densities in CS MMCs, which one may dominantly govern the response of the material under cyclic loading? How does the load partitioning between the two phases evolve during cyclic loading? To what extent various reinforcements can deflect a propagating crack and provide toughening mechanisms for MMCs?

The impact of metallic particles onto metallic substrates has been widely investigated in the field of cold spray. Fundamental phenomena, including plastic dissipation, thermal softening, large interfacial strains, and jetting, are relatively well understood, and the transitions from rebounding to bonding or erosion are theoretically welldocumented for metal-on-metal impact. The same level of understanding, however, is lacking for the impact of ceramic particles onto ceramic and/or metallic substrates. With the absence of plasticity in ceramic particle impact onto ceramic substrates, at what threshold velocity rebound gives way to fracture and fragmentation? What is the relationship between that threshold velocity and physical and thermomechanical material parameters? How can the tamping effect in ceramic particles impacting metals be quantified? These are a few fundamental questions that could be tackled by single-particle impact studies, either through wipe tests or through laser-induced particle impact tests.

These are just a few among an extensive list of potentially impactful directions for future research in the field of CS MMCs. With the recent proliferation of CS MMCs in structural applications, advanced characterization techniques, and new researchers trained in this field, we look forward to rapid progress in understanding these questions.

Acknowledgment This research was accomplished through a cooperative research agreement with the US Army Research Laboratory, Contract: W911NF1920329, "Development of Additive Manufacturing and Advanced Materials Processing for the DOD”. In addition, the authors wish to acknowledge the anonymous reviewers for their insightful comments and suggestions.

\section{Appendix}

As an addition to the discussion presented in the paper, we have prepared Table 1 where CS MMCs are grouped based on the matrix material. We have reported the reinforcement 


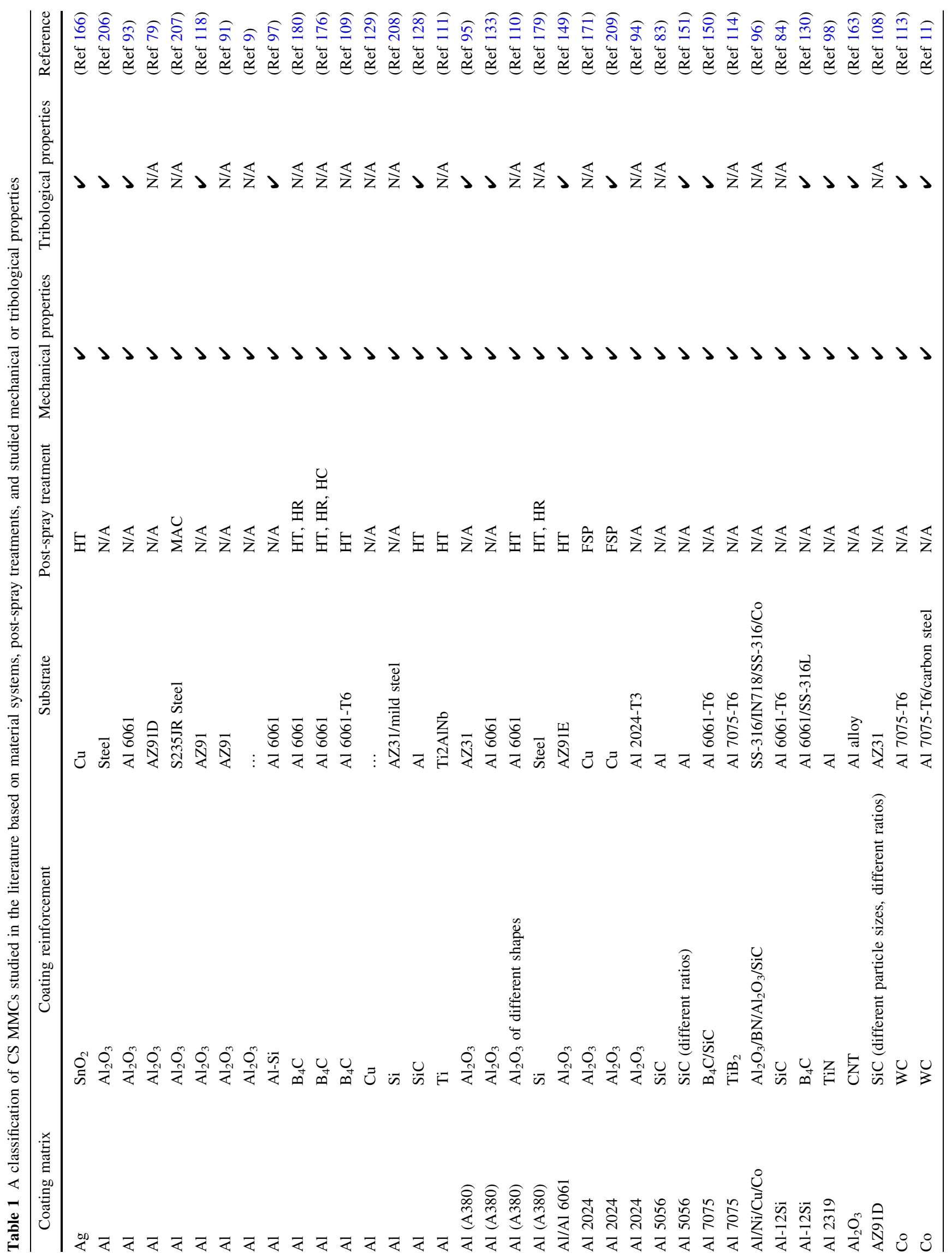




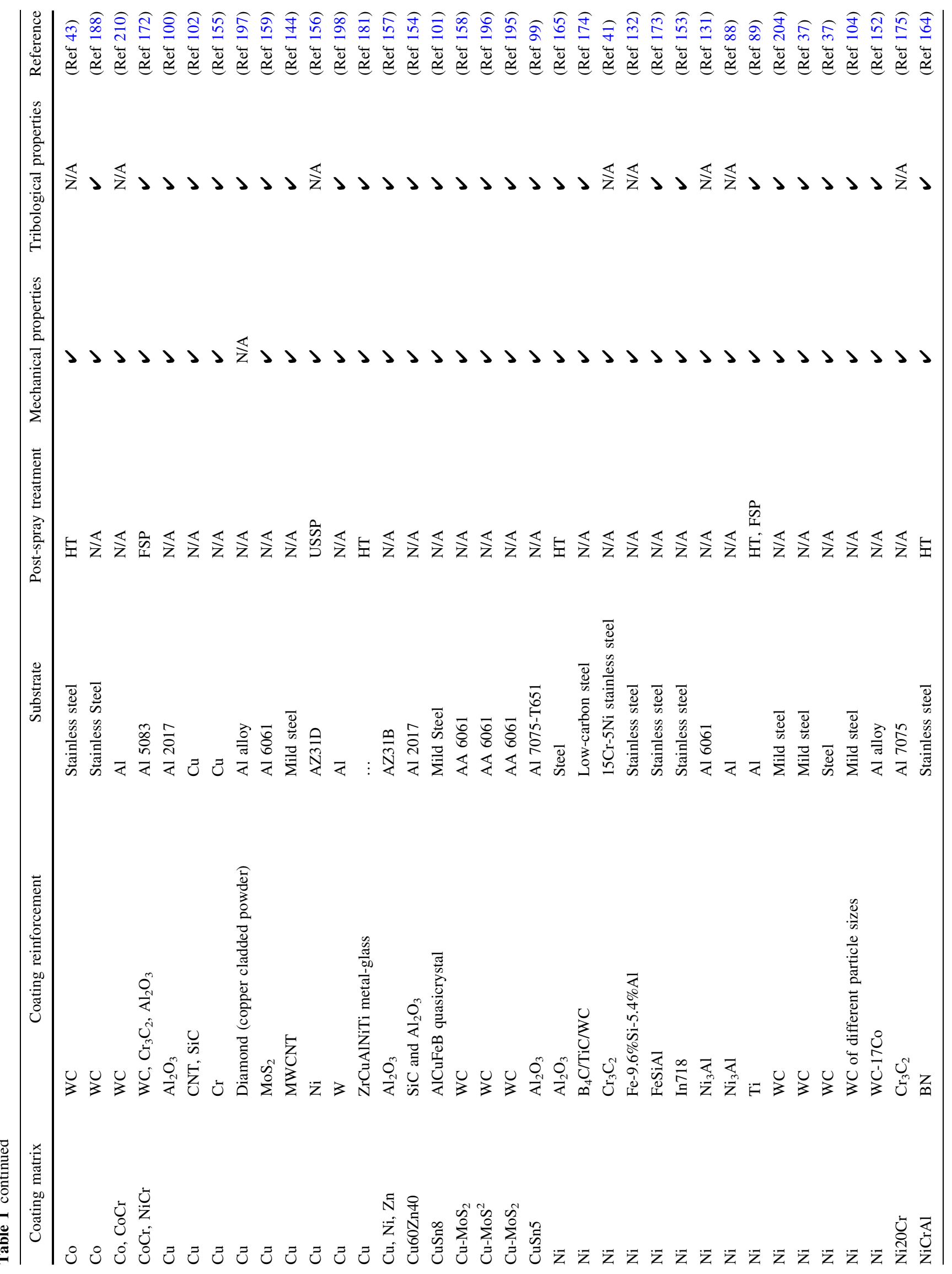




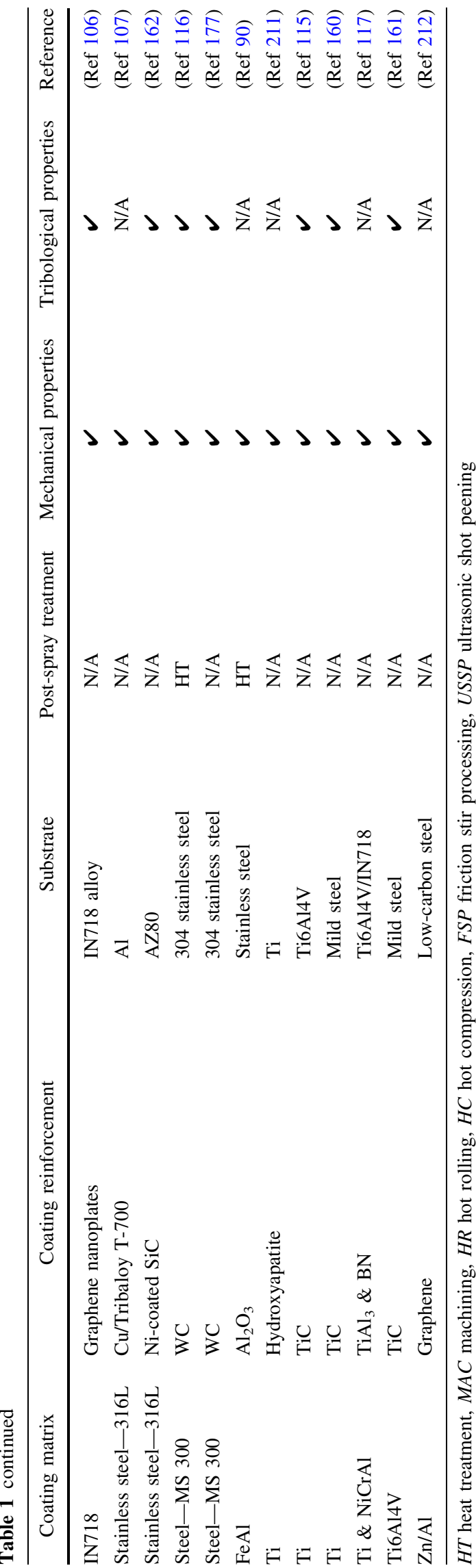

and the substrate materials and marked the properties studied by each work as well as possible post-spray treatments for readers to quickly narrow down the studies that may interest them.

\section{References}

1. A. Papyrin, V. Kosarev, S. Klinkov, A. Alkhimov, and V.M. Fomin, Cold Spray Technology, Elsevier, Amsterdam, 2006

2. S. Yoon, G. Bae, Y. Xiong, S. Kumar, K. Kang, J.J. Kim, and C. Lee, Strain-Enhanced Nanocrystallization of a CuNiTiZr Bulk Metallic Glass Coating by a Kinetic Spraying Process, Acta Mater., 2009, 57(20), p 6191-6199

3. J. Henao, A. Concustell, S. Dosta, G. Bolelli, I.G. Cano, L. Lusvarghi, and J.M. Guilemany, Deposition Mechanisms of Metallic Glass Particles by Cold Gas Spraying, Acta Mater., 2017, 125, p 327-339

4. L.-S. Wang, H.-F. Zhou, K.-J. Zhang, Y.-Y. Wang, C.-X. Li, X.T. Luo, G.-J. Yang, and C.-J. Li, Effect of the Powder Particle Structure and Substrate Hardness during Vacuum Cold Spraying of $\mathrm{Al}_{2} \mathrm{O}_{3}$, Ceram. Int., 2017, 43(5), p 4390-4398

5. D.M. Chun and S.H. Ahn, Deposition Mechanism of Dry Sprayed Ceramic Particles at Room Temperature Using a NanoParticle Deposition System, Acta Mater., 2011, 59(7), p 2693 2703

6. J.H. Lee, H.L. Jang, K.M. Lee, H.R. Baek, K. Jin, K.S. Hong, J.H. Noh, and H.K. Lee, In Vitro and in Vivo Evaluation of the Bioactivity of Hydroxyapatite-Coated Polyetheretherketone Biocomposites Created by Cold Spray Technology, Acta Biomater., 2013, 9(4), p 6177-6187

7. J.-H.G. Lee, D.-Y. Kim, J.-H.G. Lee, M. Kim, S. An, H.S. Jo, C. Nervi, S.S. Al-Deyab, M.T. Swihart, and S.S. Yoon, Scalable Binder-Free Supersonic Cold Spraying of Nanotextured Cupric Oxide $(\mathrm{CuO})$ Films as Efficient Photocathodes. ACS Appl. Mater. Interfaces, 2016, p acsami.6b03968.

8. S. Yin, W. Li, B. Song, X. Yan, M. Kuang, Y. Xu, K. Wen, and R. Lupoi, Deposition of FeCoNiCrMn High Entropy Alloy (HEA) Coating via Cold Spraying, J. Mater. Sci. Technol., 2019, 35(6), p 1003-1007

9. J. Michael Shockley, C. Desrayaud, R.R. Chromik, and S. Descartes, Significance of $\mathrm{Al}_{2} \mathrm{O}_{3}$ Particle Morphology in the Microstructure Evolution of Cold-Sprayed $\mathrm{Al}-\mathrm{Al}_{2} \mathrm{O}_{3}$ during Unconstrained High-Pressure Torsion, Mater. Sci. Eng. A, 2017, 684, p 510-516. https://doi.org/10.1016/j.msea.2016.12.078

10. S. Dosta, G. Bolelli, A. Candeli, L. Lusvarghi, I.G. Cano, and J.M. Guilemany, Plastic Deformation Phenomena during Cold Spray Impact of WC-Co Particles onto Metal Substrates, Acta Mater., 2017, 124, p 173-181

11. S. Dosta, M. Couto, and J.M. Guilemany, Cold Spray Deposition of a WC-25Co Cermet onto Al7075-T6 and Carbon Steel Substrates, Acta Mater., 2013, 61(2), p 643-652. https://doi.org/10. 1016/j.actamat.2012.10.011

12. C. Wüstefeld, D. Rafaja, M. Motylenko, C. Ullrich, R. Drehmann, T. Grund, T. Lampke, and B. Wielage, Local Heteroepitaxy as an Adhesion Mechanism in Aluminium Coatings Cold Gas Sprayed on AlN Substrates, Acta Mater. 2017, 128, p 418-427

13. M. Gardon, A. Latorre, M. Torrell, S. Dosta, J. Fernández, and J.M. Guilemany, Cold Gas Spray Titanium Coatings onto a Biocompatible Polymer, Mater. Lett., 2013, 106, p 97-99

14. J.-G. Lee, J.-H. Lee, S. An, J.Y. Yoon, J.-W. Choi, M.G. Kang, J.I. Lee, H. Song, S.S. Al-Deyab, S.C. James, Y. Kang, D. Kim, 
S.S. Yoon, and H.-S. Lee, Effects of Impact Conditions on the Electrical and Mechanical Properties of Supersonic Cold Sprayed $\mathrm{Cu}-\mathrm{Ni}$ Electrodes, J. Alloys Compd., 2016, 695, p 3714-3721

15. J.G. Lee, D.Y. Kim, B. Kang, D. Kim, H.E. Song, J. Kim, W. Jung, D. Lee, S.S. Al-Deyab, S.C. James, and S.S. Yoon, Nickel-Copper Hybrid Electrodes Self-Adhered onto a Silicon Wafer by Supersonic Cold-Spray, Acta Mater., 2015, 93, p 156163

16. V.K. Champagne, Ed., The Cold Spray Materials Deposition Process Fundamentals and Applications, Woodhead Publishing, Sawston, 2007

17. P. Anatolii, K. Vladimir, K. Sergey, A. Anatolii, and F. Vasily, Cold Spray Technology, 1st ed. 2007. https://doi.org/10.1016/ b978-0-08-045155-8.x5000-5.

18. J. Villafuerte, Ed., Modern Cold Spray, Springer, Cham, 2015, https://doi.org/10.1007/978-3-319-16772-5

19. C.M. Kay and J. Karthikeyan, Ed., High Pressure Cold Spray: Principles and Applications, ASM International, New York, 2016

20. P. Cavaliere, Cold-Spray Coatings: Recent Trends and Future Perspectives, Springer, 2017. https://doi.org/10.1007/978-3319-67183-3

21. F. Gärtner, T. Schmidt, T. Stoltenhoff, and H. Kreye, Recent Developments and Potential Applications of Cold Spraying, Adv. Eng. Mater., 2006, 8(7), p 611-618. https://doi.org/10. 1002/adem.200600048

22. Q. Wang and M.X. Zhang, Review on Recent Research and Development of Cold Spray Technologies, Key Eng. Mater., 2012, 533, p 1-52. https://doi.org/10.4028/www.scientific.net/ KEM.533.1

23. A. Moridi, S.M. Hassani-Gangaraj, M. Guagliano, and M. Dao, Cold Spray Coating: Review of Material Systems and Future Perspectives, Surf. Eng., 2014, 30(6), p 369-395. https://doi.org/ 10.1179/1743294414y.0000000270

24. S.M. Hassani-Gangaraj, A. Moridi, and M. Guagliano, Critical Review of Corrosion Protection by Cold Spray Coatings, Surf. Eng., 2015, 31(11), p 803-815. https://doi.org/10.1179/ $1743294415 y .0000000018$

25. S. Grigoriev, A. Okunkova, A. Sova, P. Bertrand, and I. Smurov, Cold Spraying: From Process Fundamentals towards Advanced Applications, Surf. Coat. Technol., 2015, 268, p 77-84. https:// doi.org/10.1016/j.surfcoat.2014.09.060

26. W. Li, H. Assadi, F. Gaertner, and S. Yin, A Review of Advanced Composite and Nanostructured Coatings by SolidState Cold Spraying Process, Crit. Rev. Solid State Mater. Sci., 2019, 44(2), p 109-156. https://doi.org/10.1080/10408436.2017. 1410778

27. H. Assadi, H. Kreye, F. Gärtner, and T. Klassen, Cold Spraying-A Materials Perspective, Acta Mater., 2016, 116, p 382407. https://doi.org/10.1016/j.actamat.2016.06.034

28. Y.T.R. Lee, T. Hussain, G.A. Fisher, and A.G. McDonald, ColdSprayed Metal Matrix Composite Coatings BT, Cold-Spray Coatings: Recent Trends and Future Perspectives, P. Cavaliere, Ed., Springer, Cham, 2018, p 275-295

29. M. Yu and W. Li, Metal Matrix Composite Coatings by Cold Spray BT, Cold-Spray Coatings: Recent Trends and Future Perspectives, P. Cavaliere, Ed., Springer, Cham, 2018, p 297318 https://doi.org/10.1007/978-3-319-67183-3_10

30. R.R. Chromik, S.A. Alidokht, J.M. Shockley, and Y. Zhang, Tribological Coatings Prepared by Cold Spray BT, Cold-Spray Coatings: Recent Trends and Future Perspectives, P. Cavaliere, Ed., Springer, Cham, 2018, p 321-348

31. Q. Wang, K. Spencer, N. Birbilis, and M.-X. Zhang, The Influence of Ceramic Particles on Bond Strength of Cold Spray Composite Coatings on AZ91 Alloy Substrate, Surf. Coat.
Technol., 2010, 205(1), p 50-56. https://doi.org/10.1016/j.surf coat.2010.06.008

32. M. Yandouzi, P. Richer, and B. Jodoin, SiC Particulate Reinforced Al-12Si Alloy Composite Coatings Produced by the Pulsed Gas Dynamic Spray Process: Microstructure and Properties, Surf. Coat. Technol., 2009, 203(20-21), p 3260-3270. https://doi.org/10.1016/j.surfcoat.2009.04.001

33. W.Y. Li, G. Zhang, C. Zhang, O. Elkedim, H. Liao, and C. Coddet, Effect of Ball Milling of Feedstock Powder on Microstructure and Properties of TiN Particle-Reinforced Al Alloy-Based Composites Fabricated by Cold Spraying, J. Therm. Spray Technol., 2008, 17(3), p 316-322

34. H.-K. Kang and S.B. Kang, Tungsten/Copper Composite Deposits Produced by a Cold Spray, Scr. Mater., 2003, 49(12), p 1169-1174. https://doi.org/10.1016/j.scriptamat.2003.08.023

35. S.R. Bakshi, V. Singh, K. Balani, D.G. McCartney, S. Seal, and A. Agarwal, Carbon Nanotube Reinforced Aluminum Composite Coating via Cold Spraying, Surf. Coat. Technol., 2008, 202(21), p 5162-5169. https://doi.org/10.1016/j.surfcoat.2008. 05.042

36. D. Lioma, N. Sacks, and I. Botef, Cold Gas Dynamic Spraying of WC-Ni Cemented Carbide Coatings, Int. J. Refract. Met. Hard Mater., 2015, 49, p 365-373. https://doi.org/10.1016/j. ijrmhm.2014.08.017

37. S.A. Alidokht, S. Yue, and R.R. Chromik, Effect of WC Morphology on Dry Sliding Wear Behavior of Cold-Sprayed Ni-WC Composite Coatings, Surf. Coat. Technol., 2019, 357, p 849863. https://doi.org/10.1016/j.surfcoat.2018.10.082

38. K.J. Hodder, J.A. Nychka, and A.G. McDonald, Comparison of $10 \mathrm{Mm}$ and $20 \mathrm{Nm} \mathrm{Al}-\mathrm{Al}_{2} \mathrm{O}_{3}$ Metal Matrix Composite Coatings Fabricated by Low-Pressure Cold Gas Dynamic Spraying, $J$. Therm. Spray Technol., 2014, 23(5), p 839-848

39. H.Y. Lee, S.H. Jung, S.Y. Lee, Y.H. You, and K.H. Ko, Correlation between $\mathrm{Al}_{2} \mathrm{O}_{3}$ Particles and Interface of $\mathrm{Al}-\mathrm{Al}_{2} \mathrm{O}_{3}$ Coatings by Cold Spray, Appl. Surf. Sci., 2005, 252(5), p 18911898. https://doi.org/10.1016/j.apsusc.2005.03.148

40. S.I. Imbriglio, M. Hassani-Gangaraj, D. Veysset, M. Aghasibeig, R. Gauvin, K.A. Nelson, C.A. Schuh, and R.R. Chromik, Adhesion Strength of Titanium Particles to Alumina Substrates: A Combined Cold Spray and LIPIT Study, Surf. Coat. Technol., 2019, 361, p 403-412. https://doi.org/10.1016/j.surfcoat.2019. 01.071

41. D.M. Jafarlou, C. Walde, V.K. Champagne, S. Krishnamurty, and I.R. Grosse, Influence of Cold Sprayed $\mathrm{Cr}_{3} \mathrm{C}_{2}-\mathrm{Ni}$ Coating on Fracture Characteristics of Additively Manufactured $15 \mathrm{Cr}-5 \mathrm{Ni}$ Stainless Steel, Mater. Des., 2018, 155, p 134-147. https://doi. org/10.1016/j.matdes.2018.05.063

42. N.M. Melendez and A.G. McDonald, Development of WCBased Metal Matrix Composite Coatings Using Low-Pressure Cold Gas Dynamic Spraying, Surf. Coat. Technol., 2013, 214, p 101-109. https://doi.org/10.1016/j.surfcoat.2012.11.010

43. X.T. Luo, C.X. Li, F.L. Shang, G.J. Yang, Y.Y. Wang, and C.J. Li, WC-Co Composite Coating Deposited by Cold Spraying of a Core-Shell-Structured WC-Co Powder, J. Therm. Spray Technol., 2014, 24(1-2), p 100-107

44. G. Bae, Y. Xiong, S. Kumar, K. Kang, and C. Lee, General Aspects of Interface Bonding in Kinetic Sprayed Coatings, Acta Mater., 2008, 56(17), p 4858-4868

45. G. Bae, S. Kumar, S. Yoon, K. Kang, H. Na, H.-J. Kim, and C. Lee, Bonding Features and Associated Mechanisms in Kinetic Sprayed Titanium Coatings, Acta Mater., 2009, 57(19), p 56545666

46. M. Grujicic, C.L. Zhao, W.S. DeRosset, and D. Helfritch, Adiabatic Shear Instability Based Mechanism for Particles/ Substrate Bonding in the Cold-Gas Dynamic-Spray Process, Mater. Des., 2004, 25(8), p 681-688 
47. H. Assadi, F. Gärtner, T. Stoltenhoff, and H. Kreye, Bonding Mechanism in Cold Gas Spraying, Acta Mater., 2003, 51(15), p 4379-4394

48. M. Hassani-Gangaraj, D. Veysset, V.K. Champagne, K.A. Nelson, and C.A. Schuh, Adiabatic Shear Instability Is Not Necessary for Adhesion in Cold Spray, Acta Mater., 2018, 158, p 430-439. https://doi.org/10.1016/j.actamat.2018.07.065

49. M. Hassani-Gangaraj, D. Veysset, K.A. Nelson, and C.A. Schuh, Supersonic Impact of Metallic Micro-Particles, arXiv:1612. 08081, 2016.

50. S. Suresh, S.W. Lee, M. Aindow, H.D. Brody, V.K. Champagne, and A.M. Dongare, Mesoscale Modeling of Jet Initiation Behavior and Microstructural Evolution during Cold Spray Single Particle Impact, Acta Mater., 2020, 182, p 197-206

51. C.J. Li, W.Y. Li, and H. Liao, Examination of the Critical Velocity for Deposition of Particles in Cold Spraying, J. Therm. Spray Technol., 2006, 15(2), p 212-222

52. M. Hassani-Gangaraj, D. Veysset, K.A. Nelson, and C.A. Schuh, In-Situ Observations of Single Micro-Particle Impact Bonding, Scr. Mater., 2018, 145, p 9-13. https://doi.org/10.1016/j.scripta mat.2017.09.042

53. M.V. Vidaller, A. List, F. Gaertner, T. Klassen, S. Dosta, and J.M. Guilemany, Single Impact Bonding of Cold Sprayed Ti6Al-4V Powders on Different Substrates, J. Therm. Spray Technol., 2015, 24(4), p 644-658

54. P.C. King, C. Busch, T. Kittel-Sherri, M. Jahedi, and S. Gulizia, Interface Melding in Cold Spray Titanium Particle Impact, Surf. Coat. Technol., 2014, 239, p 191-199

55. M. Grujicic, J.R. Saylor, D.E. Beasley, W.S. DeRosset, and D. Helfritch, Computational Analysis of the Interfacial Bonding between Feed-Powder Particles and the Substrate in the ColdGas Dynamic-Spray Process, Appl. Surf. Sci., 2003, 219(3-4), p 211-227

56. W.Y. Li, C.J. Li, and H. Liao, Significant Influence of Particle Surface Oxidation on Deposition Efficiency, Interface Microstructure and Adhesive Strength of Cold-Sprayed Copper Coatings, Appl. Surf. Sci., 2010, 256(16), p 4953-4958

57. W.Y. Li, H. Liao, C.J. Li, G. Li, C. Coddet, and X. Wang, On High Velocity Impact of Micro-Sized Metallic Particles in Cold Spraying, Appl. Surf. Sci., 2006, 253(5), p 2852-2862

58. R.C. Dykhuizen, M.F. Smith, D.L. Gilmore, R.A. Neiser, X. Jiang, and S. Sampath, Impact of High Velocity Cold Spray Particles, J. Therm. Spray Technol., 1999, 8(4), p 559-564

59. T. Schmidt, F. Gärtner, H. Assadi, and H. Kreye, Development of a Generalized Parameter Window for Cold Spray Deposition, Acta Mater., 2006, 54(3), p 729-742

60. V.K. Champagne, D. Helfritch, P. Leyman, S. Grendahl, and B. Klotz, Interface Material Mixing Formed by the Deposition of Copper on Aluminum by Means of the Cold Spray Process, $J$. Therm. Spray Technol., 2005, 14(3), p 330-334

61. L. Ajdelsztajn, B. Jodoin, G.E. Kim, and J.M. Schoenung, Cold Spray Deposition of Nanocrystalline Aluminum Alloys, Metall. Mater. Trans. A, 2005, 36(11), p 3263-3263

62. Y. Xiong, G. Bae, X. Xiong, and C. Lee, The Effects of Successive Impacts and Cold Welds on the Deposition Onset of Cold Spray Coatings, J. Therm. Spray Technol., 2010, 19(3), p 575-585

63. R. Nikbakht, S.H. Seyedein, S. Kheirandish, H. Assadi, and B. Jodoin, The Role of Deposition Sequence in Cold Spraying of Dissimilar Materials, Surf. Coat. Technol., 2019, 367, p 75-85. https://doi.org/10.1016/j.surfcoat.2019.03.065

64. J.O. Kliemann, H. Gutzmann, F. Gärtner, H. Hübner, C. Borchers, and T. Klassen, Formation of Cold-Sprayed Ceramic Titanium Dioxide Layers on Metal Surfaces, J. Therm. Spray Technol., 2011, 20(1-2), p 292-298
65. M.R. Rokni, P. Feng, C.A. Widener, and S.R. Nutt, Depositing Al-Based Metallic Coatings onto Polymer Substrates by Cold Spray, J. Therm. Spray Technol., 2019, 28(7), p 1699-1708. https://doi.org/10.1007/s11666-019-00911-y

66. M. Hassani-Gangaraj, D. Veysset, K.A. Nelson, and C.A. Schuh, Melt-Driven Erosion in Microparticle Impact, Nat. Commun., 2018, 9(1), p 5077. https://doi.org/10.1038/s41467-018-07509-y

67. M. Hassani-Gangaraj, D. Veysset, K.A. Nelson, and C.A. Schuh, Melting Can Hinder Impact-Induced Adhesion, Phys. Rev. Lett., 2017, 119(17), p 175701. https://doi.org/10.1103/physrevlett. 119.175701

68. M. Hassani-Gangaraj, D. Veysset, K.A. Nelson, and C.A. Schuh, Impact-Bonding with Aluminum, Silver, and Gold Microparticles: Toward Understanding the Role of Native Oxide Layer, Appl. Surf. Sci., 2019, 476, p 528-532. https://doi.org/10.1016/j. apsusc.2019.01.111

69. M. Hassani-Gangaraj, D. Veysset, V.K. Champagne, K.A. Nelson, and C.A. Schuh, Response to Comment on 'Adiabatic Shear Instability is Not Necessary for Adhesion in Cold Spray. Scr. Mater. 2019, 162, p 515-519. https://doi.org/10.1016/j. scriptamat.2018.12.015

70. W.Y. Li, H. Liao, C.J. Li, H.S. Bang, and C. Coddet, Numerical Simulation of Deformation Behavior of Al Particles Impacting on Al Substrate and Effect of Surface Oxide Films on Interfacial Bonding in Cold Spraying, Appl. Surf. Sci., 2007, 253(11), p 5084-5091

71. W.Y. Li and W. Gao, Some Aspects on 3D Numerical Modeling of High Velocity Impact of Particles in Cold Spraying by Explicit Finite Element Analysis, Appl. Surf. Sci., 2009, 255(18), p 7878-7892

72. S. Rahmati, A. Zúñiga, B. Jodoin, and R.G.A. Veiga, Deformation of Copper Particles upon Impact: A Molecular Dynamics Study of Cold Spray, Comput. Mater. Sci., 2020, 171, p 109219

73. A. Joshi and S. James, Molecular Dynamics Simulation Study of Cold Spray Process, J. Manuf. Process., 2018, 33, p 136-143

74. A. Shkodkin, A. Kashirin, O. Klyuev, and T. Buzdygar, Metal Particle Deposition Stimulation by Surface Abrasive Treatment in Gas Dynamic Spraying, J. Therm. Spray Technol., 2006, 15(3), p 382-386

75. A. Sova, A. Papyrin, and I. Smurov, Influence of Ceramic Powder Size on Process of Cermet Coating Formation by Cold Spray, J. Therm. Spray Technol., 2009, 18(4), p 633-641

76. A. Sova, V.F. Kosarev, A. Papyrin, and I. Smurov, Effect of Ceramic Particle Velocity on Cold Spray Deposition of MetalCeramic Coatings, J. Therm. Spray Technol., 2011, 20(1-2), p 285-291

77. H.Y. Lee, Y.H. Yu, Y.C. Lee, Y.P. Hong, and K.H. Ko, Cold Spray of $\mathrm{SiC}$ and $\mathrm{Al}_{2} \mathrm{O}_{3}$ with Soft Metal Incorporation: A Technical Contribution, J. Therm. Spray Technol., 2004, 13(2), p 184-189

78. J. Wu, Y. Tao, H. Jin, M. Li, T. Xiong, and C. Sun, Friction and Wear Properties of Cold Gas Dynamic Sprayed $\alpha-\mathrm{Al}_{2} \mathrm{O}_{3}-\mathrm{Al}$ Composite Coatings, J. Coatings, 2013, 2013, p 1-7

79. Y. Tao, T. Xiong, C. Sun, H. Jin, H. Du, and T. Li, Effect of $\alpha$ $\mathrm{Al}_{2} \mathrm{O}_{3}$ on the Properties of Cold Sprayed $\mathrm{Al} / \alpha-\mathrm{Al}_{2} \mathrm{O}_{3}$ Composite Coatings on AZ91D Magnesium Alloy, Appl. Surf. Sci., 2009, 256(1), p 261-266. https://doi.org/10.1016/j.apsusc.2009.08.012

80. C.-J. Li, X. Suo, G.-J. Yang, and C.-X. Li, Influence of Annealing on the Microstructure and Wear Performance of Diamond/NiCrAl Composite Coating Deposited through Cold Spraying, Mater. Sci. Forum, 2010, 638-642, p 894-899

81. J.M. Miguel, J.M. Guilemany, and S. Dosta, Effect of the Spraying Process on the Microstructure and Tribological Properties of Bronze-Alumina Composite Coatings, Surf. Coat. Technol., 2010, 205(7), p 2184-2190. https://doi.org/10.1016/j. surfcoat.2010.08.150 
82. E. Irissou, J.G. Legoux, B. Arsenault, and C. Moreau, Investigation of $\mathrm{Al}-\mathrm{Al}_{2} \mathrm{O}_{3}$ Cold Spray Coating Formation and Properties, J. Therm. Spray Technol., 2007, 16(5-6), p 661-668

83. M. Yu, W.-Y. Li, X.K. Suo, and H.L. Liao, Effects of Gas Temperature and Ceramic Particle Content on Microstructure and Microhardness of Cold Sprayed SiCp/Al 5056 Composite Coatings, Surf. Coat. Technol., 2013, 220, p 102-106. https://doi. org/10.1016/j.surfcoat.2012.05.050

84. E. Sansoucy, P. Marcoux, L. Ajdelsztajn, and B. Jodoin, Properties of SiC-Reinforced Aluminum Alloy Coatings Produced by the Cold Gas Dynamic Spraying Process, Surf. Coat. Technol., 2008, 202(16), p 3988-3996. https://doi.org/10.1016/j.surfcoat. 2008.02.017

85. H. Bu, M. Yandouzi, C. Lu, D. MacDonald, and B. Jodoin, Cold Spray Blended Al + Mg17Al12 Coating for Corrosion Protection of AZ91D Magnesium Alloy, Surf. Coat. Technol., 2012, 207, p 155-162. https://doi.org/10.1016/j.surfcoat.2012.06.050

86. K. Spencer, D.M. Fabijanic, and M.-X. Zhang, The Influence of $\mathrm{Al}_{2} \mathrm{O}_{3}$ Reinforcement on the Properties of Stainless Steel Cold Spray Coatings, Surf. Coat. Technol., 2012, 206(14), p 32753282. https://doi.org/10.1016/j.surfcoat.2012.01.031

87. C. Huang, W. Li, M.-P. Planche, H. Liao, and G. Montavon, InSitu Formation of Ni-Al Intermetallics-Coated Graphite/Al Composite in a Cold-Sprayed Coating and Its High Temperature Tribological Behaviors, J. Mater. Sci. Technol., 2017, 33(6), p 507-515. https://doi.org/10.1016/j.jmst.2017.01.026

88. F. Azarmi, X.W. Tangpong, and T. Chandanayaka, Investigation on Mechanical Properties of Cold Sprayed Ni-Ni3Al Composites, Surf. Eng., 2015, 31(11), p 832-839

89. C.J. Huang, X.C. Yan, W.Y. Li, W.B. Wang, C. Verdy, M.P. Planche, H.L. Liao, and G. Montavon, Post-Spray Modification of Cold-Sprayed Ni-Ti Coatings by High-Temperature Vacuum Annealing and Friction Stir Processing, Appl. Surf. Sci., 2018, 451, p 56-66. https://doi.org/10.1016/j.apsusc.2018.04.257

90. H.-T. Wang, C.-J. Li, G.-J. Yang, and C.-X. Li, Effect of Heat Treatment on the Microstructure and Property of Cold-Sprayed Nanostructured $\mathrm{FeAl} / \mathrm{Al}_{2} \mathrm{O}_{3}$ Intermetallic Composite Coating, Vacuum, Pergamon, 2008, 83(1), p 146-152. https://doi.org/10. 1016/J.VACUUM.2008.03.094

91. Q. Wang, Q. Sun, M.-X. Zhang, W.-J. Niu, C.-B. Tang, K.-S. Wang, X. Rui, L. Zhai, and L. Wang, The Influence of Cold and Detonation Thermal Spraying Processes on the Microstructure and Properties of Al-Based Composite Coatings on Mg Alloy, Surf. Coat. Technol., 2018, 352, p 627-633. https://doi.org/10. 1016/j.surfcoat.2018.08.045

92. W. Li, C. Cao, and S. Yin, Solid-State Cold Spraying of Ti and Its Alloys: A Literature Review, Prog. Mater. Sci., 2020, 110, p 100633. https://doi.org/10.1016/j.pmatsci.2019.100633

93. R. Fernandez and B. Jodoin, Cold Spray Aluminum-Alumina Cermet Coatings: Effect of Alumina Content, J. Therm. Spray Technol., 2018, 27(4), p 603-623. https://doi.org/10.1007/ s11666-018-0702-6

94. Z. Zhang, F. Liu, E.-H. Han, L. Xu, and P.C. Uzoma, Effects of $\mathrm{Al}_{2} \mathrm{O}_{3}$ on the Microstructures and Corrosion Behavior of LowPressure Cold Gas Sprayed Al 2024- $\mathrm{Al}_{2} \mathrm{O}_{3}$ Composite Coatings on AA 2024-T3 Substrate, Surf. Coat. Technol., 2019, 370, p 5368. https://doi.org/10.1016/j.surfcoat.2019.04.082

95. X. Qiu, N.U.H. Tariq, J. Wang, J. Tang, L. Gyansah, Z. Zhao, and T. Xiong, Microstructure, Microhardness and Tribological Behavior of $\mathrm{Al}_{2} \mathrm{O}_{3}$ Reinforced A380 Aluminum Alloy Composite Coatings Prepared by Cold Spray Technique, Surf. Coat. Technol., 2018, 350, p 391-400. https://doi.org/10.1016/j.surf coat.2018.07.039

96. P. Cavaliere, A. Perrone, and A. Silvello, Processing Conditions Affecting Grain Size and Mechanical Properties in
Nanocomposites Produced via Cold Spray, J. Therm. Spray Technol., 2014, 23(7), p 1089-1096

97. S.R. Bakshi, D. Wang, T. Price, D. Zhang, A.K. Keshri, Y. Chen, D.G. McCartney, P.H. Shipway, and A. Agarwal, Microstructure and Wear Properties of Aluminum/AluminumSilicon Composite Coatings Prepared by Cold Spraying, Surf. Coat. Technol., 2009, 204(4), p 503-510. https://doi.org/10. 1016/j.surfcoat.2009.08.018

98. W.-Y. Li, G. Zhang, H.L. Liao, and C. Coddet, Characterizations of Cold Sprayed TiN Particle Reinforced Al2319 Composite Coating, J. Mater. Process. Technol., 2008, 202(1-3), p 508-513. https://doi.org/10.1016/j.jmatprotec.2007.09.045

99. W. Chen, Y. Yu, A.K. Tieu, J. Hao, L. Wang, S. Zhu, and J. Yang, Microstructure, Mechanical Properties and Tribological Behavior of the Low-Pressure Cold Sprayed Tin Bronze-Alumina Coating in Artificial Seawater, Tribol. Int., 2020, 142, p 105992. https://doi.org/10.1016/j.triboint.2019.105992

100. K.I. Triantou, D.I. Pantelis, V. Guipont, and M. Jeandin, Microstructure and Tribological Behavior of Copper and Composite Copper + alumina Cold Sprayed Coatings for Various Alumina Contents, Wear, 2015, 336-337, p 96-107. https://doi. org/10.1016/J.WEAR.2015.05.003

101. X. Guo, J. Chen, H. Yu, H. Liao, and C. Coddet, A Study on the Microstructure and Tribological Behavior of Cold-Sprayed Metal Matrix Composites Reinforced by Particulate Quasicrystal, Surf. Coat. Technol., 2015, 268, p 94-98. https://doi.org/10. 1016/j.surfcoat.2014.05.062

102. E.J.T. Pialago, O.K. Kwon, and C.W. Park, Cold Spray Deposition of Mechanically Alloyed Ternary Cu-CNT-SiC Composite Powders, Ceram. Int., 2015, 41(5), p 6764-6775. https:// doi.org/10.1016/j.ceramint.2015.01.123

103. S.A. Alidokht, P. Manimunda, P. Vo, S. Yue, and R.R. Chromik, Cold Spray Deposition of a Ni-WC Composite Coating and Its Dry Sliding Wear Behavior, Surf. Coat. Technol., 2016, 308, p 424-434. https://doi.org/10.1016/j.surfcoat.2016.09.089

104. S. AhmadAlidokht, P. Vo, S. Yue, and R.R. Chromik, Erosive Wear Behavior of Cold-Sprayed Ni-WC Composite Coating, Wear, 2017, 376-377, p 566-577. https://doi.org/10.1016/j.wear. 2017.01.052

105. G. Munday, J. Hogan, and A. McDonald, On the MicrostructureDependency of Mechanical Properties and Failure of LowPressure Cold-Sprayed Tungsten Carbide-Nickel Metal Matrix Composite Coatings, Surf. Coat. Technol., 2020, 396, p 125947

106. W. Sun, A.W.-Y. Tan, A. Bhowmik, F. Xue, I. Marinescu, and E. Liu, Evaluation of Cold Sprayed Graphene Nanoplates-Inconel 718 Composite Coatings, Surf. Coat. Technol., 2019, 378, p 125065. https://doi.org/10.1016/j.surfcoat.2019.125065

107. R. Maestracci, A. Sova, M. Jeandin, J.-M. Malhaire, I. Movchan, P. Bertrand, and I. Smurov, Deposition of Composite Coatings by Cold Spray Using Stainless Steel 316L, Copper and Tribaloy T-700 Powder Mixtures, Surf. Coat. Technol., 2016, 287, p 1-8. https://doi.org/10.1016/j.surfcoat.2015.12.065

108. X.K. Suo, Q.L. Suo, W.Y. Li, M.P. Planche, and H.L. Liao, Effects of Sic Volume Fraction and Particle Size on the Deposition Behavior and Mechanical Properties of Cold-Sprayed AZ91D/SiCp Composite Coatings, J. Therm. Spray Technol., 2014, 23(1-2), p 91-97

109. N.H. Tariq, L. Gyansah, J.Q. Wang, X. Qiu, B. Feng, M.T. Siddique, and T.Y. Xiong, Cold Spray Additive Manufacturing: A Viable Strategy to Fabricate Thick B4C/Al Composite Coatings for Neutron Shielding Applications, Surf. Coat. Technol., 2018, 339, p 224-236. https://doi.org/10.1016/j.surf coat.2018.02.007

110. X. Qiu, N.U.H. Tariq, L. Qi, J.-Q. Wang, and T.-Y. Xiong, A Hybrid Approach to Improve Microstructure and Mechanical Properties of Cold Spray Additively Manufactured A380 
Aluminum Composites, Mater. Sci. Eng. A, 2020, 772, p 138828. https://doi.org/10.1016/j.msea.2019.138828

111. L. Shen, L. Kong, T. Xiong, H. Du, and T. Li, Preparation of TiAl3-Al Composite Coating by Cold Spraying, Trans. Nonferrous Met. Soc. China, 2009, 19(4), p 879-882. https://doi.org/ 10.1016/s1003-6326(08)60369-6

112. H.-T. Wang, C.-J. Li, G.-J. Yang, and C.-X. Li, Cold Spraying of Fe/Al Powder Mixture: Coating Characteristics and Influence of Heat Treatment on the Phase Structure, Appl. Surf. Sci., 2008, 255(5), p 2538-2544. https://doi.org/10.1016/j.apsusc.2008.07. 127

113. M. Couto, S. Dosta, M. Torrell, J. Fernández, and J.M. Guilemany, Cold Spray Deposition of WC-17 and 12Co Cermets Onto Aluminum. Surf. Coat. Technol. 2013, 235, p 54-61. https://doi.org/10.1016/j.surfcoat.2013.07.011

114. X. Xie, Y. Maa, C. Chen, G. Ji, C. Verdy, H. Wu, Z. Chen, S. Yuan, B. Normand, S. Yin, and H. Liao, Cold Spray Additive Manufacturing of Metal Matrix Composites (MMCs) Using a Novel Nano-TiB2-Reinforced 7075Al Powder, J. Alloys Compd., 2019, https://doi.org/10.1016/j.jallcom.2019.152962

115. J. Kusinski, S. Kac, G. Szwachta, S. Dosti, J. Garcia-forgas, and E.P. Georgiou, Wear Resistance of the TI/TIC Coatings Deposited by Means of Supersonic Cold Gas Spra Y Technique. TMS2014 Annnual Meeting Supplemental Proceedings 2014, p 1173-1180.

116. C. Chen, Y. Xie, X. Yan, R. Huang, M. Kuang, W. Ma, R. Zhao, J. Wang, M. Liu, Z. Ren, and H. Liao, Cold Sprayed WC Reinforced Maraging Steel 300 Composites: Microstructure Characterization and Mechanical Properties, J. Alloys Compd., 2019, 785, p 499-511. https://doi.org/10.1016/j.jallcom.2019.01. 135

117. P. Cavaliere and A. Silvello, Mechanical and Microstructural Behavior of Cold-Sprayed Titanium- and Nickel-Based Coatings, J. Therm. Spray Technol., 2015, 24(8), p 1506-1512

118. Q. Wang, N. Birbilis, H. Huang, and M.-X. Zhang, Microstructure Characterization and Nanomechanics of ColdSprayed Pure $\mathrm{Al}$ and $\mathrm{Al}-\mathrm{Al}_{2} \mathrm{O}_{3}$ Composite Coatings, Surf. Coat. Technol., 2013, 232, p 216-223. https://doi.org/10.1016/j.surf coat.2013.05.009

119. H. Seiner, J. Cizek, P. Sedlák, R. Huang, J. Cupera, I. Dlouhy, and M. Landa, Elastic Moduli and Elastic Anisotropy of Cold Sprayed Metallic Coatings, Surf. Coat. Technol., 2016, 291, p 342-347. https://doi.org/10.1016/j.surfcoat.2016.02.057

120. G. Bolelli, B. Bonferroni, H. Koivuluoto, L. Lusvarghi, and P. Vuoristo, Depth-Sensing Indentation for Assessing the Mechanical Properties of Cold-Sprayed Ta, Surf. Coat. Technol., 2010, 205(7), p 2209-2217. https://doi.org/10.1016/j.surfcoat. 2010.08 .146

121. Y. Tan, A. Shyam, W.B. Choi, E. Lara-Curzio, and S. Sampath, Anisotropic Elastic Properties of Thermal Spray Coatings Determined via Resonant Ultrasound Spectroscopy, Acta Mater., 2010, 58(16), p 5305-5315. https://doi.org/10.1016/j. actamat.2010.06.003

122. P. Sedmák, H. Seiner, P. Sedlák, M. Landa, R. Mušálek, and J. Matějíček, Application of Resonant Ultrasound Spectroscopy to Determine Elastic Constants of Plasma-Sprayed Coatings with High Internal Friction, Surf. Coat. Technol., 2013, 232, p 747757. https://doi.org/10.1016/j.surfcoat.2013.06.091

123. Z. Hashin and S. Shtrikman, A Variational Approach to the Theory of the Elastic Behaviour of Multiphase Materials, $J$. Mech. Phys. Solids, 1963, 11(2), p 127-140

124. B. Michel, and Mura, T., Micromechanics of Defects in Solids. Second, Revised Edition. Dordrecht Etc., Martinus Nijhoff Publishers 1987. XIII, US \$ 162.-/Dfl. 345. ISBN 90-247-3343$\mathrm{X}$ (Mechanics of Elastic and Inelastic Solids 3). ZAMM-
Journal of Applied Mathematics and Mechanics/Zeitschrift für Angewandte Mathematik und Mechanik, 1989.

125. V. Den Eindmck, Berechnung Der Elastischen Konstanten Des Vielkristalls Aus Den Konstanten Des Einkristalls, 1958, p. 518.

126. B. Budiansky, On the Elastic Moduli of Some Heterogeneous Materials, J. Mech. Phys. Solids., 1965, 13(4), p 223-227. https://doi.org/10.1016/0022-5096(65)90011-6

127. N. Chawla and Y.L. Shen, Mechanical Behavior of Particle Reinforced Metal Matrix Composites, Adv. Eng. Mater., 2001, 3(6), p 357-370

128. S. Kumar, S.K. Reddy, and S.V. Joshi, Microstructure and Performance of Cold Sprayed Al-SiC Composite Coatings with High Fraction of Particulates, Surf. Coat. Technol., 2017, 318, p 62-71. https://doi.org/10.1016/j.surfcoat.2016.11.047

129. M. Bashirzadeh, F. Azarmi, C.P. Leither, and G. Karami, Investigation on Relationship between Mechanical Properties and Microstructural Characteristics of Metal Matrix Composites Fabricated by Cold Spraying Technique, Appl. Surf. Sci., 2013, 275, p 208-216

130. M. Yandouzi, A.J. Böttger, R.W.A. Hendrikx, M. Brochu, P. Richer, A. Charest, and B. Jodoin, Microstructure and Mechanical Properties of B4C Reinforced Al-Based Matrix Composite Coatings Deposited by CGDS and PGDS Processes. Surf. Coat. Technol. 2010, 205(7), p 2234-2246. https://doi.org/ 10.1016/j.surfcoat.2010.08.143

131. T. Chandanayaka and F. Azarmi, Investigation on the Effect of Reinforcement Particle Size on the Mechanical Properties of the Cold Sprayed Ni-Ni3Al Composites, J. Mater. Eng. Perform., 2014, 23(5), p 1815-1822

132. X. Xie, C. Chen, Y. Xie, Z. Ren, E. Aubry, G. Ji, and H. Liao, A Novel Approach for Fabricating Ni-Coated FeSiAl Soft Magnetic Composite via Cold Spraying, J. Alloys Compd., 2018, 749, p 523-533. https://doi.org/10.1016/j.jallcom.2018.03.306

133. X. Qiu, N.U.H. Tariq, L. Qi, J.-R. Tang, X.-Y. Cui, H. Du, J.-Q. Wang, and T.-Y. Xiong, Influence of Particulate Morphology on Microstructure and Tribological Properties of Cold Sprayed A380/ $\mathrm{Al}_{2} \mathrm{O}_{3}$ Composite Coatings, J. Mater. Sci. Technol., 2020, https://doi.org/10.1016/j.jmst.2020.01.028

134. X.-T. Luo and C.-J. Li, Large Sized Cubic BN Reinforced Nanocomposite with Improved Abrasive Wear Resistance Deposited by Cold Spray, Mater. Des., 2015, 83, p 249-256. https://doi.org/10.1016/j.matdes.2015.06.009

135. X.K. Wu, X.L. Zhou, H. Cui, X. Zheng, and J.S. Zhang, Deposition Behavior and Characteristics of Cold-Sprayed $\mathrm{Cu}-\mathrm{Cr}$ Composite Deposits, J. Therm. Spray Technol., 2012, 21(5), p 792-799

136. D.E. Wolfe, T.J. Eden, J.K. Potter, and A.P. Jaroh, Investigation and Characterization of Cr3C2-Based Wear-Resistant Coatings Applied by the Cold Spray Process, J. Therm. Spray Technol., 2006, 15(3), p 400-412

137. Y. Zou, W. Qin, E. Irissou, J.G. Legoux, S. Yue, and J.A. Szpunar, Dynamic Recrystallization in the Particle/Particle Interfacial Region of Cold-Sprayed Nickel Coating: Electron Backscatter Diffraction Characterization, Scr. Mater., 2009, 61(9), p 899-902. https://doi.org/10.1016/j.scriptamat.2009.07. 020

138. T. Hussain, Cold Spraying of Titanium: A Review of Bonding Mechanisms, Microstructure and Properties, Key Eng. Mater., 2012, 533, p 53-90

139. M.R. Rokni, S.R. Nutt, C.A. Widener, V.K. Champagne, and R.H. Hrabe, Review of Relationship Between Particle Deformation, Coating Microstructure, and Properties in High-Pressure Cold Spray, J. Therm. Spray Technol., 2017, 26(6), p 1308-1355

140. Y. Zou, D. Goldbaum, J.A. Szpunar, and S. Yue, Microstructure and Nanohardness of Cold-Sprayed Coatings: Electron Backscattered Diffraction and Nanoindentation Studies, Scr. 
Mater., 2010, 62(6), p 395-398. https://doi.org/10.1016/j.scrip tamat.2009.11.034

141. S. Yin, X. Suo, Y. Xie, W. Li, R. Lupoi, and H. Liao, Effect of Substrate Temperature on Interfacial Bonding for Cold Spray of $\mathrm{Ni}$ onto $\mathrm{Cu}$, J. Mater. Sci., 2015, 50(22), p 7448-7457

142. K. Kim, M. Watanabe, J. Kawakita, and S. Kuroda, Grain Refinement in a Single Titanium Powder Particle Impacted at High Velocity, Scr. Mater., 2008, 59(7), p 768-771. https://doi. org/10.1016/J.SCRIPTAMAT.2008.06.020

143. N. Hansen, Hall-Petch Relation and Boundary Strengthening, Scr. Mater., 2004, 51(8), p 801-806. https://doi.org/10.1016/J. SCRIPTAMAT.2004.06.002

144. K. Kang, H. Park, J. Kim, and C. Lee, Role of Spray Processes on Microstructural Evolution, and Physical and Mechanical Properties of Multi-Walled Carbon Nanotube Reinforced $\mathrm{Cu}$ Composite Coatings, Appl. Surf. Sci., 2015, 356, p 1039-1051. https://doi.org/10.1016/J.APSUSC.2015.08.158

145. X.-T. Luo, G.-J. Yang, and C.-J. Li, Multiple Strengthening Mechanisms of Cold-Sprayed CBNp/NiCrAl Composite Coating, Surf. Coat. Technol., 2011, 205(20), p 4808-4813

146. W.-Y. Li, C. Yang, and H. Liao, Effect of Vacuum Heat Treatment on Microstructure and Microhardness of ColdSprayed TiN Particle-Reinforced Al Alloy-Based Composites, Mater. Des., 2011, 32(1), p 388-394. https://doi.org/10.1016/j. matdes.2010.06.002

147. H.S. Kim, On the Rule of Mixtures for the Hardness of Particle Reinforced Composites, Mater. Sci. Eng. A, 2000, 289(1-2), p 30-33. https://doi.org/10.1016/S0921-5093(00)00909-6

148. R. Fernandez and B. Jodoin, Cold Spray Aluminum-Alumina Cermet Coatings: Effect of Alumina Morphology, J. Therm. Spray Technol., 2019, 28(4), p 737-755. https://doi.org/10.1007/ s11666-019-00845-5

149. K. Spencer, D.M. Fabijanic, and M.-X. Zhang, The Use of Al$\mathrm{Al}_{2} \mathrm{O}_{3}$ Cold Spray Coatings to Improve the Surface Properties of Magnesium Alloys, Surf. Coat. Technol., 2009, 204(3), p 336344. https://doi.org/10.1016/J.SURFCOAT.2009.07.032

150. O. Meydanoglu, B. Jodoin, and E.S. Kayali, Microstructure, Mechanical Properties and Corrosion Performance of $7075 \mathrm{Al}$ Matrix Ceramic Particle Reinforced Composite Coatings Produced by the Cold Gas Dynamic Spraying Process, Surf. Coat. Technol., 2013, 235, p 108-116. https://doi.org/10.1016/j.surf coat.2013.07.020

151. M. Yu, X.K. Suo, W.Y. Li, Y.Y. Wang, and H.L. Liao, Microstructure, Mechanical Property and Wear Performance of Cold Sprayed A15056/SiCp Composite Coatings: Effect of Reinforcement Content, Appl. Surf. Sci., 2014, 289, p 188-196. https://doi.org/10.1016/j.apsusc.2013.10.132

152. S. Yin, E.J. Ekoi, T.L. Lupton, D.P. Dowling, and R. Lupoi, Cold Spraying of WC-Co-Ni Coatings Using Porous WC-17Co Powders: Formation Mechanism, Microstructure Characterization and Tribological Performance, Mater. Des., 2017, 126, p 305-313. https://doi.org/10.1016/j.matdes.2017.04.040

153. M. Kazasidis, S. Yin, J. Cassidy, T. Volkov-Husović, M. Vlahović, S. Martinović, E. Kyriakopoulou, and R. Lupoi, Microstructure and Cavitation Erosion Performance of NickelInconel 718 Composite Coatings Produced with Cold Spray, Surf. Coat. Technol., 2020, 382, p 125195. https://doi.org/10. 1016/j.surfcoat.2019.125195

154. C.J. Huang, H.J. Wu, Y.C. Xie, W.Y. Li, C. Verdy, M.-P. Planche, H.L. Liao, and G. Montavon, Advanced Brass-Based Composites via Cold-Spray Additive-Manufacturing and Its Potential in Component Repairing, Surf. Coat. Technol., 2019, 371, p 211-223. https://doi.org/10.1016/j.surfcoat.2019.02.034

155. Y. Chang, P. Mohanty, N. Karmarkar, M.T. Khan, Y. Wang, and J. Wang, Microstructure and Properties of $\mathrm{Cu}-\mathrm{Cr}$ Coatings
Deposited by Cold Spraying, Vacuum, Pergamon, 2020, 171, p 109032. https://doi.org/10.1016/J.VACUUM.2019.109032

156. L. Zhang, Y. Zhang, H. Wu, S. Yang, and X. Jie, Structure and Corrosion Behavior of Cold-Sprayed $\mathrm{Cu} / \mathrm{Ni}$ Composite Coating Post-Treated by Ultrasonic Shot Peening, SN Appl. Sci., 2020, https://doi.org/10.1007/s42452-020-1997-8

157. L. Zhang, S. Yang, X. Lv, and X. Jie, Wear and Corrosion Resistance of Cold-Sprayed Cu-Based Composite Coatings on Magnesium Substrate, J. Therm. Spray Technol., 2019, 28(6), p 1212-1224. https://doi.org/10.1007/s11666-019-00887-9

158. Y. Zhang, Y. Epshteyn, and R.R. Chromik, Dry Sliding Wear Behaviour of Cold-Sprayed $\mathrm{Cu}-\mathrm{MoS} 2$ and $\mathrm{Cu}-\mathrm{MoS} 2-\mathrm{WC}$ Composite Coatings: The Influence of WC, Tribol. Int., 2018, 123, p 296-306. https://doi.org/10.1016/j.triboint.2017.12.015

159. Y. Zhang, J. MichaelShockley, P. Vo, and R.R. Chromik, Tribological Behavior of a Cold-Sprayed Cu-MoS2 Composite Coating during Dry Sliding Wear, Tribol. Lett., 2016, 62(1), p 112

160. S.A. Alidokht, V.N.V. Munagala, and R.R. Chromik, Role of Third Bodies in Friction and Wear of Cold-Sprayed Ti and TiTiC Composite Coatings, Tribol. Lett., 2017, 65(3), p 1-15

161. V.N.V. Munagala, T.B. Torgerson, T.W. Scharf, and R.R. Chromik, High Temperature Friction and Wear Behavior of Cold-Sprayed Ti6Al4V and Ti6Al4V-TiC Composite Coatings, Wear, 2019, 426-427, p 357-369. https://doi.org/10.1016/J. WEAR.2018.11.032

162. J. Chen, B. Ma, G. Liu, H. Song, J. Wu, L. Cui, and Z. Zheng, Wear and Corrosion Properties of 316L-SiC Composite Coating Deposited by Cold Spray on Magnesium Alloy, J. Therm. Spray Technol., 2017, 26(6), p 1381-1392

163. W. Winarto, D. Priadi, N. Sofyan, and A. Wicaksono, Wear Resistance and Surface Hardness of Carbon Nanotube Reinforced Alumina Matrix Nanocomposite by Cold Sprayed Process, Proc. Eng., 2017, 170, p 108-112. https://doi.org/10.1016/ j.proeng.2017.03.020

164. X.T. Luo, E.J. Yang, F.L. Shang, G.J. Yang, C.X. Li, and C.J. Li, Microstructure, Mechanical Properties, and Two-Body Abrasive Wear Behavior of Cold-Sprayed 2 vol.\% Cubic BNNiCrAl Nanocomposite Coating, J. Therm. Spray Technol., 2014, 23(7), p 1181-1190

165. W. Li, C. Huang, M. Yu, D. Liu, Y. Feng, and H. Liao, Investigation of High Temperature Oxidation Behavior and Tribological Performance on Cold Sprayed Nickel-Alumina Composite Coating, Surf. Coat. Technol., 2014, 239, p 95-101. https://doi.org/10.1016/j.surfcoat.2013.11.024

166. J. Wang, X. Zhou, L. Lu, D. Li, P. Mohanty, and Y. Wang, Microstructure and Properties of $\mathrm{Ag} / \mathrm{SnO} 2$ Coatings Prepared by Cold Spraying, Surf. Coat. Technol., 2013, 236, p 224-229. https://doi.org/10.1016/j.surfcoat.2013.09.050

167. R. Arun Kumar, S. Ramesh, E.S. Kedarvignesh, M.S. Aravind Arulchelvam, and S. Anjunath, Review of Friction Stir Processing of Magnesium Alloys, Mater. Today Proc., 2019, 16, p 1320-1324. https://doi.org/10.1016/j.matpr.2019.05.230

168. R.A. Kumar, R.G.A. Kumar, K.A. Ahamed, B.D. Alstyn, and V. Vignesh, Review of Friction Stir Processing of Aluminium Alloys, Mater. Today Proc., 2019, 16, p 1048-1054. https://doi. org/10.1016/j.matpr.2019.05.194

169. G.K. Padhy, C.S. Wu, and S. Gao, Friction Stir Based Welding and Processing Technologies-Processes, Parameters, Microstructures and Applications: A Review, J. Mater. Sci. Technol., 2018, 34(1), p 1-38. https://doi.org/10.1016/j.jmst. 2017.11.029

170. K.P. Boopathiraja, R. Ramamoorthi, V. Vadivel Vivek, K. Vickram, S. Vinodh Kumar, and K.P. Yuvaraj, Characterization and Surface Modification on Composites by Friction Stir 
Processing-A Review, Mater. Today Proc., 2020, https://doi. org/10.1016/j.matpr.2020.03.524

171. K. Yang, W. Li, P. Niu, X. Yang, and Y. Xu, Cold Sprayed AA2024/ $\mathrm{Al}_{2} \mathrm{O}_{3}$ Metal Matrix Composites Improved by Friction Stir Processing: Microstructure Characterization, Mechanical Performance and Strengthening Mechanisms, J. Alloys Compd., 2018, 736, p 115-123. https://doi.org/10.1016/j.jallcom.2017.11. 132

172. T. Peat, A. Galloway, A. Toumpis, P. McNutt, and N. Iqbal, The Erosion Performance of Cold Spray Deposited Metal Matrix Composite Coatings with Subsequent Friction Stir Processing, Appl. Surf. Sci., 2017, 396, p 1635-1648. https://doi.org/10. 1016/j.apsusc. 2016.10 .156

173. C. Chen, X. Xie, Y. Xie, M.-P. Planche, S. Deng, G. Ji, E. Aubry, Z. Ren, and H. Liao, Cold Spraying of Thermally Softened Ni-Coated FeSiAl Composite Powder: Microstructure Characterization, Tribological Performance and Magnetic Property, Mater. Des., 2018, 160, p 270-283. https://doi.org/10. 1016/j.matdes.2018.09.025

174. Y.T.R. Lee, H. Ashrafizadeh, G. Fisher, and A. McDonald, Effect of Type of Reinforcing Particles on the Deposition Efficiency and Wear Resistance of Low-Pressure Cold-Sprayed Metal Matrix Composite Coatings, Surf. Coat. Technol., 2017, 324, p 190-200. https://doi.org/10.1016/j.surfcoat.2017.05.057

175. A. Góral, W. Żórawski, and M. Makrenek, The Effect of the Standoff Distance on the Microstructure and Mechanical Properties of Cold Sprayed Cr3C2-25(Ni20Cr) Coatings, Surf. Coat. Technol., 2019, 361, p 9-18. https://doi.org/10.1016/j.surfcoat. 2019.01.006

176. N.U.H. Tariq, L. Gyansah, X. Qiu, C. Jia, H. Bin Awais, C. Zheng, H. Du, J. Wang, and T. Xiong, Achieving StrengthDuctility Synergy in Cold Spray Additively Manufactured Al/ B4C Composites through a Hybrid Post-Deposition Treatment, J. Mater. Sci. Technol., 2019, 35(6), p 1053-1063. https://doi. org/10.1016/J.JMST.2018.12.022

177. X. Yan, C. Huang, C. Chen, R. Bolot, L. Dembinski, R. Huang, W. Ma, H. Liao, and M. Liu, Additive Manufacturing of WC Reinforced Maraging Steel 300 Composites by Cold Spraying and Selective Laser Melting, Surf. Coat. Technol., 2019, 371, p 161-171. https://doi.org/10.1016/j.surfcoat.2018.03.072

178. C.W. Nan and D.R. Clarke, The Influence of Particle Size and Particle Fracture on the Elastic/Plastic Deformation of Metal Matrix Composites, Acta Mater., 1996, 44(9), p 3801-3811

179. X. Qiu, N.U.H. Tariq, L. Qi, Y. Zan, Y. Wang, J. Wang, H. Du, and T. Xiong, In-Situ Sip/A380 Alloy Nano/Micro Composite Formation through Cold Spray Additive Manufacturing and Subsequent Hot Rolling Treatment: Microstructure and Mechanical Properties, J. Alloys Compd., 2019, 780, p 597-606. https://doi.org/10.1016/j.jallcom.2018.11.399

180. N.H. Tariq, L. Gyansah, X. Qiu, H. Du, J.Q. Wang, B. Feng, D.S. Yan, and T.Y. Xiong, Thermo-Mechanical Post-Treatment: A Strategic Approach to Improve Microstructure and Mechanical Properties of Cold Spray Additively Manufactured Composites, Mater. Des., 2018, 156, p 287-299. https://doi.org/10. 1016/j.matdes.2018.06.062

181. N. Kang, P. Coddet, H. Liao, and C. Coddet, The Effect of Heat Treatment on Microstructure and Tensile Properties of Cold Spray Zr Base Metal Glass/Cu Composite, Surf. Coat. Technol., 2015, 280, p 64-71. https://doi.org/10.1016/j.surfcoat.2015.08. 061

182. H. Qing and T. Liu, Micromechanical Analysis of SiC/Al Metal Matrix Composites: Finite Element Modeling and Damage Simulation, Int. J. Appl. Mech., 2015, 7(2), p 1-19

183. W.G. Jiang, R.Z. Zhong, Q.H. Qin, and Y.G. Tong, Homogenized Finite Element Analysis on Effective Elastoplastic
Mechanical Behaviors of Composite with Imperfect Interfaces, Int. J. Mol. Sci., 2014, 15(12), p 23389-23407

184. H. Qing, 2D Micromechanical Analysis of SiC/Al Metal Matrix Composites under Tensile, Shear and Combined Tensile/Shear Loads, Mater. Des., 2013, 51, p 438-447. https://doi.org/10. 1016/j.matdes.2013.04.051

185. Q. Xu and Z. Lu, An Elastic-Plastic Cohesive Zone Model for Metal-Ceramic Interfaces at Finite Deformations, Int. J. Plast, 2013, 41, p 147-164

186. J.J. Williams, J. Segurado, J. Lorca, and N. Chawla, Three Dimensional Microstructure-Based Modeling of Interfacial Decohesion in Particle Reinforced Metal Matrix Composites, Mater. Sci. Eng. A, 2012, 557, p 113-118. https://doi.org/10. 1016/j.msea.2012.05.108

187. H. Zhang, K.T. Ramesh, and E.S.C. Chin, Effects of Interfacial Debonding on the Rate-Dependent Response of Metal Matrix Composites, Acta Mater., 2005, 53(17), p 4687-4700

188. H.-T. Wang, X. Chen, X.-B. Bai, G.-C. Ji, Z.-X. Dong, and D.L. Yi, Microstructure and Properties of Cold Sprayed Multimodal WC-17Co Deposits, Int. J. Refract. Met. Hard Mater., 2014, 45, p 196-203. https://doi.org/10.1016/j.ijrmhm.2014.04. 018

189. Y.Y. Wang, Y. Liu, C.-J. Li, G.J. Yang, and K. Kusumoto, Electrical and Mechanical Properties of Nano-Structured TiN Coatings Deposited by Vacuum Cold Spray. Vacuum 2012, 86(7), p 953-959. https://doi.org/10.1016/j.vacuum.2011.06.026

190. R. Aghababaei, T. Brink, and J.-F. Molinari, Asperity-Level Origins of Transition from Mild to Severe Wear, Phys. Rev. Lett., 2018, 120(18), p 186105. https://doi.org/10.1103/physrev lett.120.186105

191. Q. An, L. Huang, Y. Jiao, Y. Bao, B. Zhong, and L. Geng, Intergrowth Microstructure and Superior Wear Resistance of $(\mathrm{TiB}+\mathrm{TiC}) / \mathrm{Ti} 64$ Hybrid Coatings by Gas Tungsten Arc Cladding, Mater. Des., 2019, 162, p 34-44

192. T. Peat, A. Galloway, A. Toumpis, P. McNutt, and N. Iqbal, The Erosion Performance of Particle Reinforced Metal Matrix Composite Coatings Produced by Co-Deposition Cold Gas Dynamic Spraying, Appl. Surf. Sci., 2017, 396, p 1623-1634. https://doi.org/10.1016/j.apsusc.2016.10.155

193. N. Argibay, M. Chandross, S. Cheng, and J.R. Michael, Linking Microstructural Evolution and Macro-Scale Friction Behavior in Metals, J. Mater. Sci., 2017, 52(5), p 2780-2799

194. I.L. Singer and H.M. Pollock, Fundamentals of Friction: Marcoscopic and Microscopic Processes, Springer, Dordrecht, Netherlands, 1992

195. Y. Zhang, D. Choudhuri, T.W. Scharf, S. Descartes, and R.R. Chromik, Tribologically Induced Nanolaminate in a ColdSprayed WC-Reinforced Cu Matrix Composite: A Key to High Wear Resistance, Mater. Des., 2019, 182, p 108009. https://doi. org/10.1016/j.matdes.2019.108009

196. Y. Zhang, S. Descartes, and R.R. Chromik, Influence of WC on Third Body Behaviour during Fretting of Cold-Sprayed CuMoS2WC Composites, Tribol. Int., 2019, 134, p 15-25. https://doi.org/10.1016/j.triboint.2019.01.033

197. S. Yin, Y. Xie, J. Cizek, E.J. Ekoi, T. Hussain, D.P. Dowling, and R. Lupoi, Advanced Diamond-Reinforced Metal Matrix Composites via Cold Spray: Properties and Deposition Mechanism, Compos. Part B Eng., 2017, 113, p 44-54. https://doi.org/ 10.1016/j.compositesb.2017.01.009

198. N. Deng, J. Tang, T. Xiong, J. Li, and Z. Zhou, Fabrication and Characterization of WCu Composite Coatings with Different W Contents by Cold Spraying, Surf. Coat. Technol., 2019, 368, p 814. https://doi.org/10.1016/j.surfcoat.2019.04.034

199. M.M. Khruschov and M.A. Babichev, Resistance to Abrasive Wear of Structurally Heterogeneous Materials, Frict. Wear Mach., 1958, 12, p 5-24 
200. K.H. Zum-Gahr, Abrasive Wear of Two-Phase Metallic Materials with a Coarse Microstructure, in K.C. Ludema (Ed.) International Conference on Wear of Materials, American Society of Material Engineering (Vancouver, 1985), p 793.

201. G.Y. Lee, C.K.H. Dharan, and R.O. Ritchie, A Physically-Based Abrasive Wear Model for Composite Materials, Wear, 2002, 252(3-4), p 322-331

202. K. Adachi, K. Kato, and N. Chen, Wear Map of Ceramics, Wear, Elsevier, 1997, 203-204, p 291-301. https://doi.org/10.1016/ S0043-1648(96)07363-2

203. A. Loganathan, S. Rengifo, A.F. Hernandez, Y. Emirov, C. Zhang, B. Boesl, J. Karthikeyan, and A. Agarwal, Effect of 2D WS2 Addition on Cold-Sprayed Aluminum Coating, J. Therm. Spray Technol., 2017, 26(7), p 1585-1597

204. T.B. Torgerson, M.D. Harris, S.A. Alidokht, T.W. Scharf, S.M. Aouadi, R.R. Chromik, J.S. Zabinski, and A.A. Voevodin, Room and Elevated Temperature Sliding Wear Behavior of Cold Sprayed Ni-WC Composite Coatings, Surf. Coat. Technol., 2018, 350, p 136-145. https://doi.org/10.1016/j.surfcoat.2018. 05.090

205. I. Smid, A.E. Segall, P. Walia, G. Aggarwal, T.J. Eden, and J.K. Potter, Cold-Sprayed Ni-HBN Self-Lubricating Coatings, Tribol. Trans., 2012, 55(5), p 599-605. https://doi.org/10.1080/ 10402004.2012.686085

206. D. Cong, Z. Li, Q. He, H. Chen, Z. Zhao, L. Zhang, and H. Wu, Wear Behavior of Corroded $\mathrm{Al}_{-} \mathrm{Al}_{2} \mathrm{O}_{3}$ Composite Coatings Prepared by Cold Spray, Surf. Coat. Technol., 2017, 326, p 247254. https://doi.org/10.1016/j.surfcoat.2017.07.063

207. M. Winnicki, A. Małachowska, T. Piwowarczyk, M. Rutkowska-Gorczyca, and A. Ambroziak, The Bond Strength of $\mathrm{Al}+\mathrm{Al}_{2} \mathrm{O}_{3}$ Cermet Coatings Deposited by Low-Pressure Cold Spraying, Arch. Civ. Mech. Eng., 2016, 16(4), p 743-752

208. Y. Hao, J. Wang, X. Cui, J. Wu, T. Li, and T. Xiong, Microstructure Characteristics and Mechanical Properties of Al12Si Coatings on AZ31 Magnesium Alloy Produced by Cold Spray Technique, J. Therm. Spray Technol., 2016, 25(5), p 1020-1028

209. K. Yang, W. Li, C. Huang, X. Yang, and Y. Xu, Optimization of Cold-Sprayed AA2024/ $\mathrm{Al}_{2} \mathrm{O}_{3}$ Metal Matrix Composites via Friction Stir Processing: Effect of Rotation Speeds, J. Mater.
Sci. Technol., 2018, 34(11), p 2167-2177. https://doi.org/10. 1016/j.jmst.2018.03.016

210. M. Yandouzi, E. Sansoucy, L. Ajdelsztajn, and B. Jodoin, WCBased Cermet Coatings Produced by Cold Gas Dynamic and Pulsed Gas Dynamic Spraying Processes, Surf. Coat. Technol., 2007, 202(2), p 382-390. https://doi.org/10.1016/j.surfcoat.2007. 05.095

211. J. Guillem-Marti, N. Cinca, M. Punset, I.G. Cano, F.J. Gil, J.M. Guilemany, and S. Dosta, Porous Titanium-Hydroxyapatite Composite Coating Obtained on Titanium by Cold Gas Spray with High Bond Strength for Biomedical Applications, Colloids Surfaces B Biointerfaces, Elsevier, 2019, 180, p 245-253. https://doi.org/10.1016/J.COLSURFB.2019.04.048

212. H. Wu, L. Zhang, C. Liu, Y. Mai, Y. Zhang, and X. Jie, Deposition of Zn-G/Al Composite Coating with Excellent Cathodic Protection on Low-Carbon Steel by Low-Pressure Cold Spraying, J. Alloys Compd., 2020, 821, p 153483. https:// doi.org/10.1016/j.jallcom.2019.153483

213. O. Tazegul, O. Meydanoglu, and E.S. Kayali, Surface Modification of Electrical Contacts by Cold Gas Dynamic Spraying Process, Surf. Coat. Technol., 2013, 236, p 159-165. https://doi. org/10.1016/j.surfcoat.2013.09.042

214. H. Koivuluoto and P. Vuoristo, Effect of Powder Type and Composition on Structure and Mechanical Properties of $\mathrm{Cu}+\mathrm{Al}_{2} \mathrm{O}_{3}$ Coatings Prepared by Using Low-Pressure Cold Spray Process, J. Therm. Spray Technol., 2010, 19(5), p 10811092

215. P.C. King and M. Jahedi, Relationship between Particle Size and Deformation in the Cold Spray Process, Appl. Surf. Sci., 2010, 256(6), p 1735-1738. https://doi.org/10.1016/j.apsusc.2009.09. 104

216. X. Guo, G. Zhang, W. Li, Y. Gao, H. Liao, and C. Coddet, Investigation of the Microstructure and Tribological Behavior of Cold-Sprayed Tin-Bronze-Based Composite Coatings, Appl. Surf. Sci., 2009, 255(6), p 3822-3828. https://doi.org/10.1016/j. apsusc.2008.10.041

Publisher's Note Springer Nature remains neutral with regard to jurisdictional claims in published maps and institutional affiliations. 